DOE/PC/79887--T18

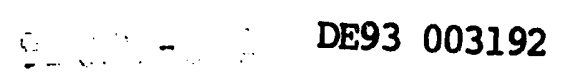

PROJECT TITLE:

\title{
EXTRACTION, SEPARATION, AND ANALYSIS OF HIGH SULFUR COAL
}

\author{
US DOE Contract: DE AC22-87PC79887
}

FINAL REPORT

\author{
REPORT COMPILED BY: \\ Susan V. Olesik, Lara A. Pekay, William Larkins,Jr. \\ The Ohio State University \\ Department of Chemistry \\ 120 West 18th \\ Columbus, $\mathrm{OH}$ \\ 43210
}

May 31, 1992

DISCLAIMER

This report was prepared as an account of work sponsored by an agency of the United States Government. Neither the United States Government nor any agency thereof, nor any of their employees, makes any warranty, express or implied, or assumes any legal liability or responsibility for the accuracy, completeness, or usefulness of any information, apparatus, product, or process disclosed, or represents that its use would not infringe privately owned rights. Reference herein to any specific commercial product, process, or service by trade name, trademark, manufacturer, or otherwise does not necessarily constitute or imply its endorsement, recommendation, or favoring by the United States Government or any agency thereof. The views and opinions of authors expressed herein do not necessarily state or reflect those of the United States Government or any agency thereof. 


\section{TABLE OF CONTENTS}

I. Introduction $\ldots \ldots \ldots \ldots \ldots \ldots \ldots \ldots \ldots \ldots \ldots \ldots \ldots$

II. Oxidative Desulfurization of Coal with $\mathrm{CuCl}_{2} \ldots \ldots \ldots \ldots \ldots$

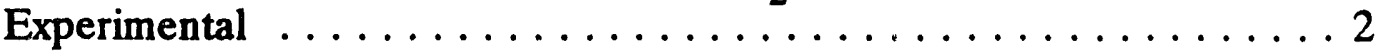

Chemicals ........................ 2

Reaction and Sample Preparation $\ldots \ldots \ldots \ldots \ldots \ldots$

Analysis ....................... 6

Results and Discussion .................. 8

Reaction of Model Compounds at 50 and $130^{\circ} \mathrm{C} \ldots \ldots \ldots 8$

Reaction of Model Compounds at $210^{\circ} \mathrm{C} \ldots \ldots \ldots \ldots \ldots 18$

Reaction of Model Compounds at $295^{\circ} \mathrm{C} \ldots \ldots \ldots \ldots \ldots . \ldots 34$

Aqueous $\mathrm{CuCl}_{2}$ Coal Desulfurization Experiments ...... 40

Reaction Mechanism . . . . . . . . . . . . . . . . 42

References .......................... 48

III. Further Studies on the Interaction of Cupric Salts with Coal . . . . . . 49

Experimental ........................ 50

Chemicals ........................ 50

Reaction and Sample Preparation $\ldots \ldots \ldots \ldots \ldots \ldots 50$

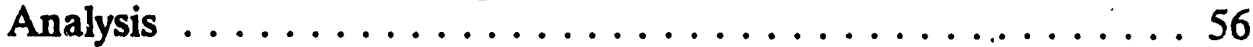

Results and Discussion ................... 56

$\mathrm{CuCl}_{2}$ Reactions with Model Compounds in Different Solvents 56

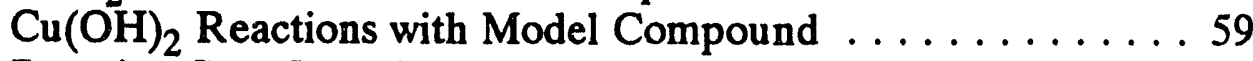

Reactive Coal Desulfurization ..................61 61

Solvent Effect on Interaction of $\mathrm{CuCl}_{2}$ with Coal $\ldots \ldots \ldots 64$

Interaction of $\mathrm{Cu}(\mathrm{OH})_{2}$ with Coal ...........6. 67

$\mathrm{CuCl}_{2}$ Assisted Chlorinolysis Reaction with Coal . . . . . . 67

References ............................ 75

IV. Selective Solvolysis With Supercritical Ethanol . . . . . . . . . . 76

Previous Work ...................... 76

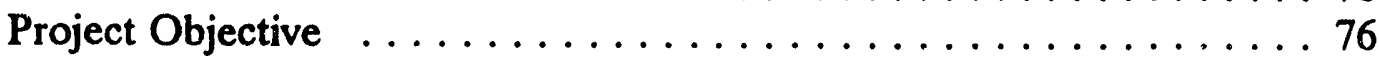

Experimental ......................... 77

Model Compound Studies . . . . . . . . . . . . . . . 77

Coal Studies . . . . . . . . . . . . . . . . . . . . 78

Results and Discussion ...................8 80

Interaction of Supercritical Ethanol with Model Compounds . . 80

Interaction of Supercritical Ethanol with Coal . . . . . . . 86

References ............................. 105 


\section{TABLE OF TABLES}

Table

1. Names and structures of compounds used to model the organic fraction of sulfur in coal $\ldots \ldots \ldots \ldots \ldots \ldots \ldots \ldots \ldots \ldots \ldots \ldots \ldots \ldots \ldots$

2. GC/IRD/MS experimental parameters $\ldots \ldots \ldots \ldots \ldots \ldots$

3. Sulfur analysis of Illinois \#6 coal before and after reaction with $50 \%$ $\mathrm{CuCl}_{2}$ - water solution. Reaction temperature is $210^{\circ} \mathrm{C}$ held for 10 hrs 41

4. Results of $\mathrm{CuCl}_{2}$ desulfurization of Illinois \#6 coal. Reaction time

was 10 hrs. 65

5. Results of $\mathrm{Cu}(\mathrm{OH})_{2}$ desulfurization of Illinois \#6 coal. Reaction time -

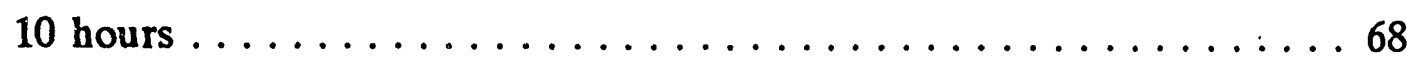

6. Results of chlorinolysis type desulfurization of Illinois \#6 coal. Reaction

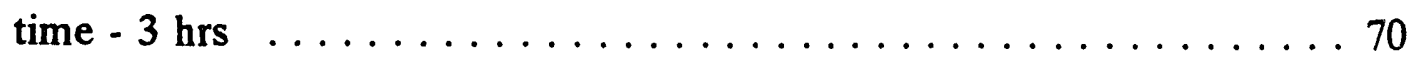

7. Comparison of desulfurization efficiency with other researchers current work in chlorinolysis $\ldots \ldots \ldots \ldots \ldots \ldots \ldots \ldots$

8. Interaction of supercritical ethanol with model compounds . . . . . 81

9. Sulfur analysis of Illinois \#6 coal and coal extracts $\ldots \ldots \ldots 6$ 


\section{TABLE OF TABLES (cont.)}

Table

10. Effect of $\mathrm{HNO}_{3}$ pretreatment on sulfur removal $\ldots \ldots \ldots 8$

11. Comparison of organic sulfur removal for select premium coals from Argonne National Lab Coal Bank . . . . . . . . . . . . . . . . . . . 89

12. Compounds identified by GC/MS of Illinois \#6 extract using 30 - meter DB -17 column . . . . . . . . . . . . . . . . . . 92

13. Compounds identified by GC/MS of Illinois \#6 extract using a 30 - meter DB-Wax column ........................ 93

14. Compounds identified by GC/MS of Illinois \#6 after Pyrite removal using a 30 - meter DB- Wax Column .................. 94 


\section{TABLE OF FIGURES}

Figure

1. Diagram showing pyrex reaction vessels produced in-house for the study of model coal compound reactions $\ldots \ldots \ldots \ldots \ldots \ldots$

2. Variation of relative proportions of organic species detected in GC/MS analysis as a function of time for the reaction of methyl p-tolyl sulfide with $50 \% \mathrm{CuCl}_{2}$ - water at A) $50^{\circ} \mathrm{C}$ and B) $130{ }^{\circ} \mathrm{C} \ldots \ldots \ldots$

3. Kinetic analysis of methyl p-tolyl sulfide reaction at $50^{\circ} \mathrm{C} \ldots \ldots \ldots 11$

4. Plot of relative product yields versus percent copper chloride for the reaction of methyl p-tolyl sulfur at $130^{\circ} \mathrm{C} \ldots \ldots \ldots \ldots . \ldots \ldots$

5. Variation of relative proportions of organic species detected in GC/MS analyses as a function of time for the reaction of diphenyl sulfide with $50 \% \mathrm{CuCl}_{2}$ - water at $130{ }^{\circ} \mathrm{C} \ldots \ldots \ldots \ldots \ldots$

6. Variation of relative proportions of organic species detected in GC/MS analyses as a function of time for the reaction of tetrahydrothiophene with $50 \% \mathrm{CuCl}_{2}$ - water at A) $50{ }^{\circ} \mathrm{C}$ and B) $130{ }^{\circ} \mathrm{C} \ldots \ldots 15$

7. Variation of relative proportions of organic species detected in GC/MS analyses as a function of time for the reaction of benzo[b]thiophene with $50 \% \mathrm{CuCl}_{2}$ - water at $130{ }^{\circ} \mathrm{C} \ldots \ldots \ldots \ldots$

8. Plots of relative amounts of organic products produced (in terms of percent response) versus time for thiophenol reacting with $50 \% \mathrm{CuCl}_{2}$ -

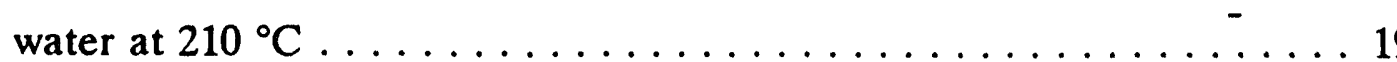




\section{TABLE OF FIGURES (cont.)}

Figure

9. Plots of percentage conversion to sulfate form organic sulfur detected using ion chromatography for the reaction of thiophenol at $210^{\circ} \mathrm{C}$ with $50 \% \mathrm{CuCl}_{2}$ - water solutions $\ldots \ldots \ldots \ldots \ldots$

10. Plots of the relative amounts of organic products produced versus time for the reaction of cyclohexyl mercaptan reaction at $210{ }^{\circ} \mathrm{C}$ with $50 \% \mathrm{CuCl}_{2}$ water solution. ....................... 22

11. Results of cyclohexyl mercaptan reaction with $50 \% \mathrm{CuCl}_{2}$ - water solution at $210^{\circ} \mathrm{C}$ showing $\mathrm{A}$ ) the percent sulfate conversion and $\mathrm{B}$ ) total organic species response versus time $\ldots \ldots \ldots \ldots \ldots \ldots \ldots$

12. Plots of the relative amounts of organic products produced versus time for the reaction of methyl p-tolyl sulfide at $210{ }^{\circ} \mathrm{C}$ with $50 \% \mathrm{CuCl}_{2}$ - water

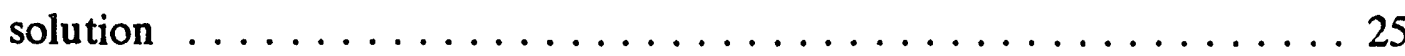

13. Results of methyl p-tolyl sulfide reaction with $50 \% \mathrm{CuCl}_{2}$ - water solution at $210^{\circ} \mathrm{C}$ showing $\mathrm{A}$ ) the percent sulfate conversion and $\mathrm{B}$ ) total organic species response versus time $\ldots \ldots \ldots \ldots \ldots$

14. Plots of the relative amounts of organic products versus time for the reaction of dip.ienyl sulfide at $210^{\circ} \mathrm{C}$ with $50 \% \mathrm{CuCl}_{2}$ - water solution

15. Resalts of methyl p-tolyl sulfide reaction with $50 \% \mathrm{CuCl}_{2}$ - water solution at $210^{\circ} \mathrm{C}$ showing the percent sulfate conversion versus reaction time . 29 


\section{TABLE OF FIGURES (cont.)}

Figure

16. Plots of the relative amounts of organic products versus time for the reaction of benzo[b]thiophene at $210{ }^{\circ} \mathrm{C}$ with $50 \% \mathrm{CuCl}_{2}$ - water

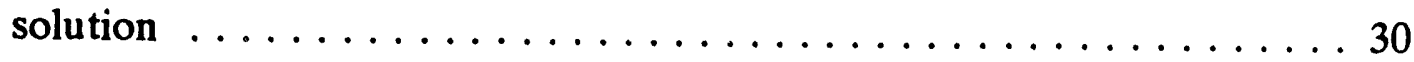

17. Results of benzo[b]thiophene reaction with $50 \% \mathrm{CuCl}_{2}$ - water solution at $210{ }^{\circ} \mathrm{C}$ showing A) the percent total organic species response and $\mathrm{B}$ ) the percent sulfate conversion versus reaction time $\ldots \ldots \ldots \ldots \ldots$

18. Plots of the relative amounts of organic products versus time for the reaction of dibenzothiophene at $210{ }^{\circ} \mathrm{C}$ with $50 \% \mathrm{CuCl}_{2}$ - water solution $\ldots \ldots \ldots \ldots \ldots \ldots \ldots \ldots \ldots \ldots \ldots \ldots \ldots \ldots \ldots \ldots \ldots \ldots$

19. Reaction products for reaction of $50 \% \mathrm{CuCl}_{2}$ - water with thiophenol at $295^{\circ} \mathrm{C}$. Plot of percent response of each reaction product at different

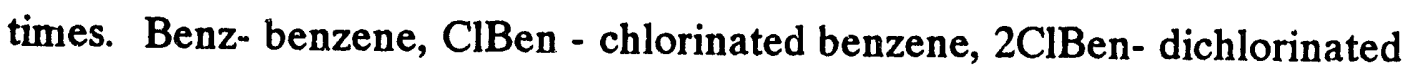
benzene, 3ClBen- trichlorinated benzene, $4 \mathrm{ClBen}$ - Tetrachlorinated benzene, 5,6 ClBen - penta and hexachlorinated benzene, $\mathrm{ClPhnol} \mathrm{-}$ chlorinated phenol, and CIDBT - chlorinated dibenzothiophene . . . . . 35

20. Reaction products for reaction of $50 \% \mathrm{CuCl}_{2}$ - water with phenyl disulfide at $295^{\circ} \mathrm{C}$. Plot of percent response of each reaction product at different times. Benz- benzene, ClBen - chlorinated benzene, $2 \mathrm{ClBen}$ - dichlorinated benzene, $3 \mathrm{ClBen}$ - trichlorinated benzene, 4ClBen - Tetrachlorinated benzene, 5,6ClBen - penta and hexachlorinated benzene, CIPhnol chlorinated phenol, and CIDBT - chlorinated dibenzothiophene . . . . . 37 


\section{TABLE OF FIGURES (cont.)}

Figure

21. Reaction products for reaction of $50 \% \mathrm{CuCl}_{2}$ - water with diphenyl disulfide at $295^{\circ} \mathrm{C}$. Plot of percent response of each reaction product at different times. Benz- benzene, ClBen - chlorinated benzene, $2 \mathrm{ClBen-}$ dichlorinated benzene, $3 \mathrm{ClBen}$ - trichlorinated benzene, $4 \mathrm{ClBen}$ Tetrachlorinated benzene, 5,6 ClBen - penta and hexachlorinated benzene, CIPhnol - chlorinated phenol, and CIDBT - chlorinated

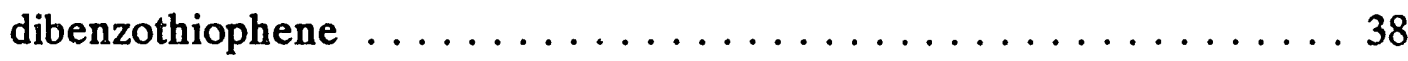

22. Reaction products for reaction of $50 \% \mathrm{CuCl}_{2}$ - water with dibenzothiophene at $295^{\circ} \mathrm{C}$. Plot of percent response of each reaction product at different times. Benz- benzene, ClBen - chlorinated benzene, 2ClBen- dichlorinated benzene, $3 \mathrm{ClBen}$ - trichlorinated benzene, $4 \mathrm{ClBen}$ Tetrachlorinated benzene, 5,6ClBen - penta and hexachlorinated benzene, ClPhnol - chlorinated phenol, and CIDBT - chlorinated dibenzothiophene.

23. Plot of percentage response of organic products for the reaction of methyl p-tolyl sulfide with $20 \% \mathrm{CuSO}_{4} /$ water solution at $210{ }^{\circ} \mathrm{C} \ldots \ldots \ldots 45$

24. Extraction efficiency of pentane for organosulfur model compounds from a $\mathrm{DMF} / \mathrm{H}_{2} \mathrm{O}$ solution versus the mole fraction of waster in the solution. Model compounds are A) thiophenol, B) methyl p-tolyl sulfide and C) benzo[b]thiophene. ..................... 52

25. Inductively coupled plasma atomic emission spectra of copper atoms solvated in supercritical $10 \% \mathrm{DMF} / \mathrm{CO}_{2}$ solution

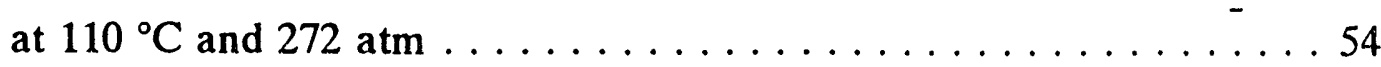




\section{TABLE OF FIGURES (cont.)}

Figure

26. Plot of unreacted parent organosulfur compound for the reaction with solvated $\mathrm{CuCl}_{2}$ plotted versus volume fraction of dimethylformamide in water DMF solvent. Compounds studied are A) methyl p-tolyl sulfide, B) benzo[b]thiophene, C) thiophenol, D) diphenyl disulfide. Reaction conditions $-90^{\circ} \mathrm{C}$ for a reaction time of $8 \mathrm{hrs} \ldots \ldots \ldots 57$

27. FTIR spectrum of unreacted Illinois $\# 6$ coal. . . . . . . . . . . 62

28. FTIR spectrum of Illinois \#6 coal extracted with nitric acid for $24 \mathrm{hrs}$. 63

29. FTIR spectrum of Illinois \#6 coal treated with nitric acid and reacted with chlorine gas in a $10 \%$ solution of $\mathrm{CuCl}_{2}$ /methanol for 3 hours at

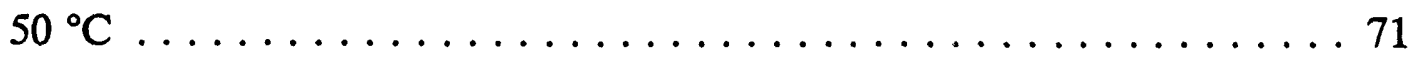

30. GC/FPD chromatogram of known sulfur containing compounds on the DBWax column. Compounds are 1 thiophenol, 2 methyl p-tolyl sulfide, 3 benzo[b]thiophene, 4 diphenylsulfide . . . . . . . . . . . 95

31. GC/FPD chromatogram of known sulfur containing compounds on $\mathrm{DB} / 17$ column. Compounds are 1 ethyl sulfide , 2 ethyl disulfide, 3 thiophenol, 4 benzyl mercaptan, 5 ethyl phenyl sulfide, 6 methyl p-tolyl sulfide, 7 benzo[b] thiophene, and 8 phenyl sulfide. . . . . . . . . . . . . 96

32. GC/FPD chromatogram of the supercritical ethanol extract from Illinois \#6 on DB- Wax column. Compounds are 1 thiophenol, and 2 methyl ptolyl sulfide . . . . . . . . . . . . . . . . . . . . . . . 97 


\section{TABLE OF FIGURES (cont.)}

Figure

33. GC/FPD chromatogram of the supercritical ethanol extract of Illinois \#6 on the DB-17 column. Compounds are 1 ethyl sulfide and ethyl disulfide . . . . . . . . . . . . . . . . . 98

34. GC/FPD chromatogram of the supercritical ethanol extract from pyriteremoved Illinois \#6 on DB- Wax column. Compounds are 1 thiophenol, 2 methyl p-tolyl sulfide, 3 phenyl sulfide. . . . . . . . . . . . . . 99

35. GC/FPD chromatogram of the supercritical ethanol extract of pyriteremoved Illinois \#6 on the DB-17 column. Compounds are 1 ethyl sulfide and 2 ethyl disulfide . . . . . . . . . . . . . . . . . 100

36. GC/FPD chromatogram of the supercritical ethanol extract from pyriteremoved Pittsburgh \#8 on DB- Wax column. Compounds are 1 thiophenol, 2 methyl p-tolyl sulfide, 3 phenyl sulfide . . . . . . . . . 101

37. GC/FPD chromatogram of the supercritical ethanol extract of pyriteremoved Pittsburgh \#8 on the DB-17 column. Compounds are 1 ethyl sulfide, 2 ethyl disulfide and 3 benzyl mercaptan . . . . . . . . . . . 102

38. GC/FPD chromatogram of the supercritical ethanol extract from pyriteremoved Pennsylvania Upper Freeport on DB- Wax column. Compounds are 1 thiophenol 2 metiryl p-tolyl sulfide, 3 phenyl sulfide . . . . . . 103

39. GC/FPD chromatogram of the supercritical ethanol extract of pyriteremoved Pennsylvania Upper Freeport on the DB-17 column. Compound is 1 ethyl disulfide . . . . . . . . . . . . . . . . . . . . . 104 


\section{INTRODUCTION}

Optimum future use of our nation's chemical resources will require a much greater use of coal. Coal will be needed to supply energy, and function as a feedstock for the production of various chemicals. Unfortunately the continued use of coal will cause several problems. The principal concerns when coal is burned are the effects that this has on the environment. Considerable quantities of ash are produced in the coal burning process which will put increased stress on the waste disposal problem that this country has. However, the ash is relatively inert and therefore could be placed in landfills. A second problem is the production of carbon dioxide when coal is burned. It has been hypothesized that this gas contributes to the "greenhouse" effect or global warming problem. Collection of this gas may be eventually necessary. A third problem is the production of noxious gaseous such as sulfur dioxide. Present clean air laws limit the emissions of such gases. Accordingly, many of the eastern U.S. coals must be cleaned before burning. Presently, this cleaning process involves physical removal by flotation of inorganic compounds such as pyrite. In an effort to use our coal resources more efficiently, finer processing techniques are being developed for the beneficiation of coal. Many very cost effective methods have been developed to remove pyrite. However, further removal of the sulfur found in the organic matrix of coal is difficult.

The work described in this report studies the removal of sulfur by oxidative interaction of various cupric salts with coal and also considers the possibility of removing organic sulfur by the selective interaction of supercritical ethanol with the organic coal matrix. Either one of these methods could potentially be used io pretreat coals before burning. The primary purpose of these studies is to ascertain the nature of the chemical reactions occurring, the chemical composition of the resultant products, and information on possible reaction mechanisms. This information should allow prediction of reasonable reaction conditions for the removal of organosulfur compound from coal. 


\section{OXIDATIVE DESULFURIZATION OF COAL WITH $\mathrm{CuCl}_{2}$}

In this portion of the research the cheninical oxidization of organically-bound sulfur by reactive desulfurization with aqueous $\mathrm{CuCl}_{2}$ was studied. This reaction was considered in the past as a possible coal desulfurization technique ${ }^{1,2}$. The results of previous studies, however, showed divergent desulfurization yields. In addition, these studies provided minimal insight on possible reaction mecinanisms producing the desulfurization. By extensively studying this desulfurization reaction, a greater understanding of the exact reaction mechanism was sought, with the hope that this information would enhance its applicability to coal desulfurization.

To achieve this goal, the reaction was studied first with a series of organosulfur compounds. The structures of the model compounds (Table 1) span the range of possible sulfur species in coal: thiophenic, sulfide, disulfide, and thiol. The utility of studying these organosulfur compounds was that reaction products could be readily identified without the added complexities of the coal matrix.

After having studied the reaction of $\mathrm{CuCl}_{2}$ with model coal compounds, the desulfurization of several coal samples was undertaken. The reaction conditions chosen were based both upon earlier literature results and the work on the model compounds in this study. The results of this coal analysis is reported herein and is compared with results of the model coal compounds.

\section{EXPERIMENTAL}

\section{Chemicals}

The model organosulfur compounds used in this study (carbon disulfide, tetrahydrothiophene, cyclohexyl mercaptan, thiophenol, methyl $p$-tolyl sulfide, benzo[b]thiophene, phenyl sulfide, dibenzothiophene, phenyl disulfide, and thianthrene) were analytical grade $(99+\%$ purity) or higher and were obtained from Aldrich Chemical (Milwaukee, WI). Cupric chloride, dimethylformamide, and pentane were reagent grade and were obtained from J.T. Baker Company 
TABLE 1: Names and Structures of Coal Model Compounds Used to Model Organic Fraction of Sulfur in Coal

1. tetrahydrothiophene

2. cyclohexyl mercaptan

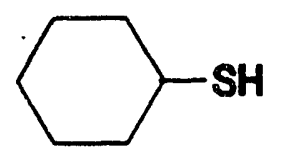

3. thiophenol

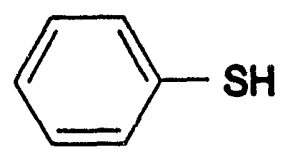

4. methyl p-tolyl sulfide<smiles>CSc1ccc(C)cc1</smiles>

5. benzo[b]thiophene<smiles>c1ccc2sccc2c1</smiles>

6. diphenyl sulfide<smiles>c1ccc(Sc2ccccc2)cc1</smiles>

7. dibenzothiophene

8. diphenyl disulfide<smiles>c1ccc2c(c1)sc1ccccc12</smiles><smiles>c1ccc(SSc2ccccc2)cc1</smiles>

9. thianthrene<smiles>c1ccc2c(c1)Sc1ccccc1S2</smiles> 
(Phillipsburg, NJ). Dichloromethane (reagent grade) was obtained from Mallinckrodt Chemical Company (Paris, KT). Distilled $\mathrm{H}_{2} \mathrm{O}$ was produced inhouse. The coal samples studied were -100 mesh Illinois \#6 obtained from the premium coal bank at Argonne National Laboratories ${ }^{3}$ (Argonne, IL).

\section{Reaction and Sample Preparation}

The conditions used for the reactions were based upon previous work ${ }^{1,2}$ which demonstrated the highest degree of reaction for the $50 \% \mathrm{CuCl}_{2} / \mathrm{H}_{2} \mathrm{O}$ reaction solution. Reaction temperatures used in previous studies ranged fr $: \mathrm{m} 150$ $-200^{\circ} \mathrm{C}$. Reaction temperatures used in this study spanned a broader rarig $295{ }^{\circ} \mathrm{C}$, to allow a thorough study of the reaction mechanism(s) involved in desulfurization. Ideally, it would be most beneficial to operate this reaction at the lowest temperature possible, since this both reduces energy consumption and will potentially cause the least amount of structural degradation to the coal matrix. Reaction times of $1-24$ hours were used to allow modelling of the reaction kinetics and identification of possible intermediates of the reaction.

The model compounds were reacted in pyrex reaction vessels which were produced in-house (figure 1$)$. These vessels were made from $1 / 4^{\prime \prime}$ o.d. (1/8" i.d.) pyrex tubing, were ca. 6" long, and were initially sealed at one end. The samples were weighed, by difference, in the reaction vessels and a known amount of reaction solution was added. The vessels were immediately sealed and placed into an oven at a predetermined reaction temperature. After a specified reaction time, the vessels were removed and cooled for approximately 30 minutes. The seals were broken and the solution was quantitatively transferred to glass extraction vessels. The aqueous fraction was diluted to $5 \mathrm{~mL}$. This solution was extracted with a $4 \mathrm{~mL}$ aliquot of dichloromethane which was then diluted to $5 \mathrm{~mL}$. Solid precipitates were separated through vacuum filtration followed by washing with distilled $\mathrm{H}_{2} \mathrm{O}$.

The coal desulfurization experiment was conducted in a $300 \mathrm{~mL}$ stainless steel autoclave (Autoclave Engineers, Inc., Erie, PA). The vessel was heated to 210 ${ }^{\circ} \mathrm{C}$ for a reaction time of 6 hours. Temperature was controlled to $\pm 0.5^{\circ} \mathrm{C}$ with a 

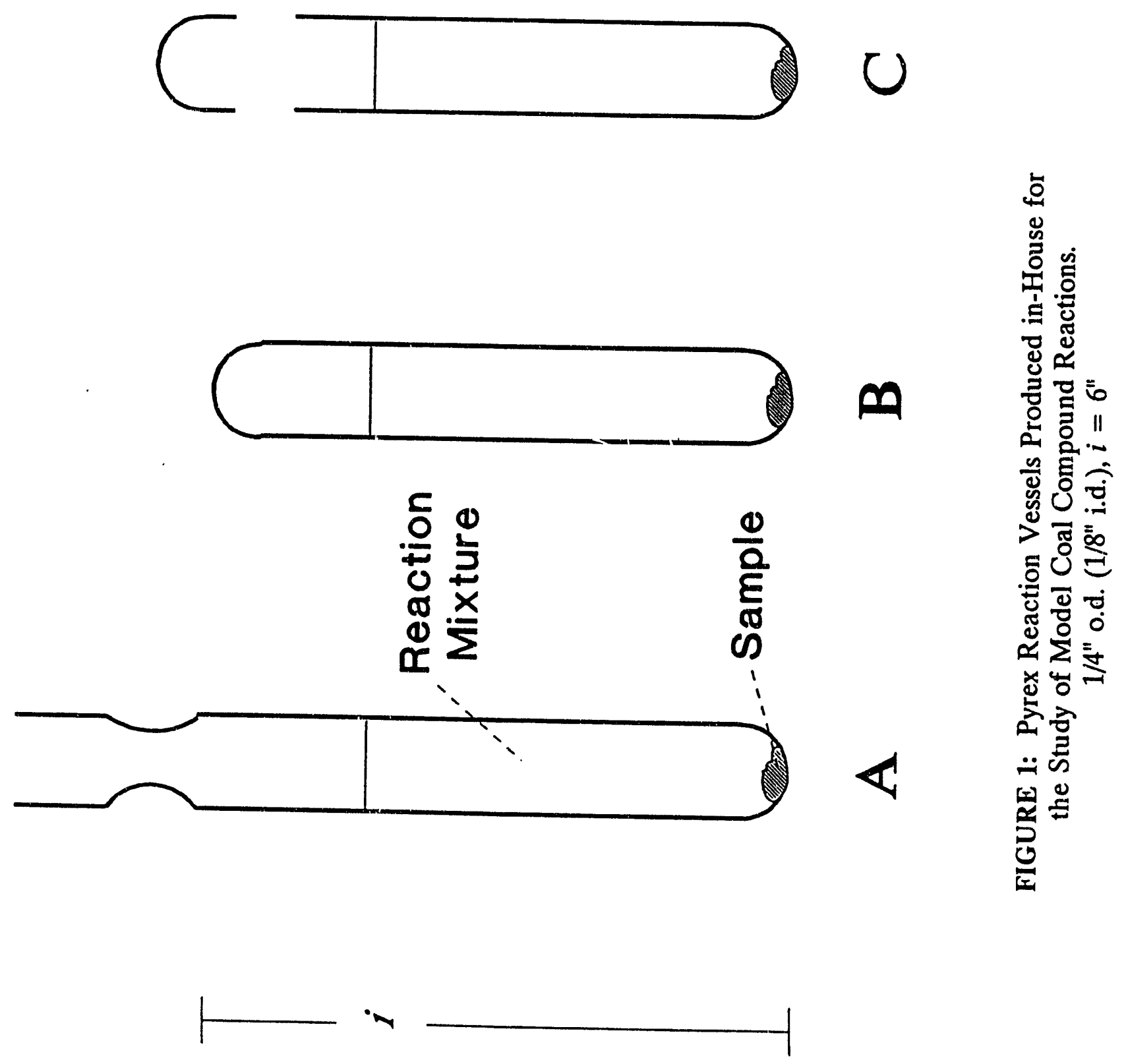
microprocessor-controlled temperature controller, series CN9000, using a type-J thermocouple (Omega Engineering, Inc., Stanford, CN). Approximately 6 g. of coal and $250 \mathrm{~mL}$ of $50 \%(\mathrm{wt} / \mathrm{wt}) \mathrm{CuCl}_{2} / \mathrm{H}_{2} \mathrm{O}$ solution were placed in the autoclave. After the reaction was completed, the vessel was repeatedly washed with distilled $\mathrm{H}_{2} \mathrm{O}$ to remove all reaction products. Coal was isolated from the inorganic copper precipitate using the following flocculation procedure. The copper precipitate/coal mixture was added to a beaker of distilled $\mathrm{H}_{2} \mathrm{O}$ that was magnetically stirred. Due to the difference in densitie, the copper precipitate sank, while the coal remained suspended. The coal/ $\mathrm{H}_{2} \mathrm{O}$ mix was then decanted off. This procedure was repeated twice to ensure removal of all copper precipitate.

\section{Analysis}

The organic reaction products were analyzed using a gas chromatographmass spectrometer, GC-MSD, (Hewlett-Packard, Avondale, PA). Separation of the products was accomplished on a $15 \mathrm{~m} \times 250 \mu \mathrm{m}, 50 \%$ phenyl/50\% methyl polysiloxane capillary column (Alltech RSL300, Alltech Associates, Inc., Deerfield, IL). A temperature program was used for the separation. Experimental conditions are listed in Table 2. Solid precipitates of the model coal compound react: ns were analyzed in $\mathrm{KBr}$ pellets on an RFX C-60 Fourier transform infrared spectrometer (Laser Precision Corporation, Irvine, CA).

Sulfate analysis was conducted on a Dionex Ion Chromatography system, series 4500 (Dionex Corp., Sunnyvale, CA), using a conductivity detector. The column utilized was an IonPack AS4A (Dionex Corp.). The mobile phase used was $1 \% \mathrm{Na}_{2} \mathrm{CO}_{3}$ degassed with helium. Data was collected and analyzed using the VAX-based Multichrom system (V.G. Laboratory Systems). The sulfur and chlorine analysis of the coal sample was conducted by Black Rock Test Labs (Morgantown, WV) according to standard ASTM procedures.

The presence of chlorine gas in the reaction mixture was detected using an Extrel C-50 quadrupole mass spectrometer (Extrel Corp, Pittsburgh, PA). A $4 \mathrm{~mL}$ sample of $50 \% \mathrm{CuCl}_{2} / \mathrm{H}_{2} \mathrm{O}$ was placed in a mass spectrometer sample flask. The 
TABLE 2: GC/IRD/MS Experimental Parameters

\section{GC CONDITIONS:}

Temperature Zones:

Oven Program

Injection Method:

$\begin{array}{lll}\text { Injection Port } & - & 220{ }^{\circ} \mathrm{C} \\ \text { Transfer Line } & - & 300{ }^{\circ} \mathrm{C}\end{array}$

$\begin{array}{ll}\text { Initial Temp - } & 30^{\circ} \mathrm{C} \\ \text { Initial Time - } & 5.00 \mathrm{~min} \\ \text { Ramp Rate } & -\quad 10.0^{\circ} \mathrm{C} / \mathrm{min} \\ \text { Final Temp - } & 230^{\circ} \mathrm{C} \\ \text { Final Time - } & 5.00 \mathrm{~min}\end{array}$

Carrier Gas:

Helium Automatic Injection (Split) \# of Sample Pumps

\# of Sample Washes Sample Volume Injection Mode

$\begin{array}{ll}- & 4 \\ - & 2 \\ - & 1 \mu \mathrm{L} \\ - & \text { Fast }\end{array}$

Flow - $13.5 \mathrm{~mL} / \mathrm{min}$

Column Head Pressure - 10 psi

Column: $\quad 15 \mathrm{~m} \times 250 \mu \mathrm{m}, 50 \%$ phenyl/50\% methyl polysiloxane (Alltech RSL300)

DETECTOR: values obtained after autotuning the instrument. 
initial solution was degassed by freezing it with liquid nitrogen and evacuating the remaining gases. Then the vessel was sealed and heated for 10 hours using an oil bath under the reaction temperatures in question $\left(50^{\circ}\right.$ and $\left.130^{\circ} \mathrm{C}\right)$. After allowing the vessel to cool to room temperature, the gases in the vessel were introduced into the mass spectrometer inlet system. The resulting mass spectra were collected using electron impaci ionization using at $70 \mathrm{eV}$ electron energy. Data were collected and analyzed on a ZEOS $80386,20 \mathrm{MHz}$ computer using software written in the ASYST programming language.

\section{RESULTS AND DISCUSSION}

Reactions of Model Coal Compounds at Low Temperatures $\left(50^{\circ} \mathrm{C}\right.$ and $\left.130{ }^{\circ} \mathrm{C}\right)$

Thiols, Disulfides. The most reactive of the model organosulfur compounds to $\mathrm{CuCl}_{2}$ were the thiols: cyclohexyl mercaptan and thiophenol. No degradation occurred when these compounds were heated to the highest temperature studied, $295^{\circ} \mathrm{C}$. However, they quickly converted (ca. $100 \%$ yield) to disulfides at room temperature when the oxidant, $\mathrm{CuCl}_{2}$, was added. This result was expected since thiols easily oxidize to form the disulfide. Additional heating, however, produced no further reaction products. Therefore, although the thiol group is very reactive at room temperature, the disulfide linkage is unreactive under these low temperature conditions. These results were confirmed since heating phenyl disulfide to $50^{\circ} \mathrm{C}$ or $130{ }^{\circ} \mathrm{C}$ also showed no reaction products.

Sulfides. The next class of compounds examined was the aliphatic sulfides. The compounds used to study the reactivity of this sulfide moiety were: methyl $p$ tolyl sulfide (MpTS), phenyl sulfide, and tetrahydrothiophene. The products and yields plotted as a function of time for the reaction of methyl $p$-tolyl sulfide with $50 \% \mathrm{CuCl}_{2} / \mathrm{H}_{2} \mathrm{O}$ are shown in Figures $2 \mathrm{~A}\left(50^{\circ} \mathrm{C}\right)$ and $2 \mathrm{~B}\left(130^{\circ} \mathrm{C}\right)$. The quantity of methyl $p$-tolyl sulfide decreases with reaction time while the quantity of the reaction product, methyl $p$-tolyl sulfoxide, increases with reaction time. These plots show that at $50^{\circ} \mathrm{C}$ (figure $2 \mathrm{~A}$ ), the conversion to the oxidized form, methyl $p$-tolyl 
A

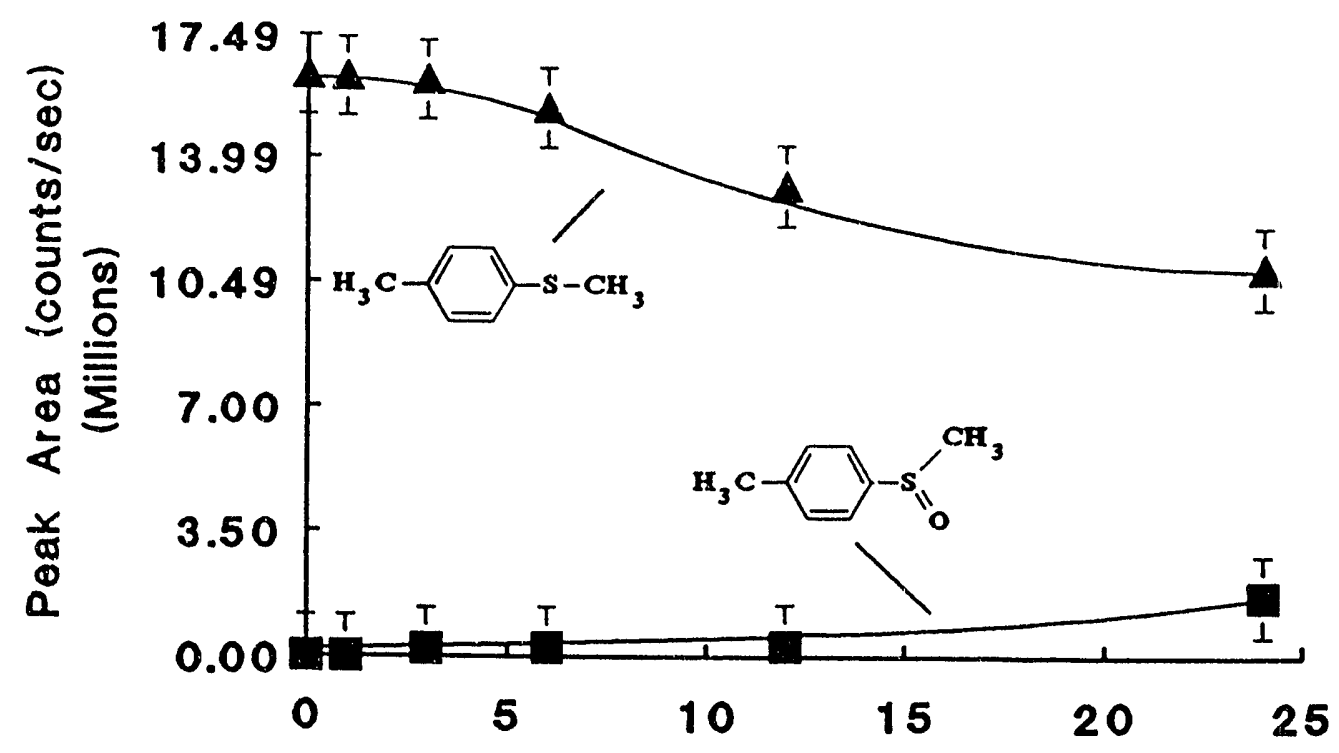

B

Time (hours)

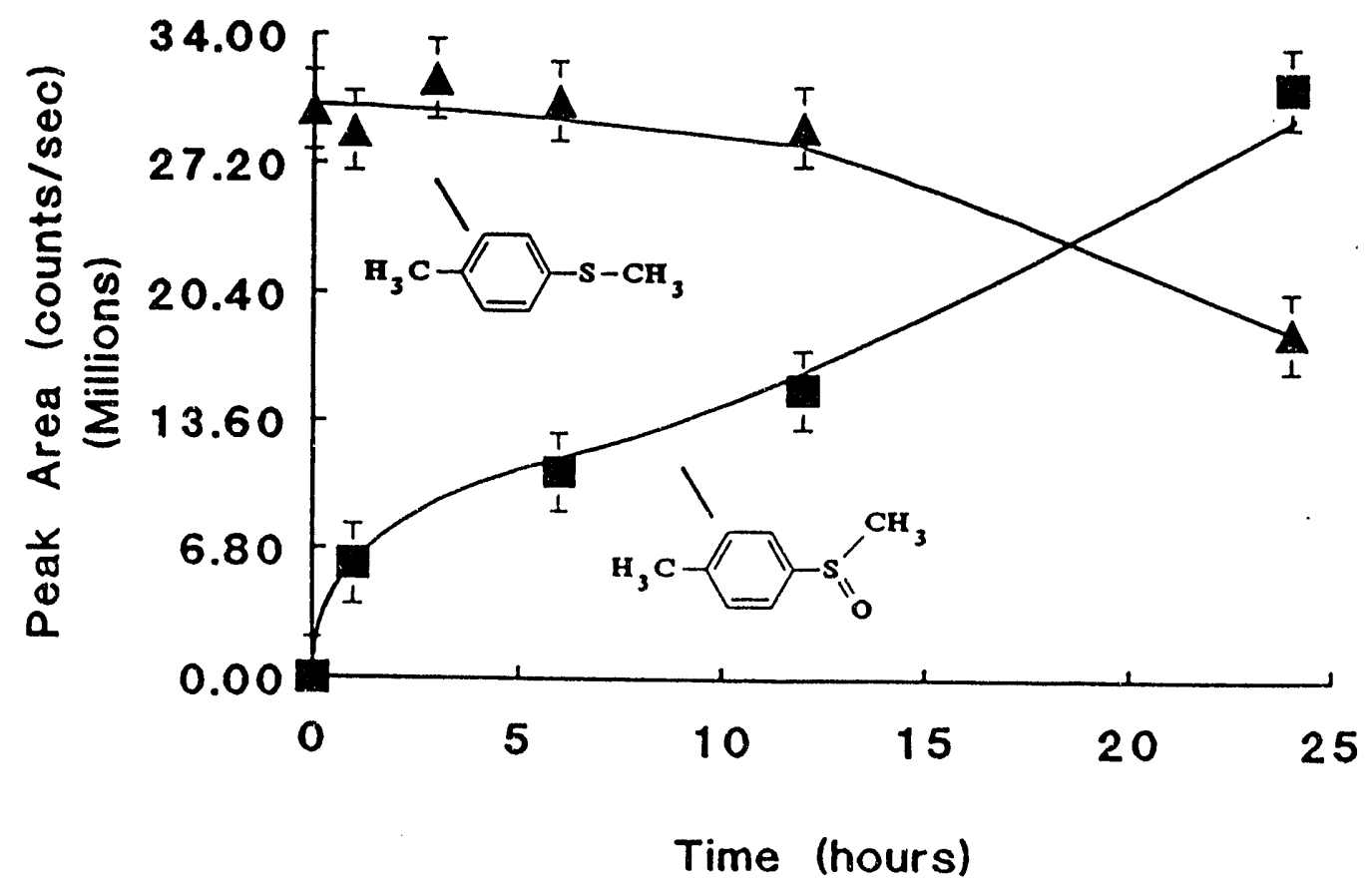

FIGURE 2: Variation of Relative Prop̄ortions of Organic Species Detected in GC/MS Analysis as a Function of Time for the Reaction of Methyl $p$-tolyl Sulfide with - $50 \% \mathrm{CuCl}_{2}-$ Water at A) $50^{\circ} \mathrm{C}$ and $\left.\mathrm{B}\right) 130^{\circ} \mathrm{C}$ 
sulfoxide, is very slow. Raising the reaction temperature to $130{ }^{\circ} \mathrm{C}$ (figure $2 \mathrm{~B}$ ) dramatically increases the conversion rate. This comparison of reaction product yields at the two temperatures shows that the overall reaction is thermodynamically driven and endothermic. The sulfoxide products appeared stable at these temperatures.

Kinetic analysis of this reaction at $50{ }^{\circ} \mathrm{C}$ is shown 111 Figure 3 in which $\left.\mathrm{Ln}\left(\left[\mathrm{MpTS}_{1 \mathrm{hr}}\right] / \mathrm{MpTS}_{\mathrm{t}}\right]\right)$ is plotted versus the time of the reaction, $t$. The result is a straight line with a correlation coefficient of 0.992 , which indicates a pseudo-first order reaction with respect to the methyl $p$-tolyl sulfide species. The reaction was made pseudo-first order by 'loading' the solvent with excess copper ions. Thus, for all practical considerations, the concentration of the copper species was constant and factored out. The use of this high concentration of cupric chloride removed the possible dependence of the reaction rate on $\mathrm{CuCl}_{2}$. The reaction rate constant, for the conversion of methyl $p$-tolyl sulfide to the product sulfoxide was calculated to be about $5.03 \times 10^{-6} \mathrm{sec}^{-1}$, which corresponds to a reaction half-life of 38.3 hours. As can be clearly seen, this reaction is much too slow to be effectively scaled up. Copper chloride 'loading' was further verified by running a series of reactions at $130^{\circ} \mathrm{C}$ in which the concentration of the reactant, $\mathrm{CuCl}_{2}$, was varied from $10-50 \%$. This is shown in Figure 4 where the concentration of the reactant is plotted versus the relative product yields. The reaction is clearly no longer limited by the concentration of the copper chloride reactant.

A final reaction product of methyl $p$-tolyl sulfide with $\mathrm{CuCl}_{2}$ at $130^{\circ} \mathrm{C}$ was sulfate. The percentage conversion of sulfur from the parent compound to the sulfate species ranged from only 1 to $4 \%$. An additional oxidation reaction must be occurring which leads to the production of trace levels of sulfate. However, this reaction does not appear to be favored under these conditions.

The reaction of diphenyl sulfide with $\mathrm{CuCl}_{2}$ at $50^{\circ} \mathrm{C}$ showed no detected reaction products, under GC/MS analysis, except for the parent species. However, the same experiment at $130^{\circ} \mathrm{C}$ produced similar results to that of the methyl $p$-tolyl sulfide. Aside from the starting species, a second detectable organic compound was 


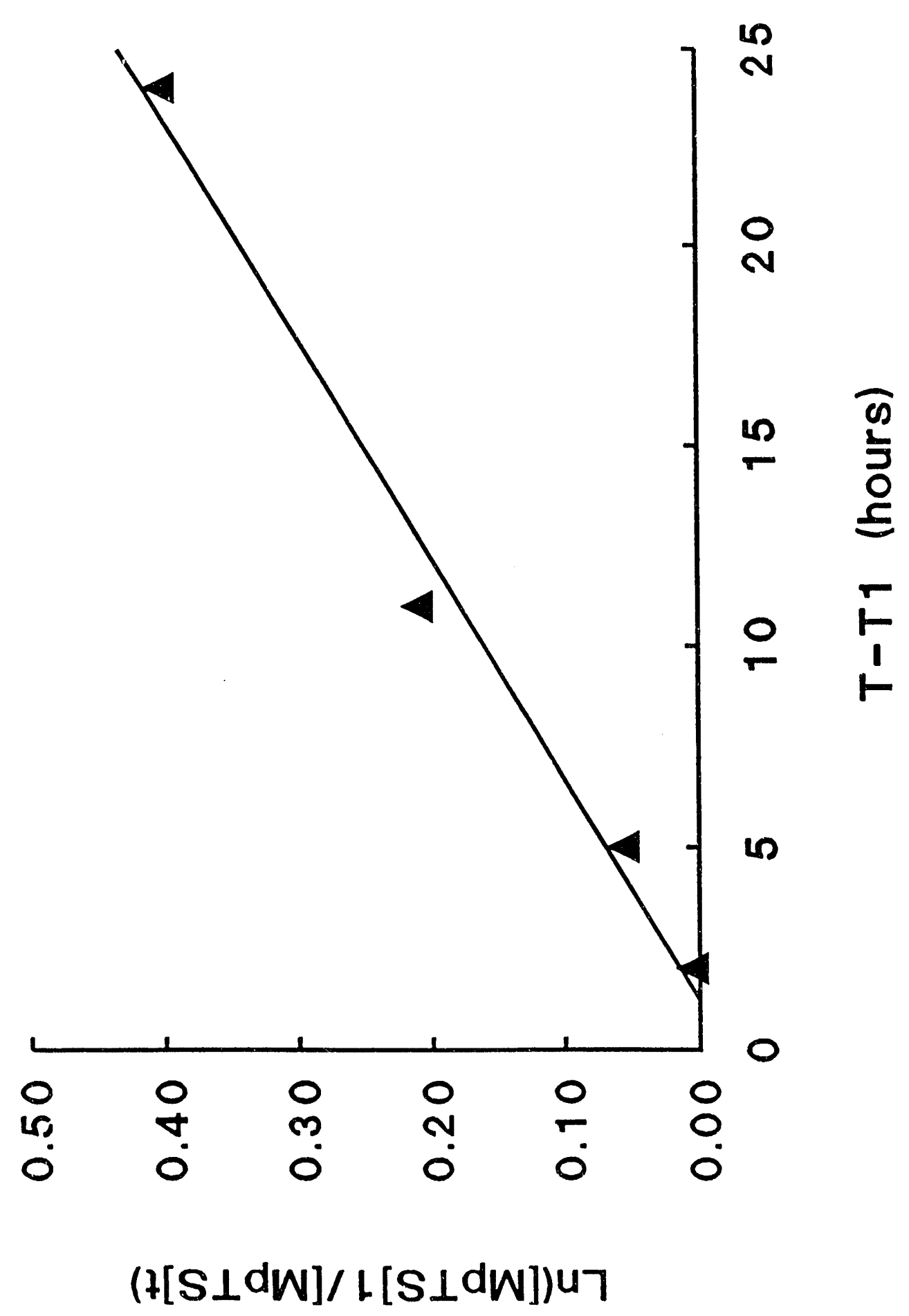




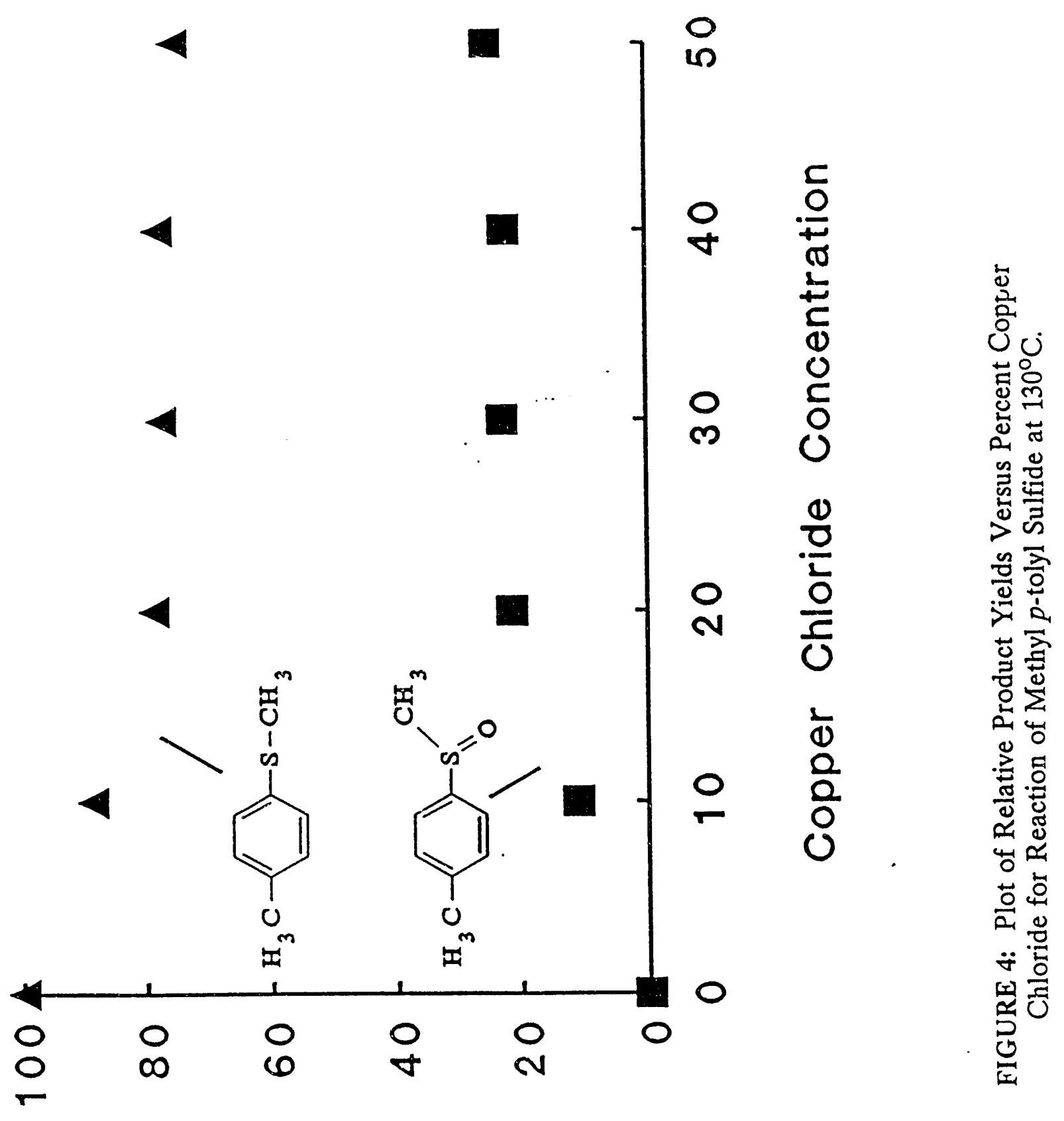

(ogs/2funoo) eara yeyd 
diphenyl sulfoxide. However, this latter species was only detected in small quantities with respect to the amount of starting material (figure 5). The relatively low yield from this reaction compared to that of methyl $p$-tolyl sulfide can most likely be attributed to the presence of the second phenyl ring which acts as both a stabilization force and an electron withdrawing species which makes the sulfur moiety less electronegative. As will be shown later, this effect is very significant. No sulfate was detected in the aqueous fraction, indicating that sulfoxide was the final product of the reaction of phenyl sulfide, and no other oxidation reactions appeared to occur.

The final sulfide studied, tetrahydrothiophene, proved to be highly reactive to the aqueous $\mathrm{CuCl}_{2}$ system at $50^{\circ}$ and $130^{\circ} \mathrm{C}$. Figure 6 shows product yields as a function of time. The shapes of these curves are decisively different than those previously examined for the other sulfides. The previcus sulfide curves appeared to be limited by the kinetics of the reaction. This limitation was shown by the decrease in parent species, with a slow increase in the product compound. In the tetrahydrothiophene reaction, equilibrium between the cyclic sulfide and the product sulfoxide was reached during the time frame of the analysis, as shown since the two curves mirror one another. This finding is supported by the fact that at shorter reaction times (1-3 hours), the ratio between the parent species and the oxidized species is constant under both temperature conditions ( ratio $_{50}=5.5$, ratio $_{130}=3.0$ ). At longer reaction times, both of these ratios increase.

The sulfoxide underwent an additional oxidation reaction, demonstrated by the decrease in the total quantity of detected organic species at both temperature conditions and by the presence of sulfate in the aqueous fraction and the formation of a solid precipitate. This reaction of the sulfoxide producing another species may be the rate limiting step in this process. The sulfate concentration produced varied from 1 - 5\% sulfur conversion (amount of sulfur as sulfate/total amount of sulfur in parent compound) over the reaction times studied. Due to the low molecular weight of tetrahydrothiophene, any organic species produced as a byproduct of the sulfate formation may have eluted with the solvent in the GC/MS analysis and was 
(suo!!!!W)
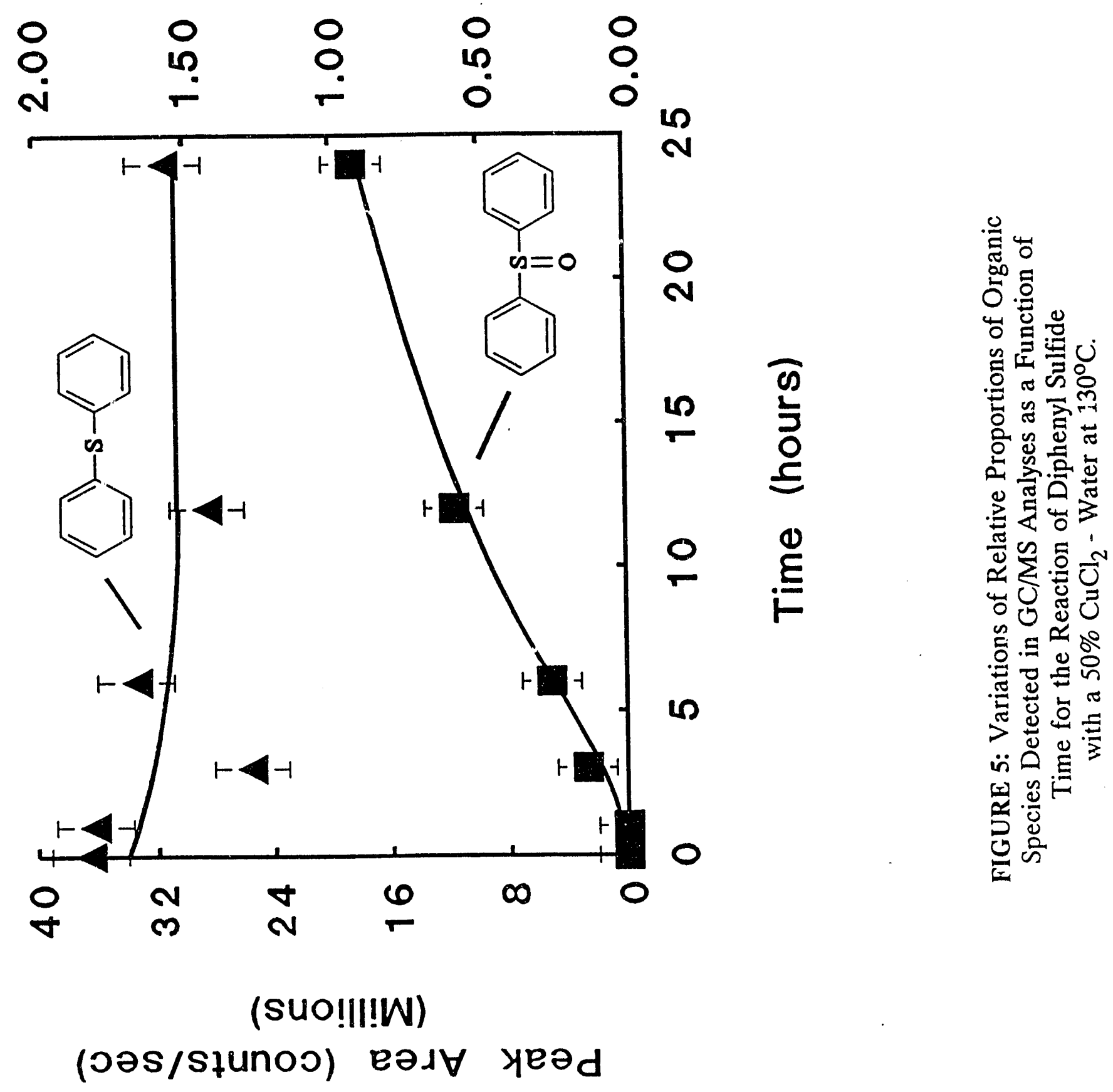
A

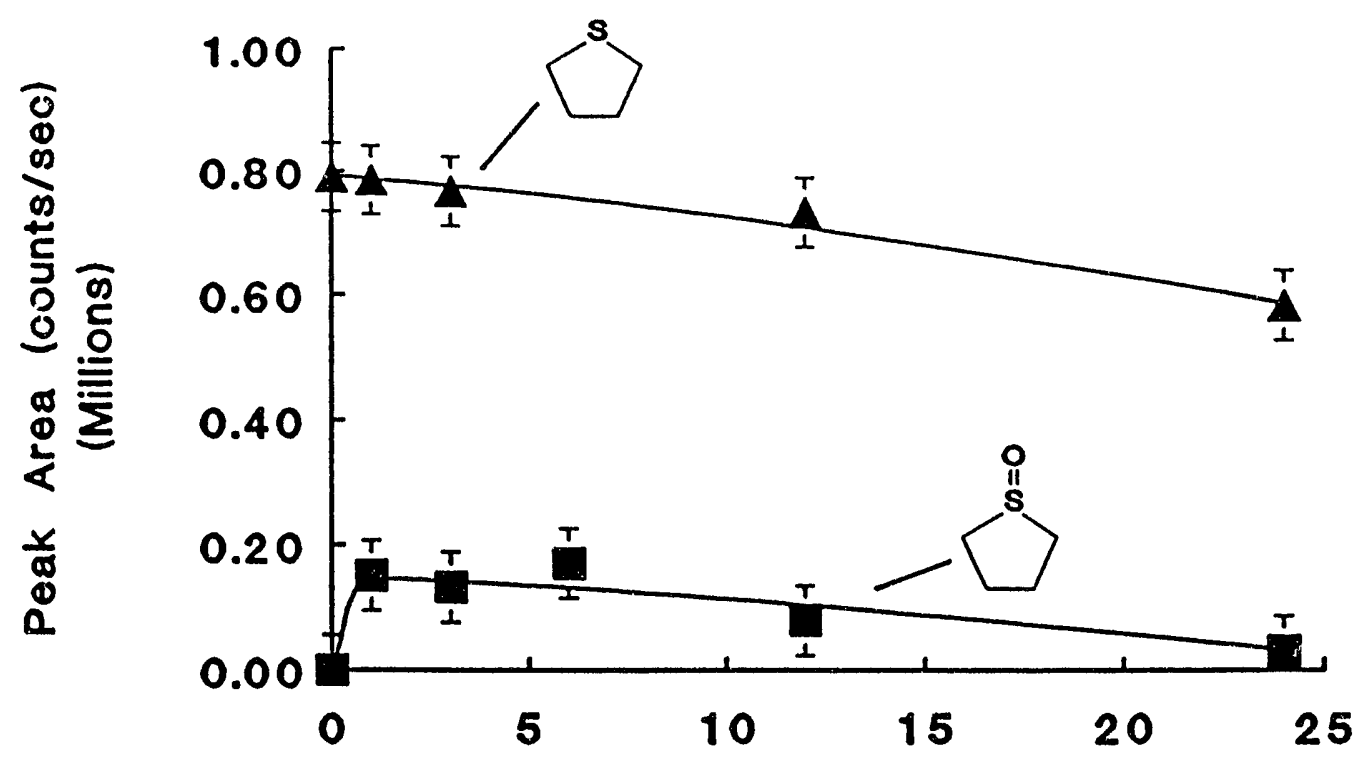

Time (hours)

B

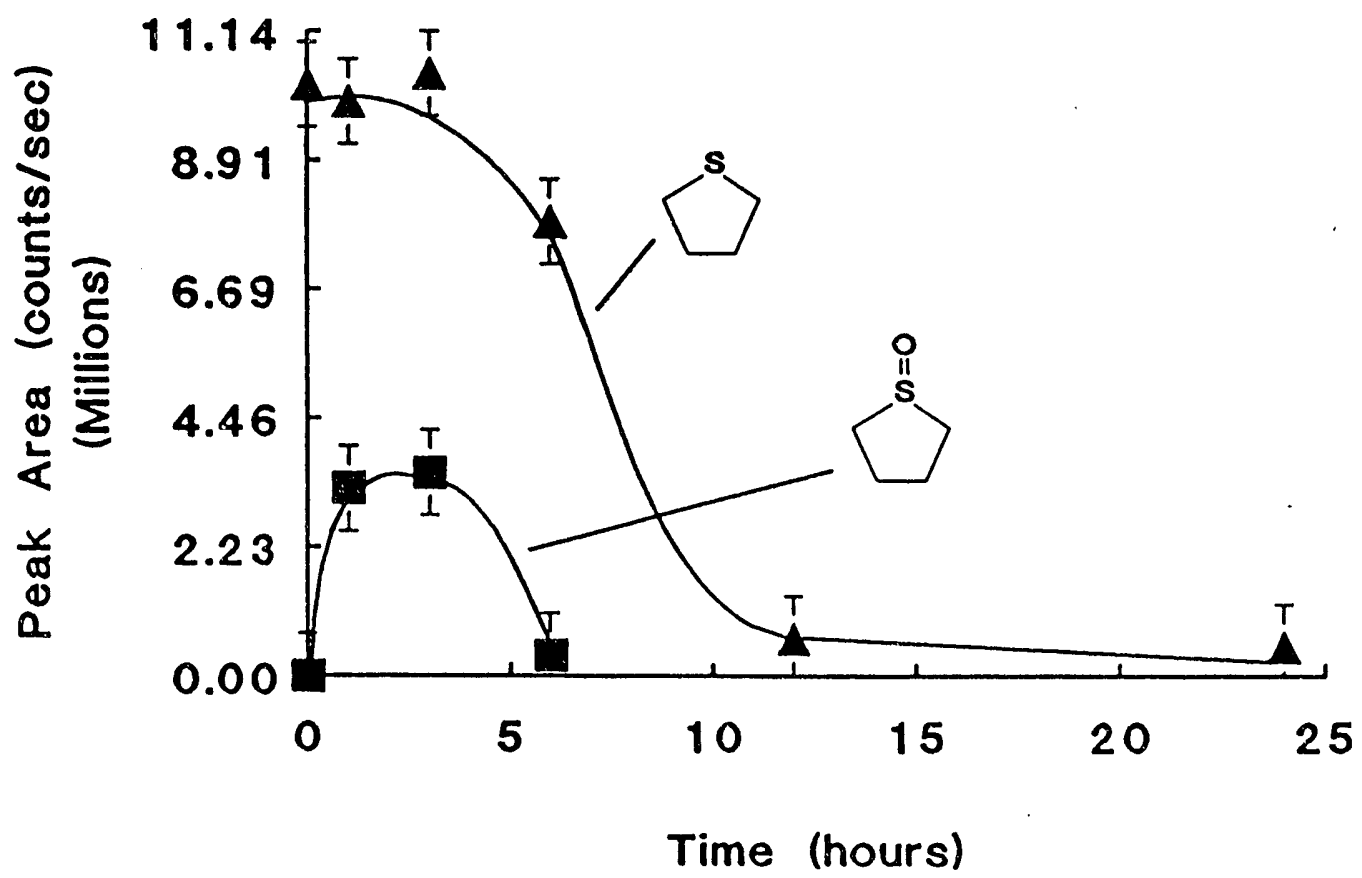

FIGURE 6: Variations of Relative Proportions of Organic Species Detected in GC/MS Analyses as a Function of Time for the Reaction of Tetrahydrothiophene with a $50 \% \mathrm{CuCl}_{2}$ - Water at (A) $50^{\circ} \mathrm{C}$ and (B) $130^{\circ} \mathrm{C}$. 
therefore undetectable. At $130^{\circ} \mathrm{C}$, a solid precipitate was obtained in large enough quantities to perform FTIR analysis. From the infrared spectra, this compound was identified as a derivative of dicyclohexyl sulfone. This compound was not soluble in a variety of solvents such as acetone, dimethylformamide, cyclohexane, or water. Therefore, it was concluded that it was a polymeric species.

Thiophenes. At $50^{\circ} \mathrm{C}$, none of the thiophenic model compounds, benzo[b]thiophene, dibenzothiophene, and thianthrene reacted with $\mathrm{CuCl}_{2}$. The only reaction observed for any of the thiophenic compounds at $130^{\circ} \mathrm{C}$ was for benzo[b]thiophene which underwent a chlorination substitution on the thiophenic ring. These results are shown in Figure 7. This plot shows a stepwise chlorination reaction in which the hydrogens on the thiophenic ring were substituted with chlorine atoms. This reaction indicates that the stabilization of the sulfur moiety, through resonance stabilization, is large enough that no oxidation of the sulfur species occurs.

A comparison of the reaction characteristics of these thiophenic species with the reaction characteristics of tetrahydrothiophene provides insight into the effects of $\pi$-bonding stabilization and its electron withdrawing nature on the reactivity of the sulfur species. Tetrahydrothiophene is a cyclic saturated hydrocarbon and has no $\pi$-bonds. Apparently when the sulfur atom is an integral part of an aromatic ring, such as the thiophenic ring, enough resonance stabilization is obtained to prevent the oxidation reaction from occurring. This stabilization has been attributed to the interaction of the sulfur $d$-orbitals with the $\pi$-bonds of the ring structure ${ }^{4}$.

In comparing these results with the aforementioned requirements for effective desulfurization, it is clear that the $\mathrm{CuCl}_{2}$ reaction at these temperatures is not well-suited for desulfurization. The extent of oxidation of organosulfur compounds was minimum. In the best cases, sulfoxides were created which did not further react. Further oxidation to sulfones, followed by thermal bond cleavage, would have been preferred. Therefore this reaction was attempted at higher temperatures. 
(suo!!I!W)

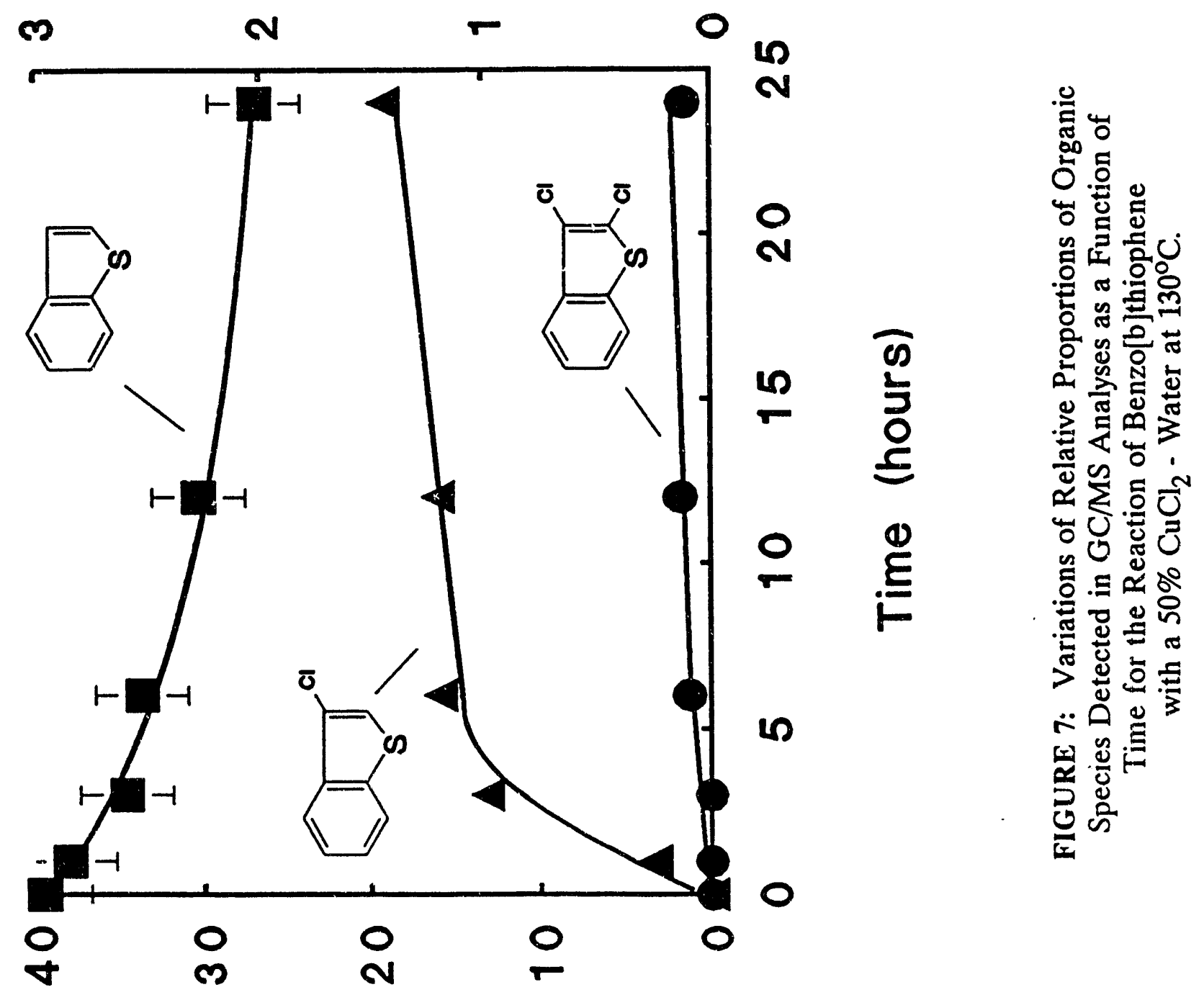

(suo!l!!W)

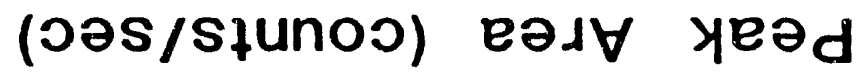


Reaction of Model Coal Compounds at $210{ }^{\circ} \mathrm{C}$

Thiols, Disulfides. Examination of the reactivity of the disulfide species with $\mathrm{CuCl}_{2}$, which are represented by: phenyl disulfide, thiophenol, and cyclohexyl mercaptan (recall that the thiol group was immediately oxidized to a disulfide linkage), showed no further copper-promoted reactive oxidation as demonstrated in Figure 8 and Figure 10. The principle organic products produced in the thiophenol reaction were: benzene, an isomeric mix of trichlorobiphenyls, chlorobenzene, phenyl sulfide, and mono-chlorinated phenyl sulfide. Figure 8 is a plot of the relative proportions of the products as shown in percent response, relative to the reaction time for the thiophenol reaction. In addition to these species, there is a large fraction (ca. 80\%) of the total response due to diphenyl disulfide at the 1 hour reaction time. However, this species is not detected at any of the other reaction times. At longer reaction times (12 and 24 hours), small quantities (less than $10 \%$ total response) of dichloro- and trichloro- benzene and trichlorophenol were also detected. The phenyl disulfide results were very similar to those of oxidized thiophenol, with the exception that trace quantities (less than $5 \%$ total response) of dichlorothianthrene and small amounts $(10-15 \%$ total response) of dichlorodibenzothiophene were produced at the longer reaction times. These results indicate that the only reactions occurring were catalyzed thermal cleavage reactions (shown by the increase in benzene and other one-ring organic species) and chlorination (shown by the increase in both sulfur and non-sulfur containing chlorinated species). In addition to the organic species produced, the percent conversion of sulfur species to sulfate varied linearly with respect to reaction time as shown in Figure 9. This is a plot of percent conversion to sulfate for the thiophenol reaction. This shows that the sulfur moiety undergoes oxidation, leading to the production of sulfate.

The other disulfide, produced by the immediate oxidation of cyclohexyl mercaptan, reacted to form a precipitate and several organic products: naphthalene (some of which were partially hydrogenated), methyl-substituted naphthalene, biphenyl species, dibenzothiophenes (some of which were partially hydrogenated), 


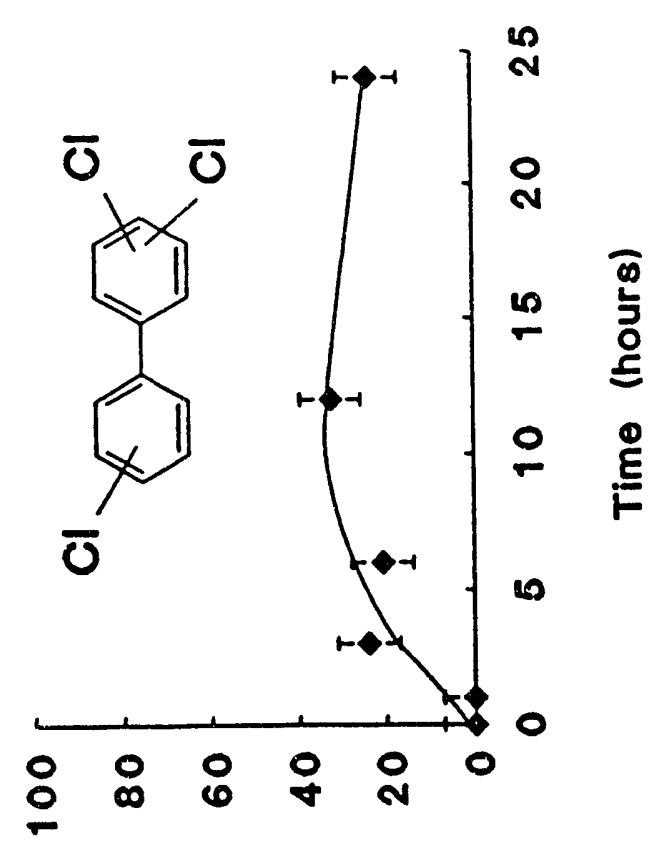

әsuodsəy juəodəd

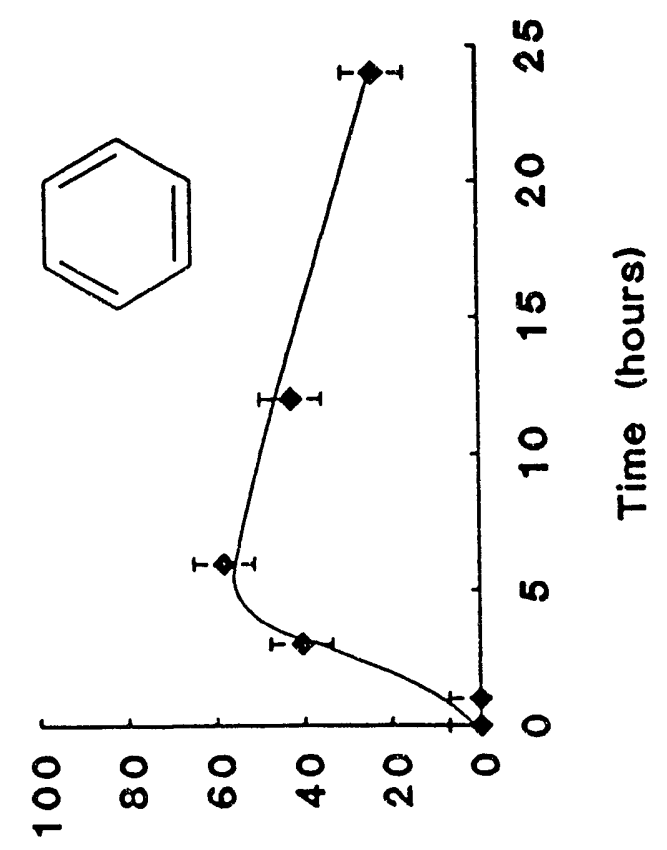

esuodsay fuәOdәd
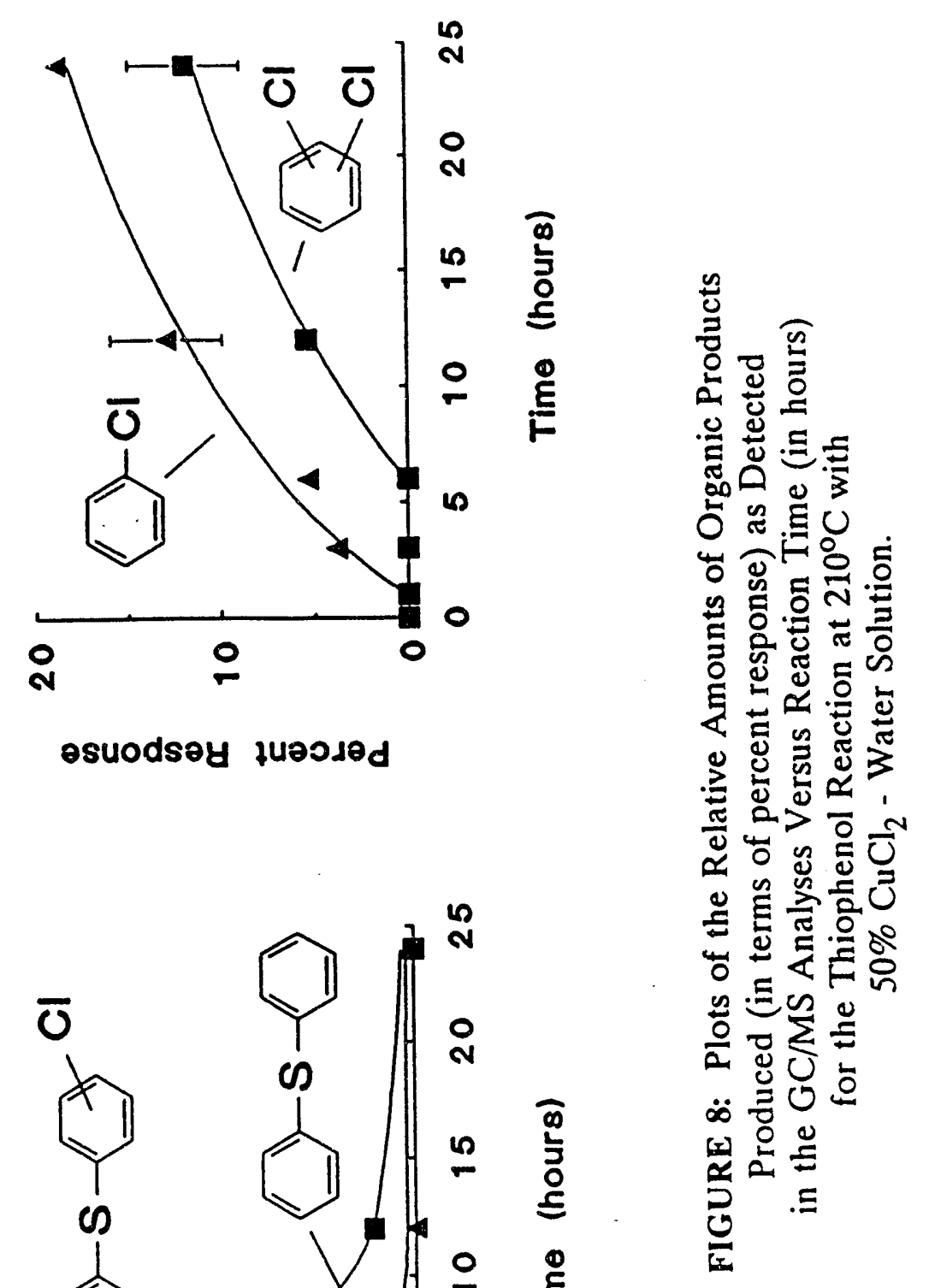

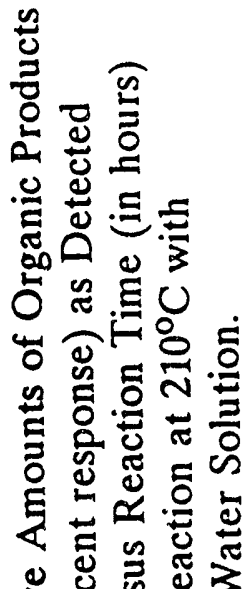

0 ठ

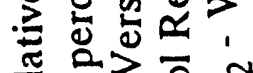

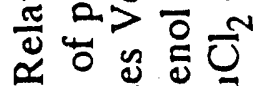

n

ป造管。

○

응 $\sum_{0} \equiv$

。

욍ㅇㅁ욤

苯

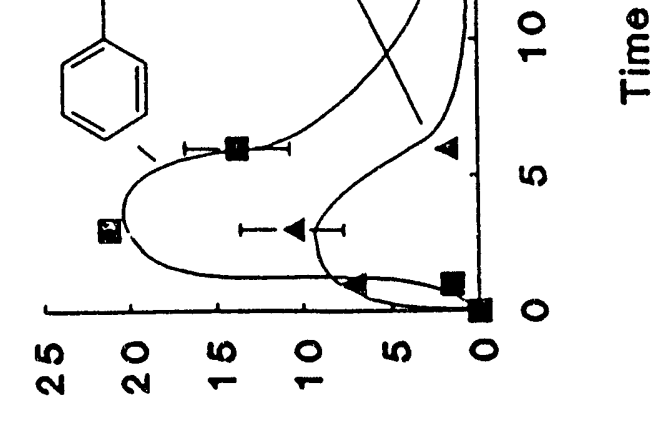

әsuodsay juəodad 


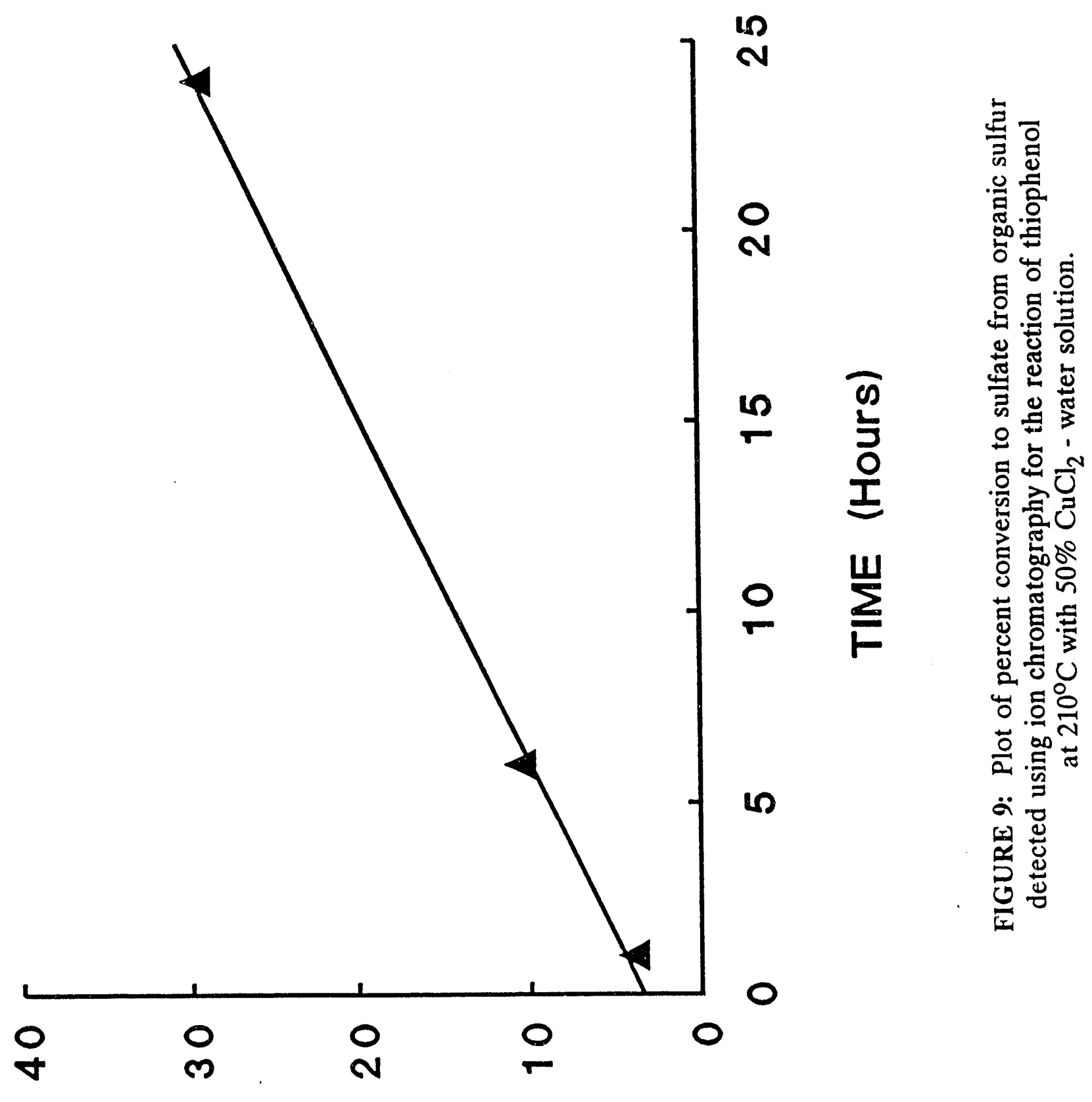

uo!stonuos әfefing quә0גәd 
mono- and dichlorinated phenols, benzene, and cyclopentyl benzene. Figure 10 shows these predominant organic phase products and their relative responses with respect to reaction time. The only other organic products produced were phenol and 3-(methylcyclopentyl) benzene, both in trace quantities and detected only at the longer reaction times.

The only difference between cyclohexyl mercaptan and phenyl disulfide is the aromaticity of the benzene rings. Due to this lack of structural stabilization in the cyclohexyl mercaptan species and its electron-withdrawing group, the disulfide produced from cyclohexyl mercaptan underwent carbon-carbon bond cleavage and rearrangement reactions more easily than phenyl disulfide, producing a variety of organic compounds, as well as sulfur-containing dibenzothiophene. At the longer reaction times, dibenzothiophene was most likely converted to substituted naphthalene, while sulfur was converted, in a small fraction, to sulfate (as shown in Figure 11A) or, with other organic species at the longer reaction times, incorporated into the solid (polymer) matrix (as shown in Figure 11B by the decrease in total organic species concentration).

Sulfides. Examination of sulfide compounds (tetrahydrothiophene, methyl $p$-tolyl sulfide, and phenyl sulfide) at $210^{\circ} \mathrm{C}$ revealed oxidation products, chlorinated species, and organic degradation products. The reaction of $\mathrm{CuCl}_{2}$ at $210^{\circ} \mathrm{C}$ with tetrahydrothiophene produced the polymer examined previously, a small fraction of 2,3,6-trichlorothianthrene, and sulfate. The 2,3,6-trichlorothianthrene species was not detected at either the very short ( 1 hour) or long (12 and 24 hours) reaction times. However, it made up approximately $50 \%$ of the total organic response (with the balance being the parent tetrahydrothiophene species) for the 3 and 6 hour reaction times. This demonstrates that although the kinetics of formation of this species are not fast enough to produce 2,3,6-trichlorothianthrene at short reaction times, the subsequent degradation ultimately takes over at longer reaction times.

Reacting methyl $p$-tolyl sulfide with $\mathrm{CuCl}_{2}$ at $210^{\circ} \mathrm{C}$ produced, principally, the following organic species: toluene, methyl p-tolyl sulfone, 4-methyl 


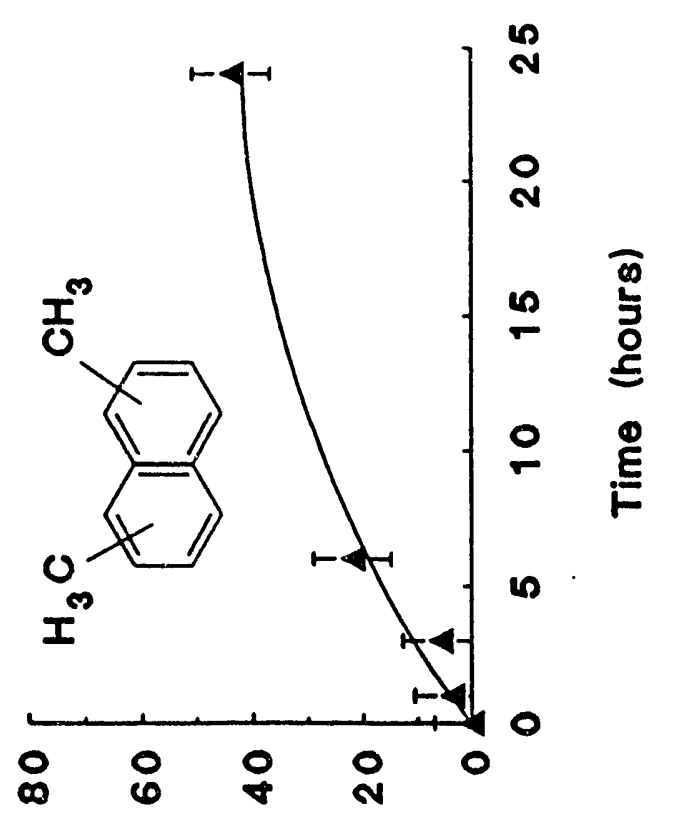

esuodsey fueoded
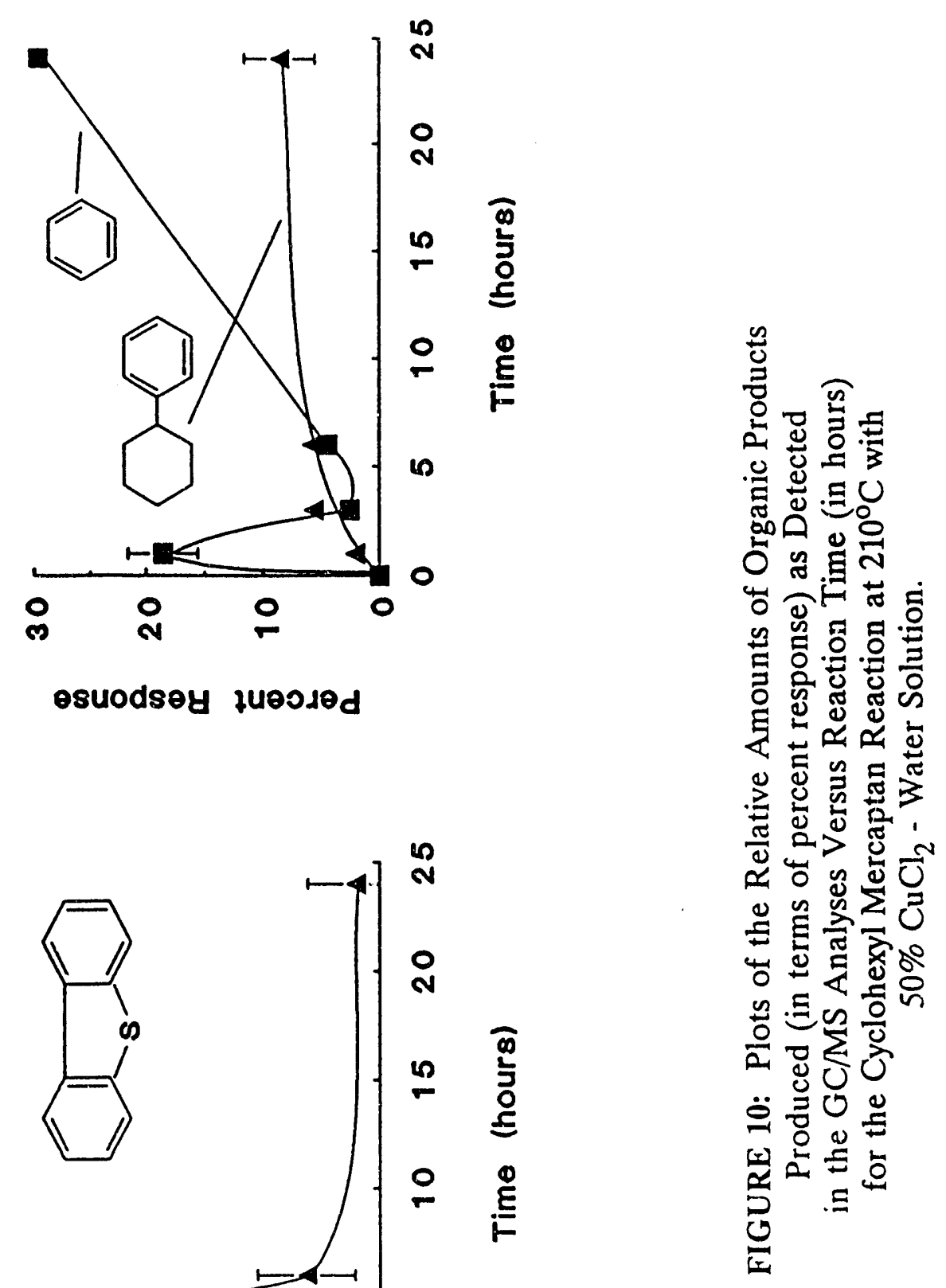
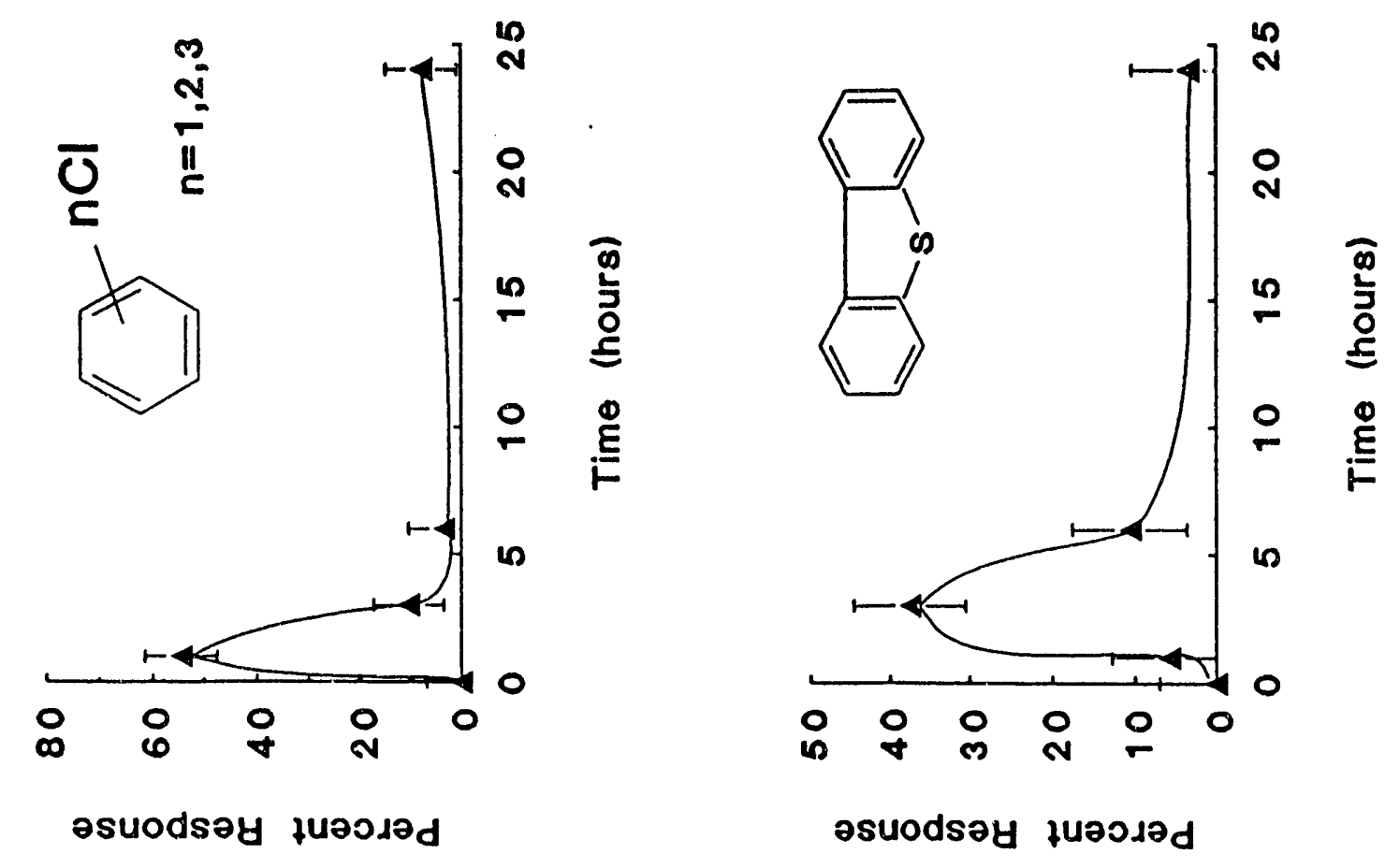
A

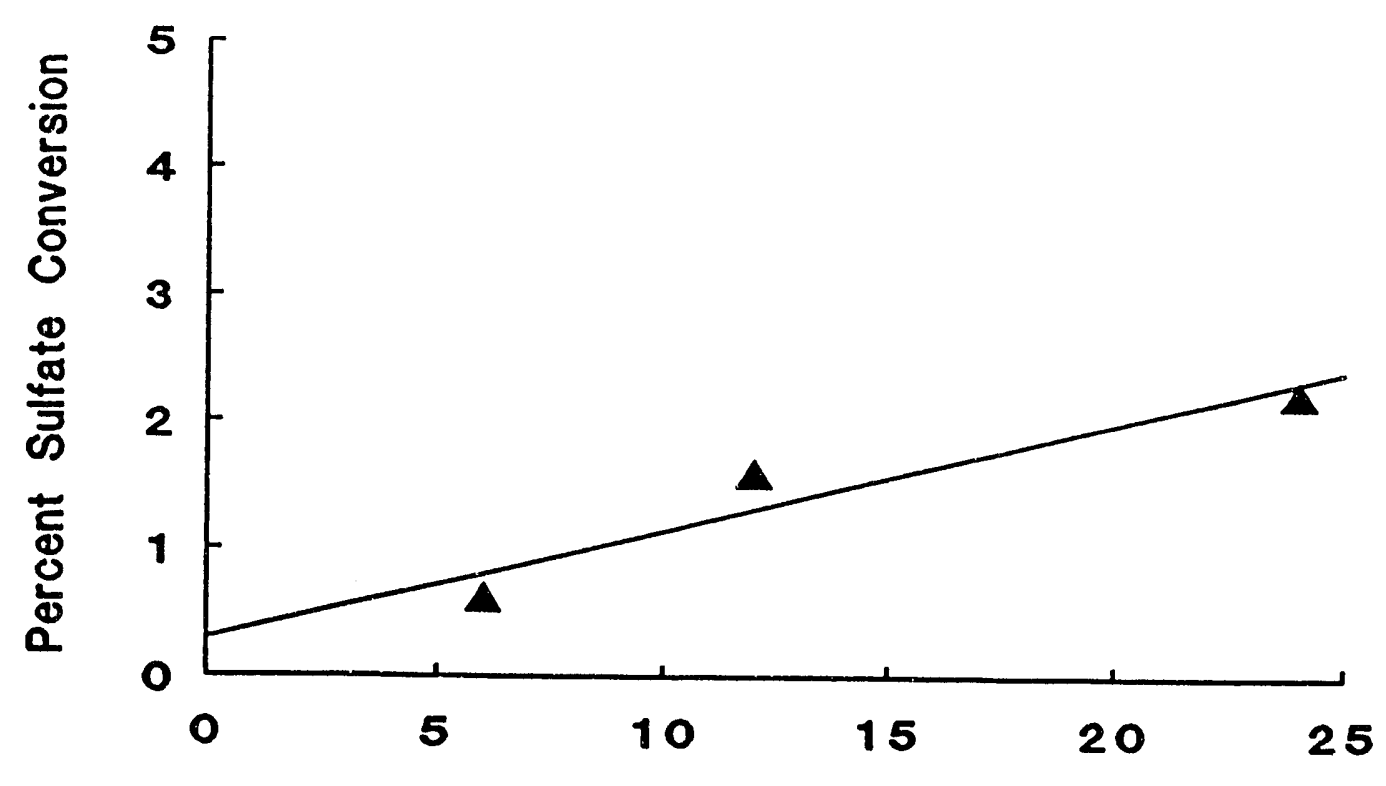

TIME (Hours)
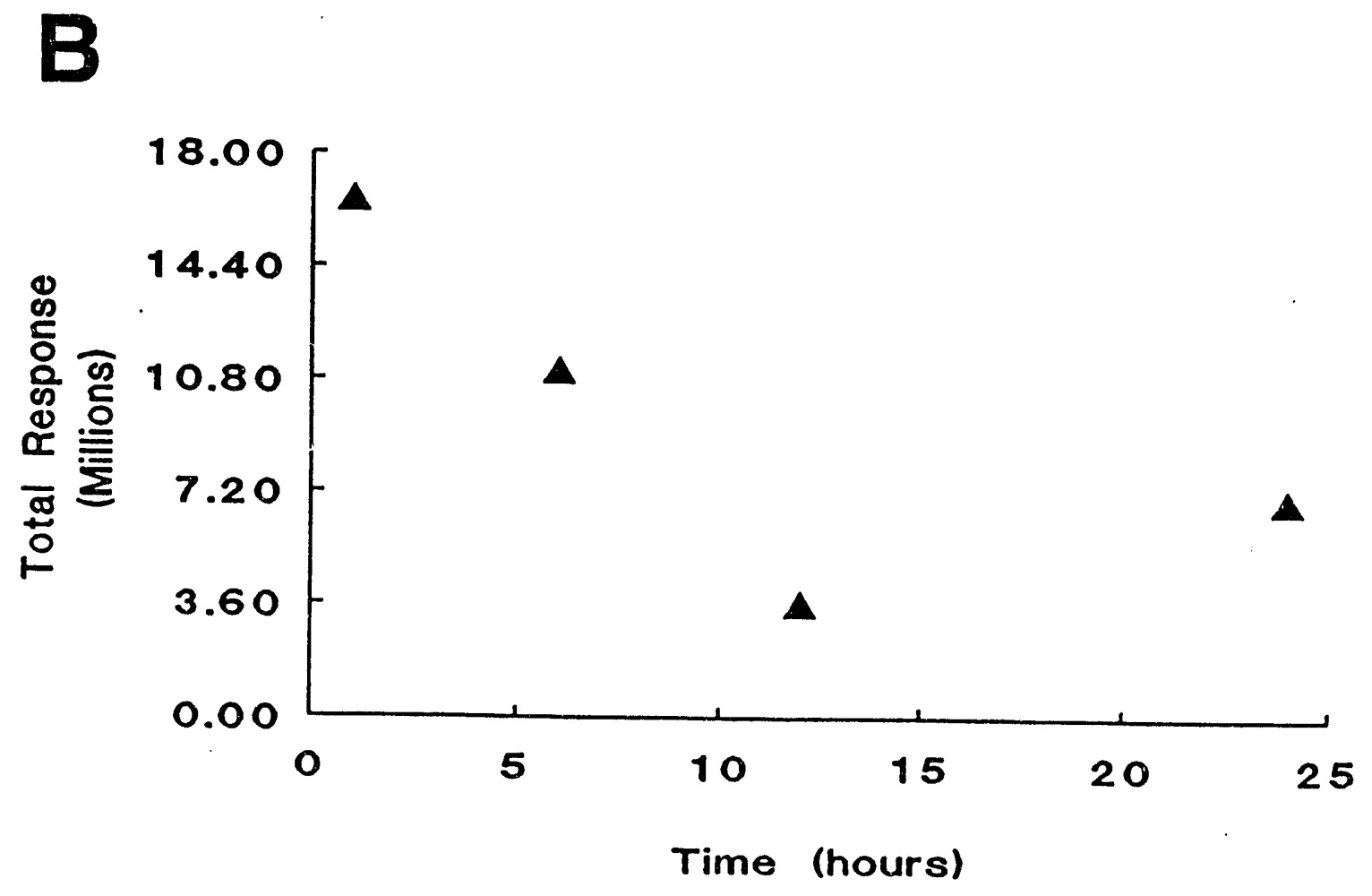

FIGURE 11: Results of cyclohexyl mercaptan reaction with $50 \% \mathrm{CuCl}_{2}$ - water solution at $210^{\circ} \mathrm{C}$ showing: (A) the percent sulfate conversion, and (B) total organic species response versus reaction time. 
benzaldehyde, and a variety of chlorinated organic species (2,4,6-trichlorophenol, $p$-chlorotoluene, and $o$-chlorotoluene). Figure 12 shows the percent total response for the principle organic species produced at $210^{\circ} \mathrm{C}$, versus reaction time for the methyl $p$-tolyl sulfide reaction. Trace levels ( $<5 \%$ total response) of bitolylmethane were also detected. In addition, sulfate was detected in significant quantities in the aqueous layer, with the amount ranging from 5 to $40 \%$ sulfur conversion, increasing with reaction time (see Figure 13A). A decrease in the total organic species response (figure 13B) coupled with the formation of a solid precipitate, most likely a polymer, suggests a polymerization reaction was occurring. While infrared analysis of this precipitate was conducted, the identification of the solid could not be determined.

Figure 12 shows that thermal cleavage reactions of methyl $p$-tolyl sulfide occur quickly at $210^{\circ} \mathrm{C}$. This is indicated by the initial large fractions of toluene and methyl $p$-benzaldehyde. Further oxidation of the initial reactant is slightly slower, as shown by the relatively small concentration of oxidized methyl p-tolyl sulfide detected at the short reaction time. As reaction time increased, the conversion of the sulfate, organic, and methyl $p$-benzaldehyde species to the polymer increased. This was demonstrated by a decrease in total concentration of these species detected after the reaction. The chlorinated species and the methyl $p$-tolyl sulfone, however, comprised a larger fraction of the remaining organic species in the products. Apparently, methyl $p$-tolyl sulfone was not being incorporated into the polymer matrix, and the chlorinated species are quite stable under these conditions.

The predominant organic species detected after the reaction of phenyl sulfide with $\mathrm{CuCl}_{2}$ at $210^{\circ} \mathrm{C}$ are shown in Figure 14. These species included: the parent phenyl sulfide, mono- and dichlorinated phenyl sulfide, phenyl sulfone, diphenyl- dihydroxyl sulfide, and mono-, di-, and tri- chlorinated benzene, dibenzothiophene and mono-chlorinated dibenzothiophene. The site of chlorination, for the mono- and dichlorinated phenyl sulfide and the chlorinated 


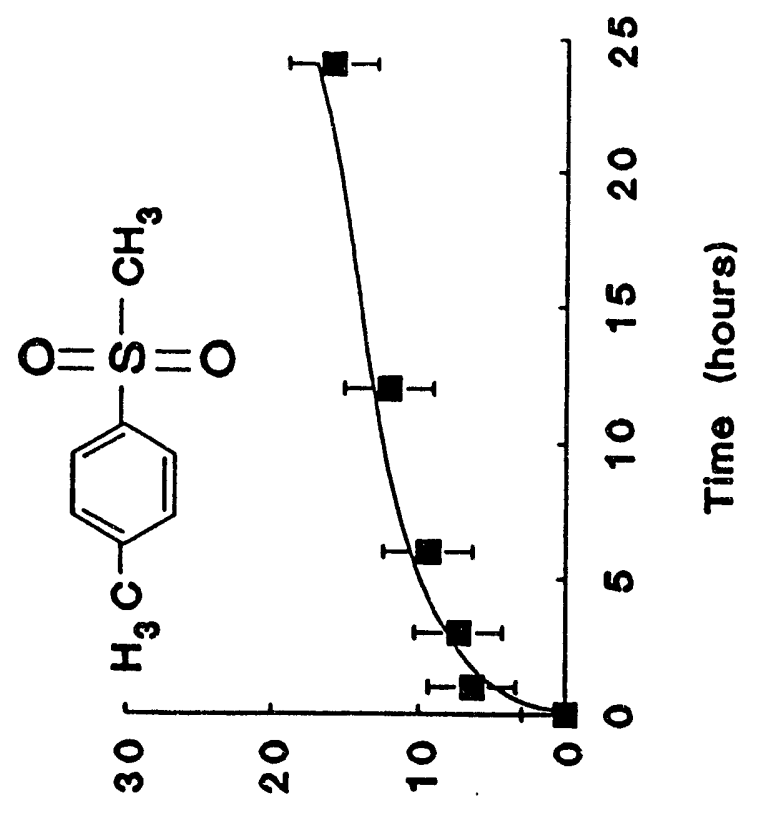

esuodsey fuөoded

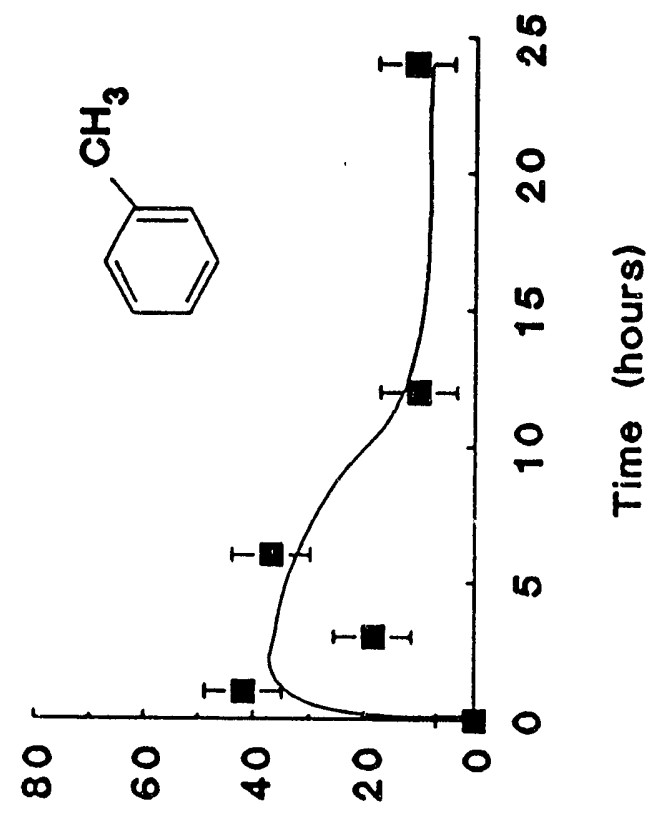

әsuodsəy fuəodəd

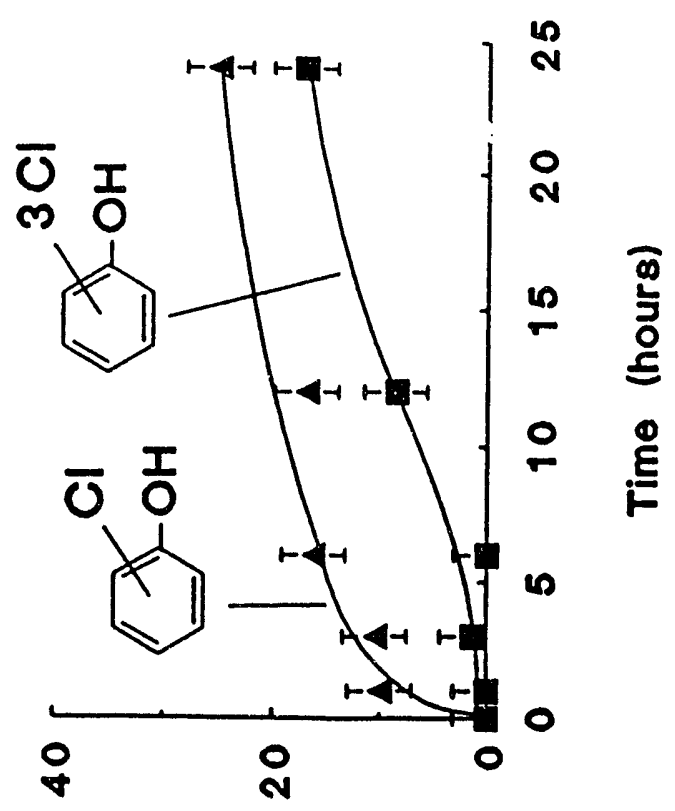

esuodsey juesded

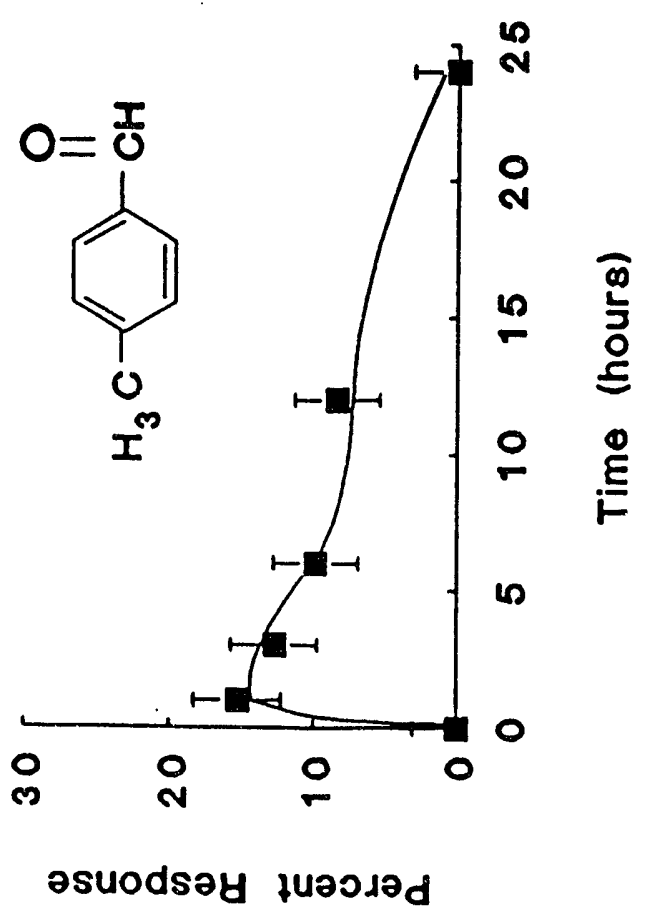

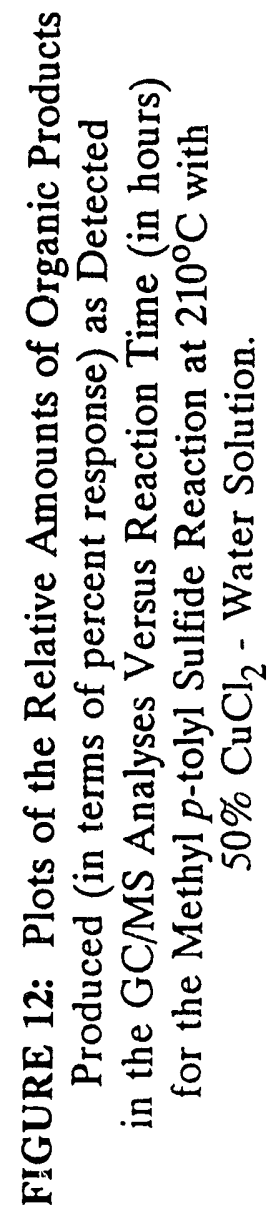


A

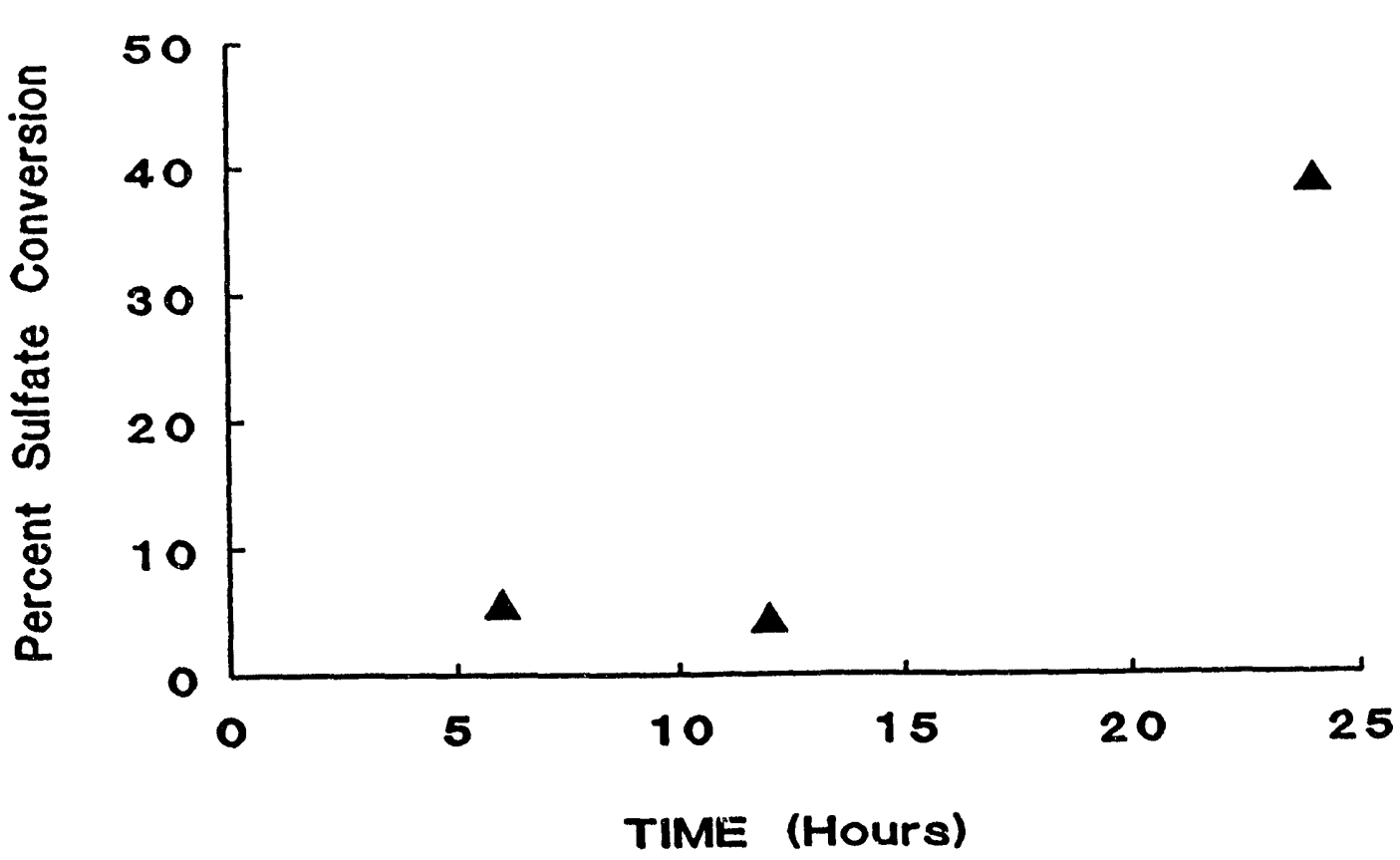

B

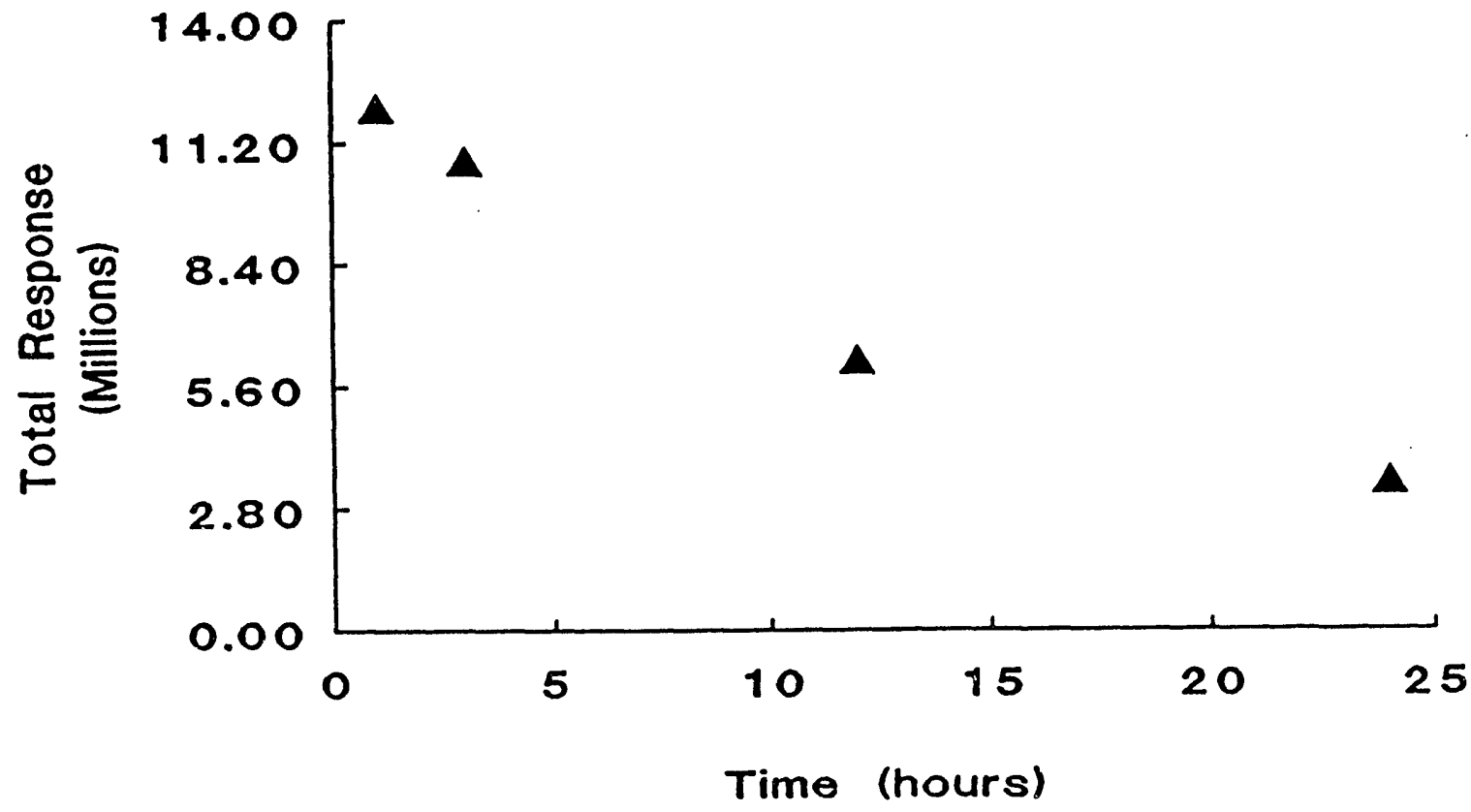

FIGURE 13: Results of Methyl $p$-tolyl Sulfide Reaction with $50 \% \mathrm{CuCl}_{2}$ - Water Solution at $210^{\circ} \mathrm{C}$ Showing: (A) the ${ }^{-}$Percent Sulfate Conversion, and (B) Total Organic Species Response Versus Reaction Time. 


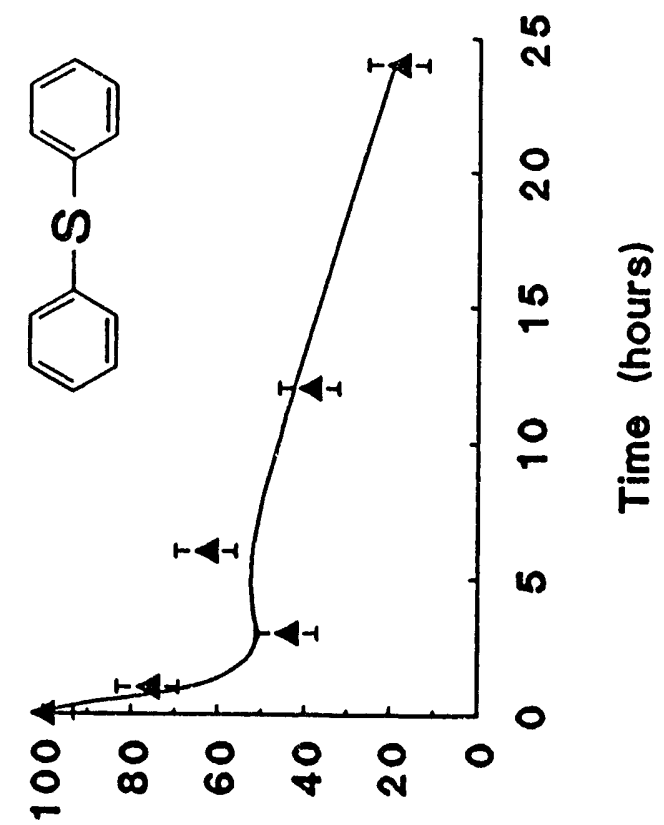

әsuodsey fuəosed

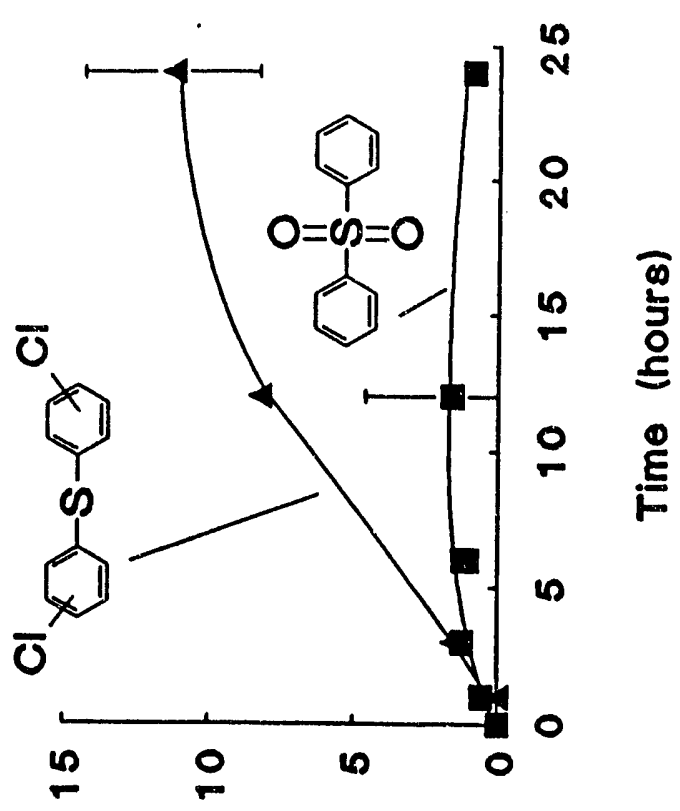

өsuodsəy fuəosəd $\bar{u}$
1

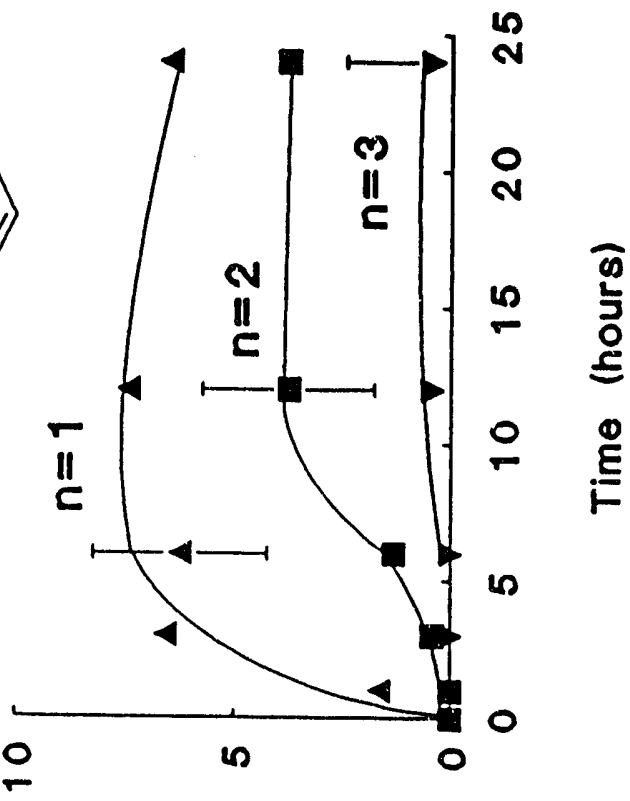

әsuodsəy tuəodəd

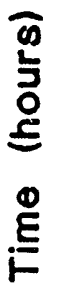

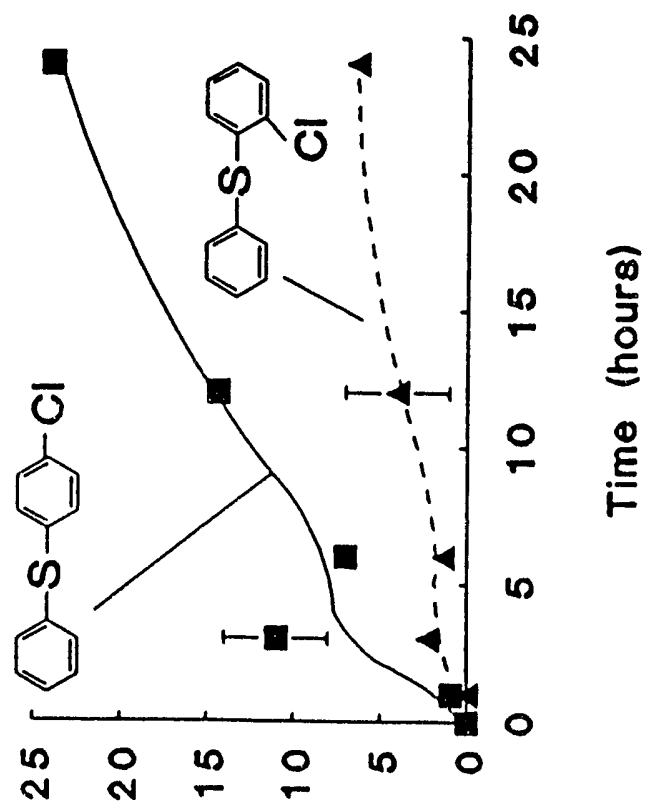

әsuodsəy fuәวגәd

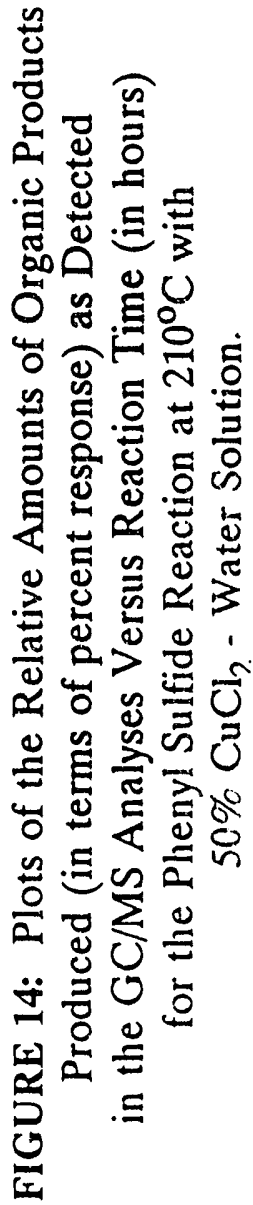


dibenzothiophene, was equally distributed among ortho, meta, and para substitution. Other species produced, but only in trace quantities (less then $5 \%$ of organic products detected) were: 2,4,6-trichlorophenol and biphenyl. A notable difference between the products of the reaction of this sulfide and methyl $p$-tolyl sulfide is the lack of precipitate formed from phenyl sulfide and negligible sulfate formation (about 1-2\% sulfur conversion over the reaction times studied - see Figure 15). Most likely these differences are due to the presence of the second phenyl ring. This hypothesis is supported by the relative unreactive nature of tive sulfur moiety on phenyl sulfide to undergo oxidation. Although trace amounts of oxidized phenyl sulfide and sulfate were formed, the predominant fraction of organic species detected were unreacted phenyl sulfide or chlorinated phenyl sulfide. These results suggest that, if this species is present in the coal matrix, it preferentially undergoes chlorination over oxidative desulfurization under the above conditions.

Thiophenes. The final class of organosulfur species examined, the thiophenes (represented by benzo[b]thiophene and dibenzothiophene), showed little oxidative reaction of the sulfur moiety. The predominant reaction mechanism occurring was chlorination of the organic species. Figure 16 shows the results of the benzo[b]thiophene reaction at $210^{\circ} \mathrm{C}$ and the relative response of the products detected, versus reaction time. The predominant products were: the parent benzo[b]thiophene compound, and mono-, di-, and tri-chlorinated benzo[b]thiophene. Chlorobenzene structures (mono-, di-, and trichlorobenzene) were detected at the longer reaction times (6-24 hours) and were directly related to reaction time, but accounted for less than $10 \%$ of the total products. The decrease in the total response curve (figure 17A), which was determined by GC/MS analysis of the organic extract, was caused by the formation of an organic precipitate and sulfate found in the aqueous extract (figure 17B). Since the only organic species detected, aside from the parent compound, were either chlorinated aromatic species or chlorinated benzo[b]thiophene species, the presence of sulfate in the aqueous phase is attributed to conversion via chlorinolysis. 


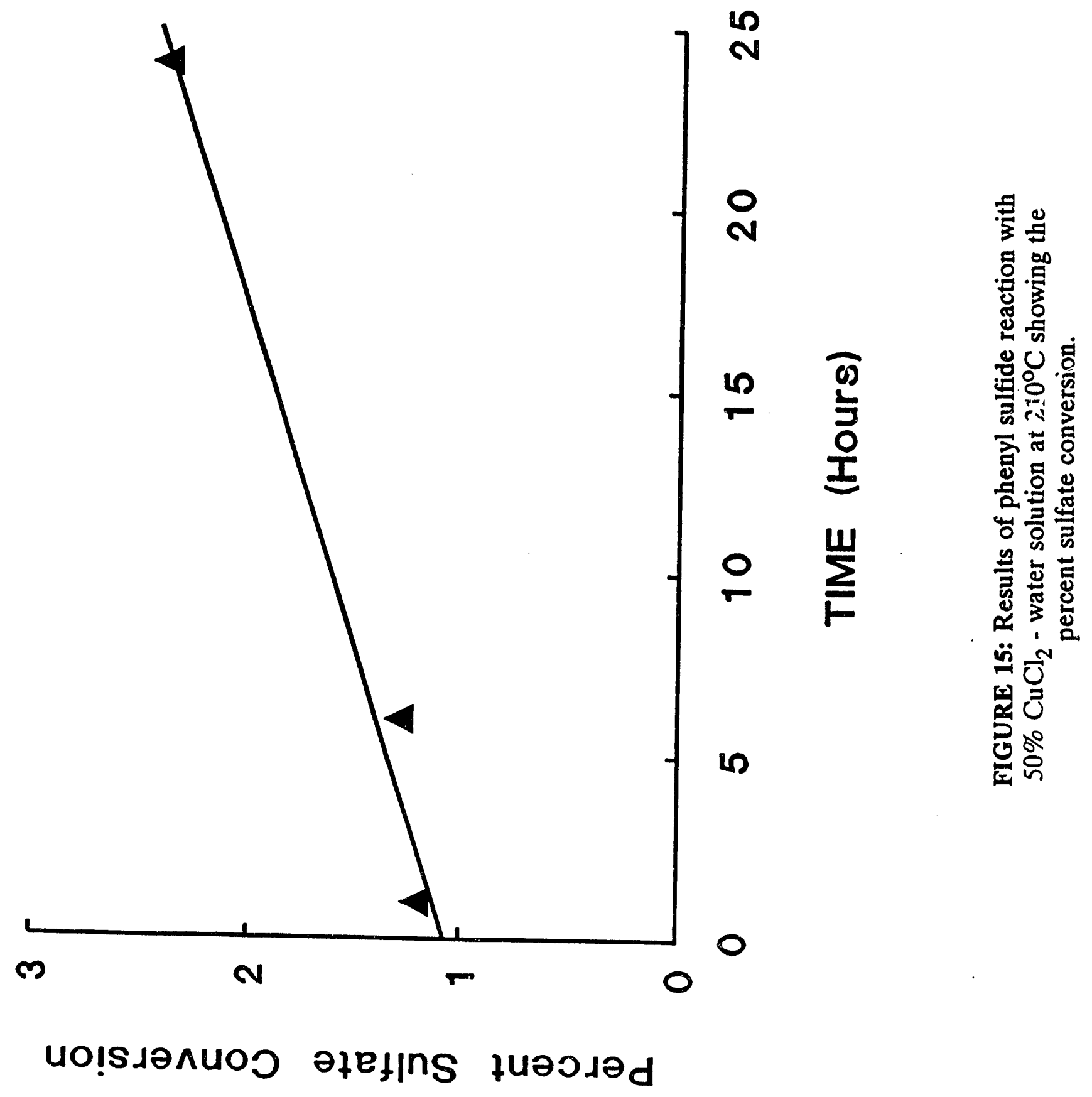




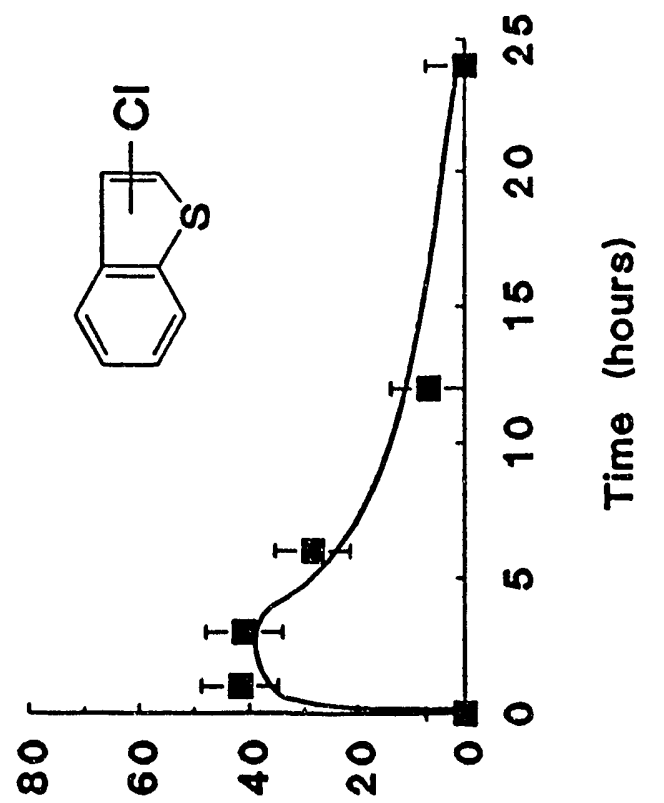

osuodsey fueosed

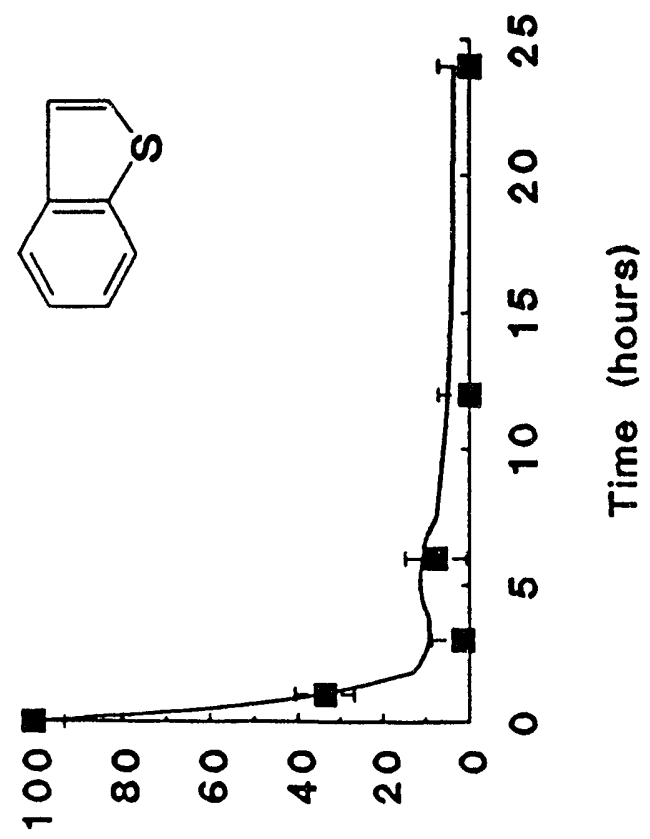

əsuodsəy fuəosəd

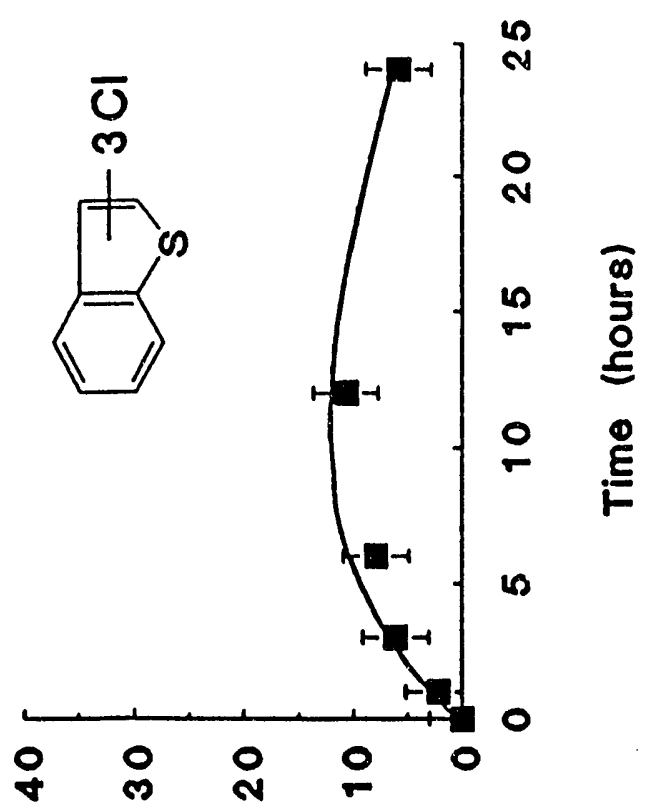

өsuodsey นuөoded

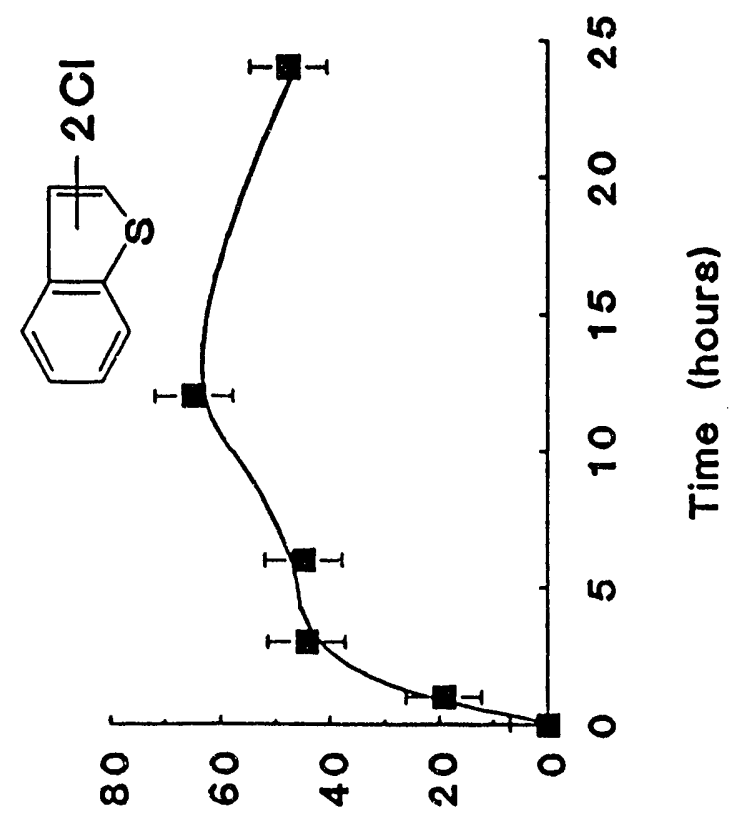

әsuodsay fuəodəd

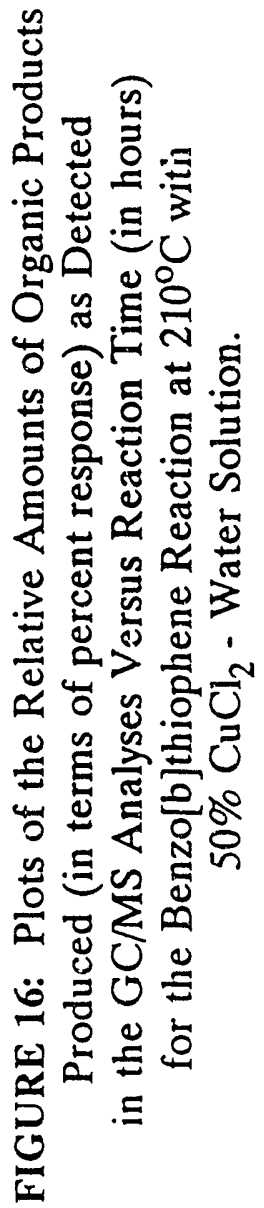


A

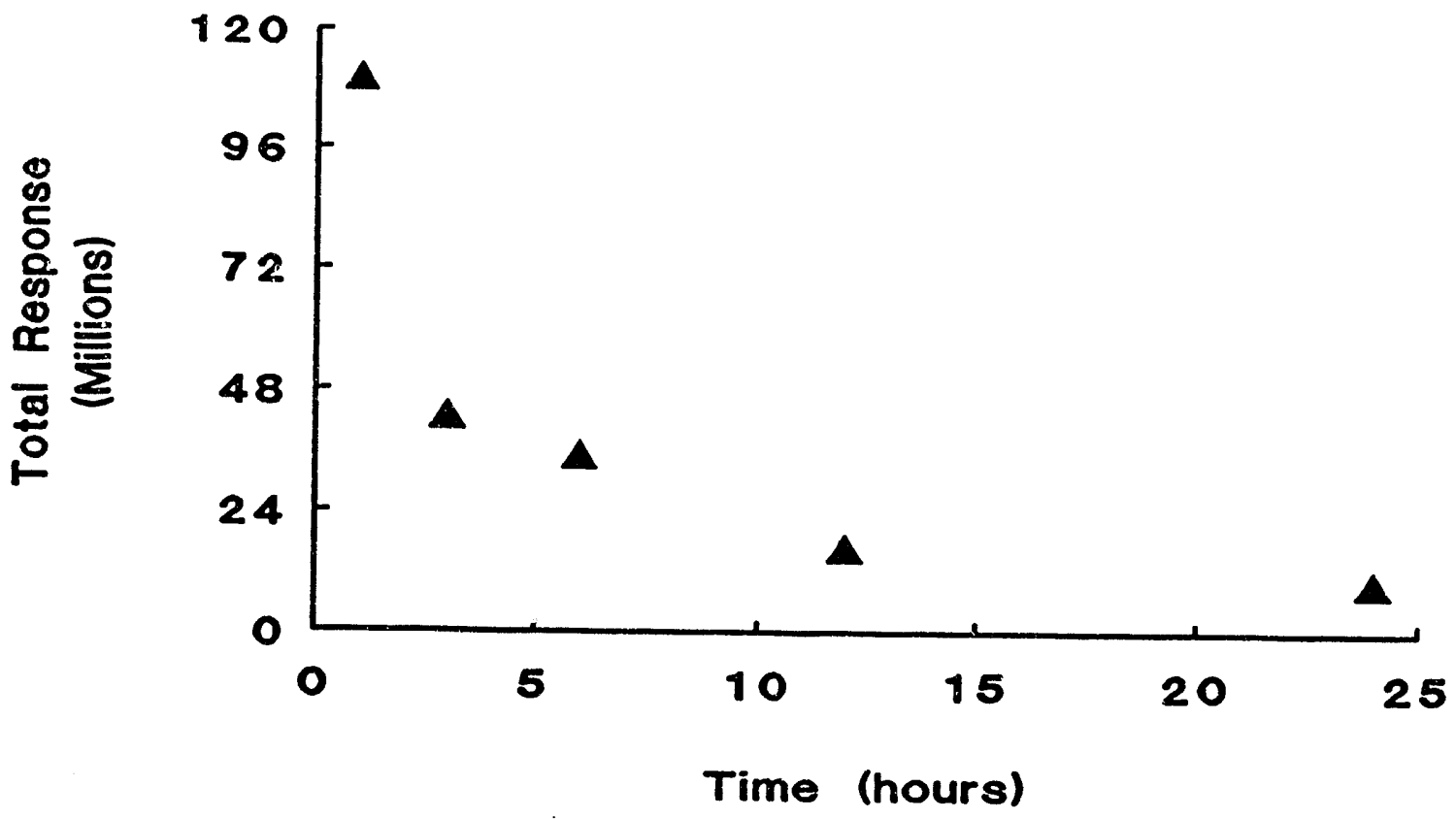

B

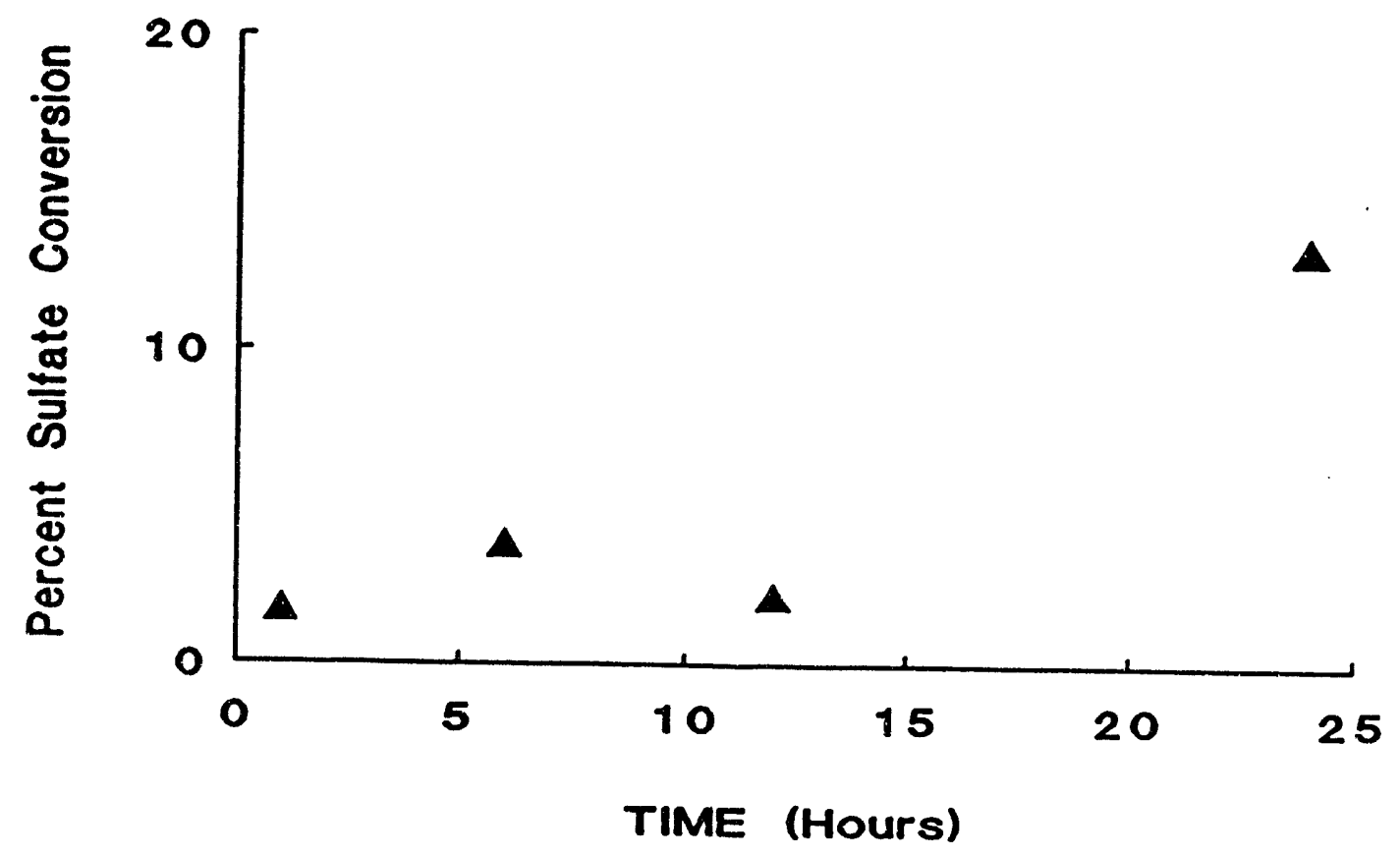

FIGURE 17: Results of Benzo[b]thiophene Reaction with $50 \% \mathrm{CuCl}_{2}$ - Water Solution at $210^{\circ} \mathrm{C}$ Showing: (A) the Total Organic Species Response, and (B) Percent Sulfate Conversion Versus Reaction Time. 
Figure 18 is a plot of the percentage of total response in the organic phase of major organic species present versus reaction time for the $\mathrm{CuCl}_{2}$ - dibenzothiophene reaction at $210^{\circ} \mathrm{C}$. The predominant species detected were: the parent dibenzothiophene and dichlorinated dibenzothiophene (all isomers of dichlorinated dibenzothiophene were equally present). Other organic species detected were: diphenyl disulfide and diphenyl sulfide, present in large amounts at the 1 hour reaction time, but not present at longer reaction times; mono-, di-, and trichlorinated benzene, not present at the short reaction times, but increasing at the longer ( 6,12 , and 24 hour) reaction times; and dichlorinated thianthrene, present only at the intermediate ( 12 hour) reaction time. However these species were detected only at trace levels. No additional species (such as precipitate or sulfate). were detected. Therefore, it is believed that these organic species are the only products of this reaction. The primary reaction is chlorine substitution on the aromatic ring structure of dibenzothiophene. Thus, under these reaction conditions, dibenzothiophene, which is the compound commonly used to model coal structure, shows no reactive desulfurization.

In summary, compared to the $50{ }^{\circ} \mathrm{C}$ and $130{ }^{\circ} \mathrm{C}$ reactions, the increased temperature of this reaction enhanced desulfurization of the model compounds. The methyl $p$-tolyl sulfide reaction produced toluene at short reaction times and the phenyl sulfide reaction produced phenyl sulfone. Reacting thiophenol (and phenyl disulfide) produced a large amount of benzene, the desulfurized form of the parent compound, at short reaction times. In the benzo[b]thiophene reaction, only chlorination of the aromatic ring was detected in the mass spectrum. However the proportion of sulfate in the $\mathrm{H}_{2} \mathrm{O}$ soluble extract increased with reaction time, indicating that some oxidative desulfurization of the benzo[b]thiophene had occurred. In coal under these conditions, the benefits of the desulfurization process are somewhat negated by the added contamination of chlorine in the coal matrix. This was shown throughout the model coal compound reactions as chlorination of both the desulfurized and parent compounds occurred to a large degree, 
A

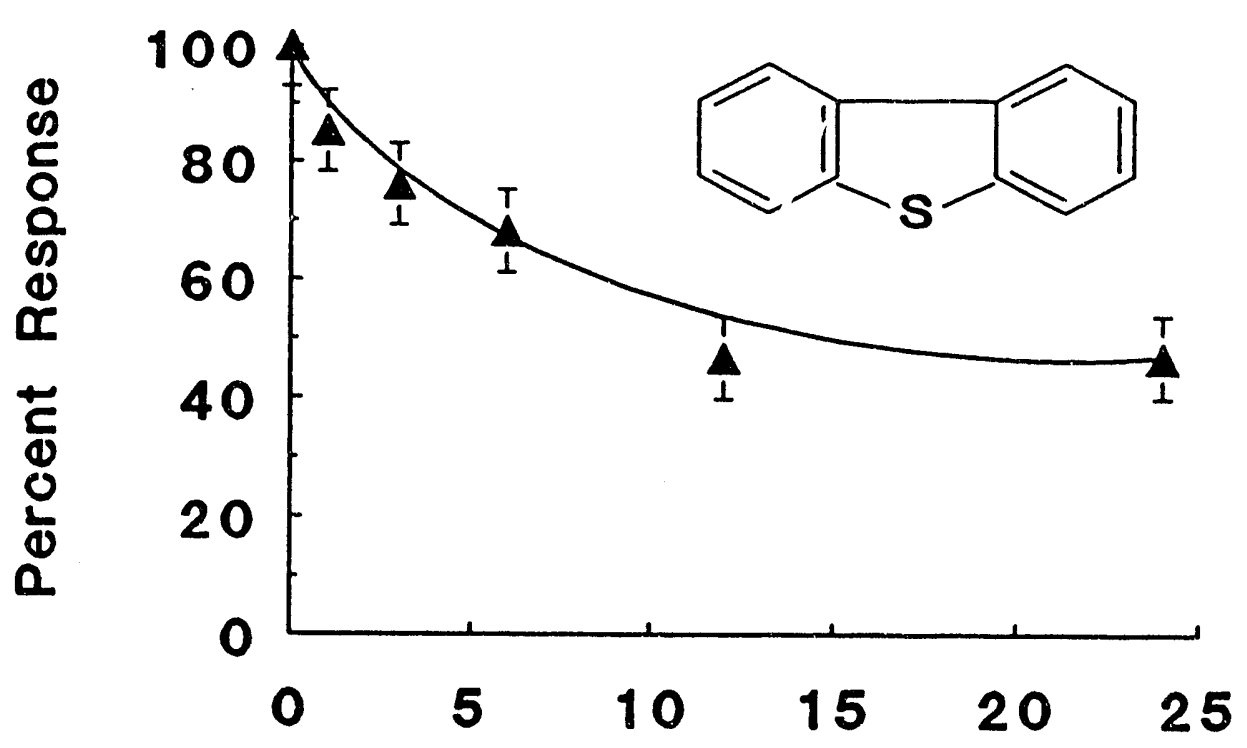

\section{Time (hours)}

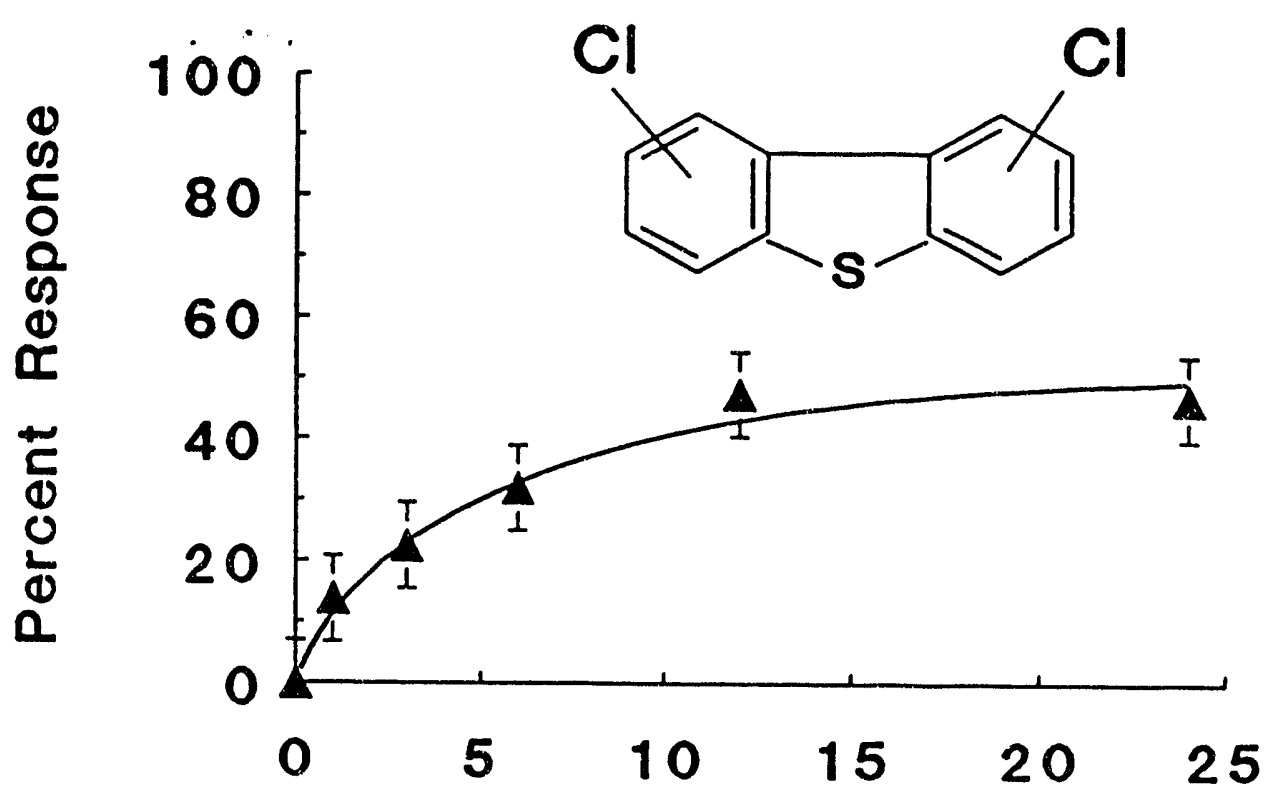

Time (hours)

FIGURE 18: Plots of the Relative Amounts of Organic Species [(A) Dibenzothiophene, (B) 1-chloro,dibenzothiophene] Detected (in terms of percent response) in the GC/MS Analyses Versus Reaction Time (in hours) for the Dibenzothiophene - Reaction at $210^{\circ} \mathrm{C}$ with $50 \% \mathrm{CuCl}_{2}$ - Water Solution. 
proportional to the reaction time. With this information, the reaction was attempted at an even higher temperature to determine if the desulfurization reaction could be increased over the chlorination reaction.

\section{Reactions of Model Coal Compounds at $295^{\circ} \mathrm{C}$}

At the highest temperature examined, $295^{\circ} \mathrm{C}$, all compounds underwent cleavage, chlorination, and oxidation reactions to varying degrees when reacted with aqueous $\mathrm{CuCl}_{2}$. The reaction products were the same for all the model compounds studied, but the relative amounts of the products differed for each species. Since there was no weighing for any particular isomer of each of the products formed and there was a considerable amount of species produced, each product was classified into its empirical formula, disregarding isomeric structure. The results for the species studied are displayed in Figures 19-22 in bar chart format as relative amount of total response versus type of species produced. These plots show that the only products detected (and their designations) for all the model compounds were: benzene [Benz], chlorobenzene [ClBen], dichlorobenzene [2ClBen], trichlorobenzene [3ClBen], tetrachlorobenzene [4ClBen], penta- and hexachlorobenzene [5,6 ClBen], chlorinated phenols [ClPhnol], and chlorinated (mono-, di-, and tri-) dibenzothiophene [CIDBT].

Thiols, Disulfides. Cyclohexyl mercaptan did not have any detectable organic-based reaction products or parent species in the GC/MS analysis. This suggests that the organic species produced were of low enough molecular weight to be masked by the solvent peak in the chromatogram. The reaction of thiophenol under these conditions is shown in Figure 19. As expected, due to the presence of only a single phenyl ring, no dibenzothiophene was formed in the reaction. The extent of chlorination, at the short reaction times, was minimal. At these short reaction times, the predominant species detected was unsubstituted benzene, probably due to the cleavage of the C-S bond. A second product detected was chlorinated phenol. However, this was only seen at the shorter reaction times. As the reaction proceeds, cleavage of the $\mathrm{C}-\mathrm{OH}$ bond occurs, and chlorination of 


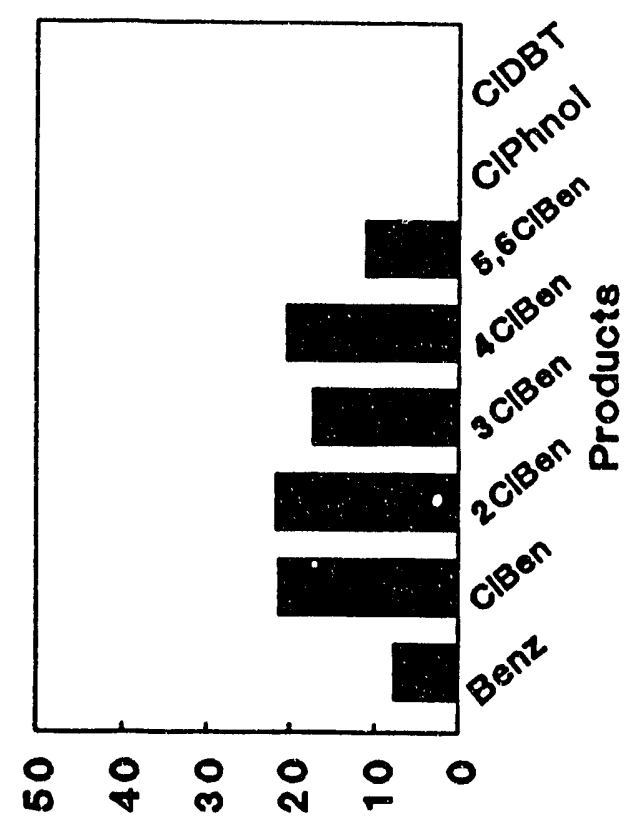

点

esuodsey fueosed

6

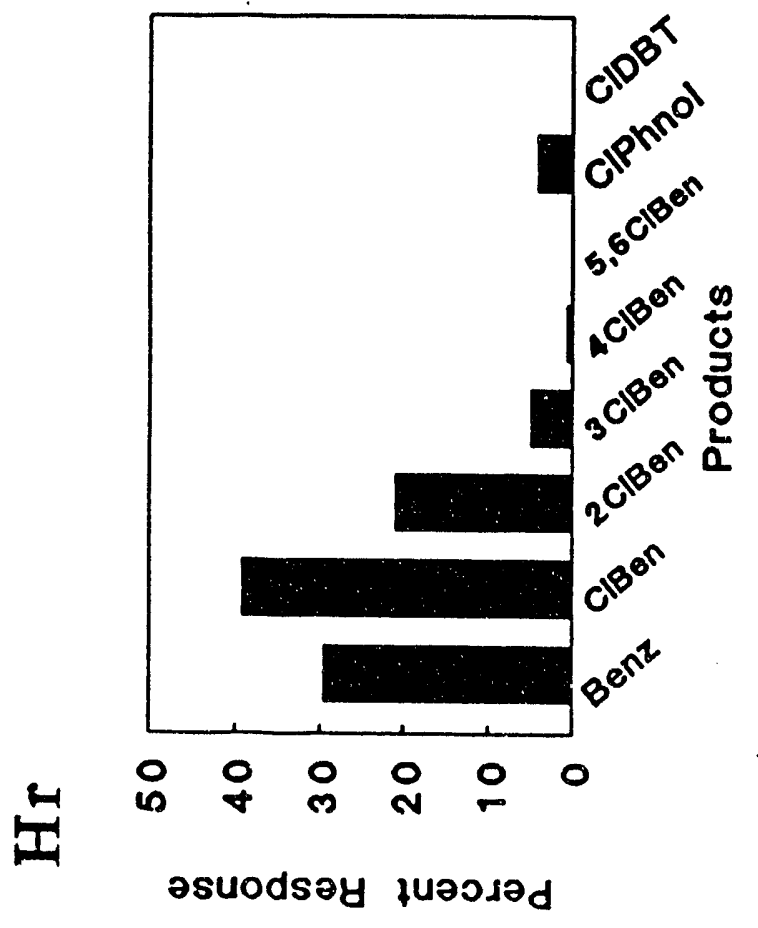

논

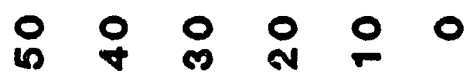

esuodsey jueodod

N

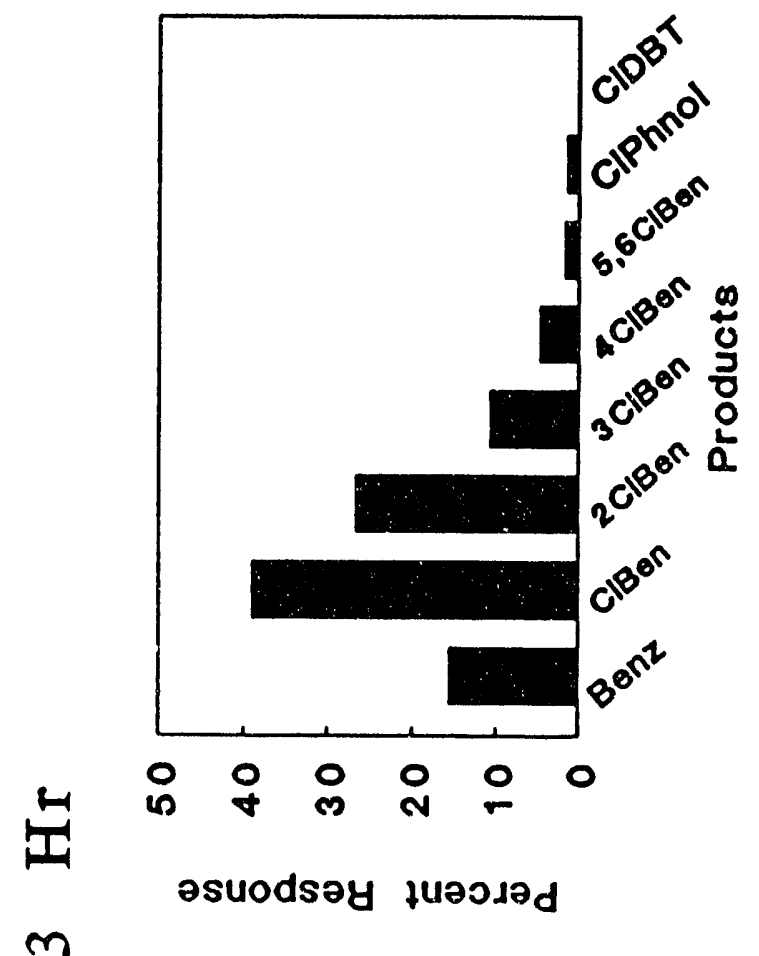

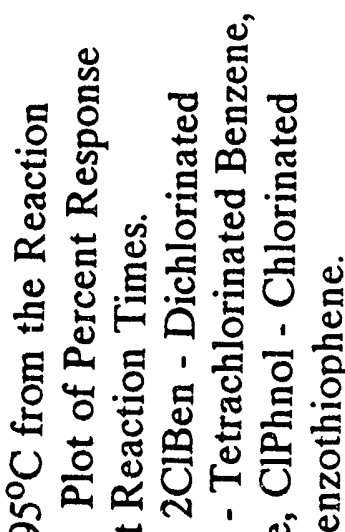

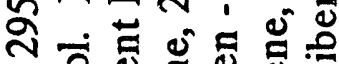
๘ ত : ญั.

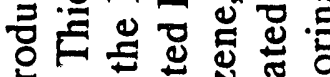
는 논 올

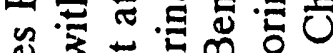
.

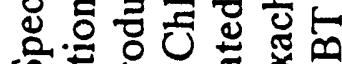

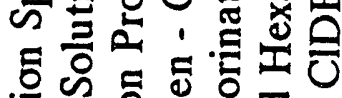

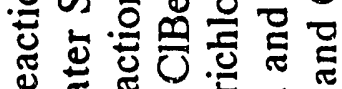
む)

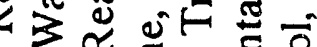
.

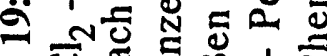

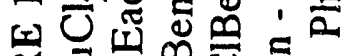

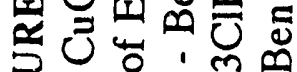
O̊

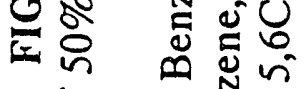

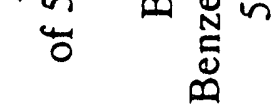


benzene is the predominant reaction. At the longest reaction time, 12 hours, there is a mean chlorination number of about four.

Results of the $295^{\circ} \mathrm{C}$ reaction for phenyl disulfide with $\mathrm{CuCl}_{2}$ are shown in Figure 20. The initial reactions were ring closure, chlorination, and bond cleavage. This is demonstrated by the presence of a series of chlorinated benzene rings, chlorinated phenol, benzene, and chlorinated dibenzothiophene. At short reaction times, dibenzothiophene is the predominant product, while at longer reaction times, the dibenzothiophene species is degraded as the chlorination reaction proceeds. At the final 12 hour reaction time, the mean degree of chlorination is ca. 5 . A slight decrease in the total response curve also occurs as the reaction proceeds.

Sulfides. No products or parent species were detected in the GC/MS analyses for the other sulfides: methyl $p$-tolyl sulfide and tetrahydrothiophene. This finding suggests that the organic species produced from these reactions were small enough to be masked by the solvent peak in the chromatogram. Figure 21 summarizes the results of the reaction of phenyl sulfide with $50 \% \mathrm{CuCl}_{2} / \mathrm{H}_{2} \mathrm{O}$ at $295^{\circ} \mathrm{C}$ at various reaction times. These plots (figure 21) show that the initial reactions are C-S bond cleavage, chlorination of the benzene ring, and ring closure of the phenyl disulfide to produce dibenzothiophene. Ring closure predominates at short reaction times, while chlorination increases with increasing reaction time. Continuation of the reaction completely depletes the dibenzothiophene concentration through ring cleavage, while the chlorination reaction proceeds, with the number of chlorines on the benzene ring increasing to a mean value between three and four at the 12 hour reaction time.

Thiophenes. Figure 22 summarizes the results of the reaction of dibenzothiophene and $\mathrm{CuCl}_{2}$ at $295^{\circ} \mathrm{C}$ for various reaction times. The predominant initial reaction is chlorination, both of any cleaved benzene rings and of the dibenzothiophene starting species. Cleavage of the C-S and C-C bonds occurs, producing free benzene rings. However, chlorination of the benzene rings must be fast because no unchlorinated benzene was detected. At longer reaction times, the concentration of the chlorinated dibenzothiophene decreases, while the 


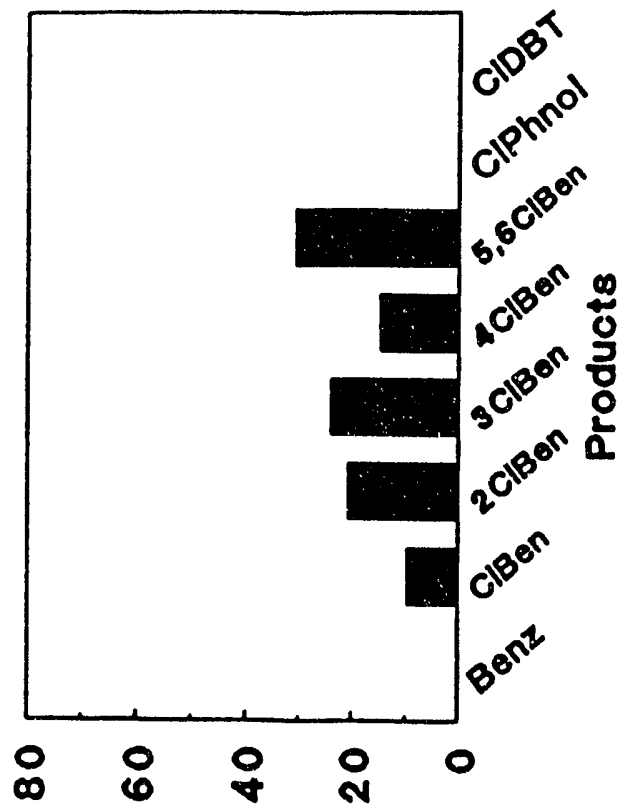

өsuodsey jueoded

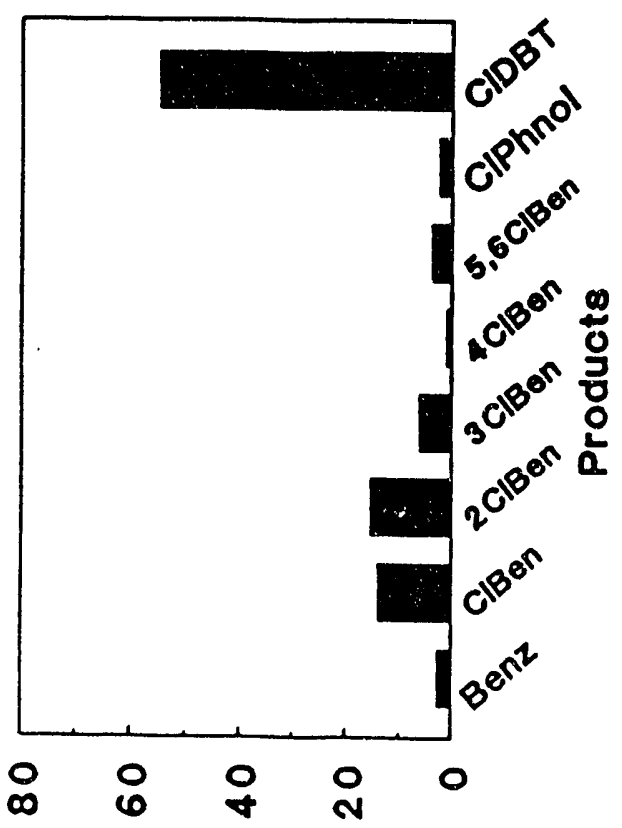

əsuodsat fuәədәd

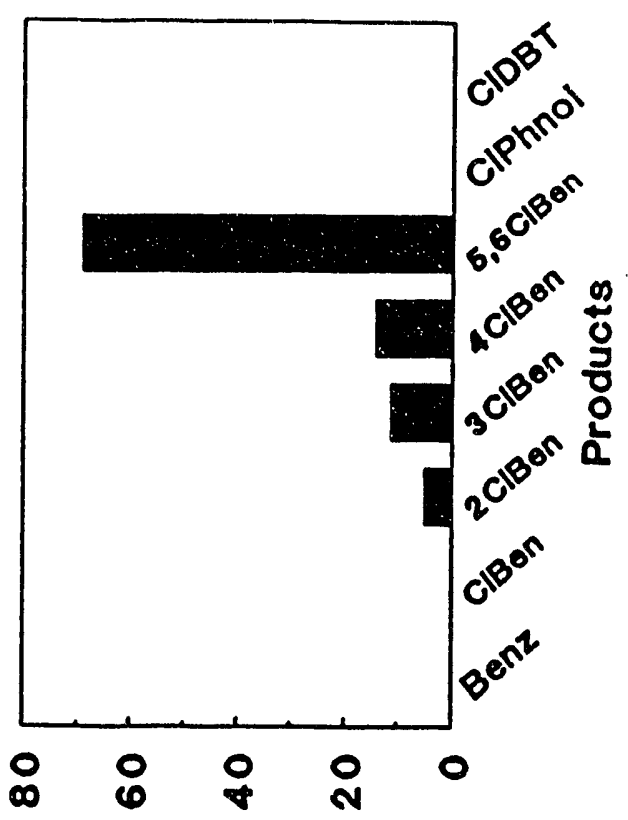

esuodsey fueoded

N

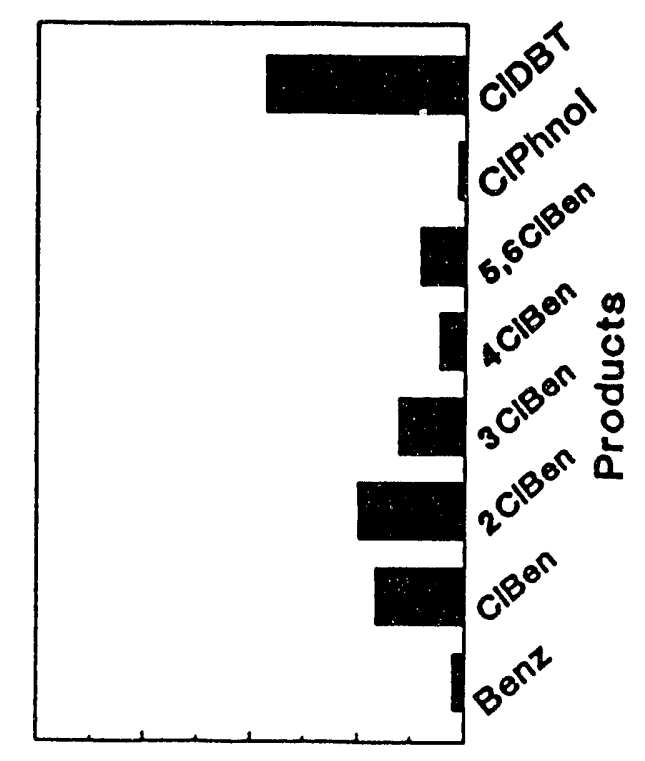

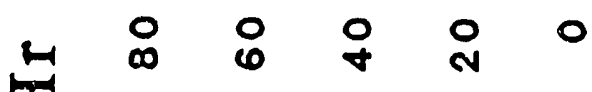
əsuodsəy fuəosəd

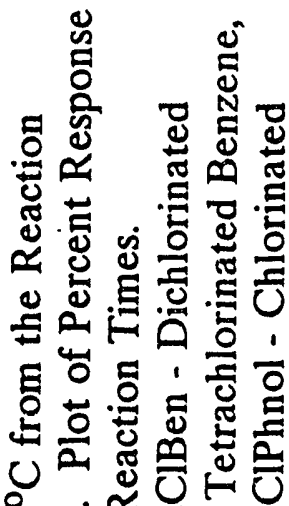

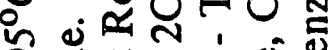

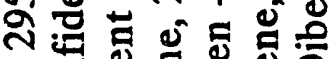

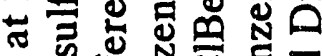

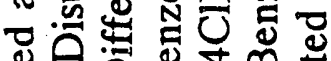

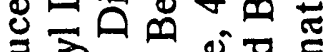

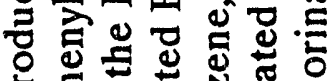

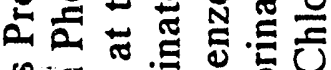
$\mathscr{2}=0$

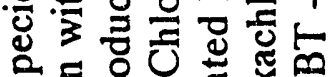
की ㄷํ유

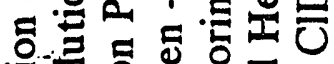

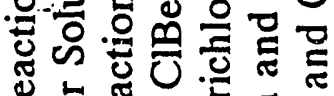

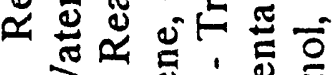

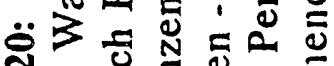

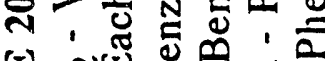
원

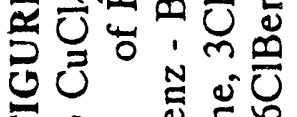
U U 号 

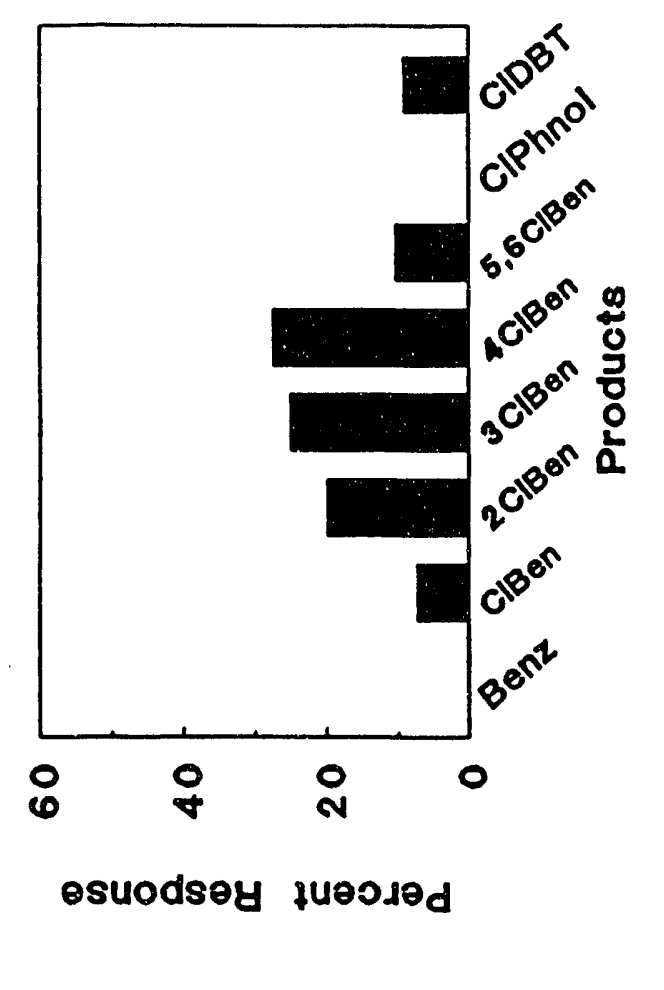

兵
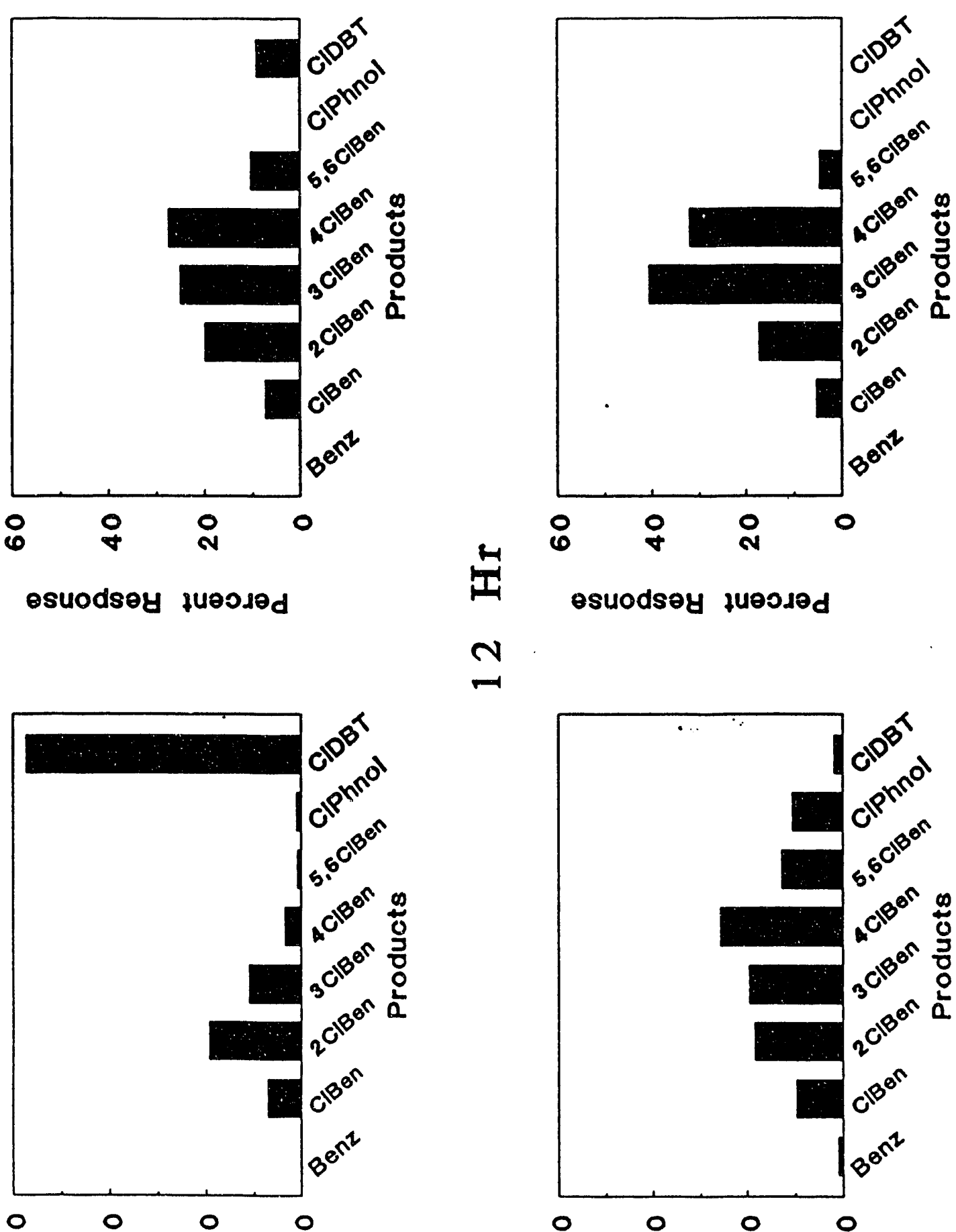

$+\begin{array}{llll}0 & 0 & 0 & 0\end{array}$ әsuodsəy tuəodəd
N
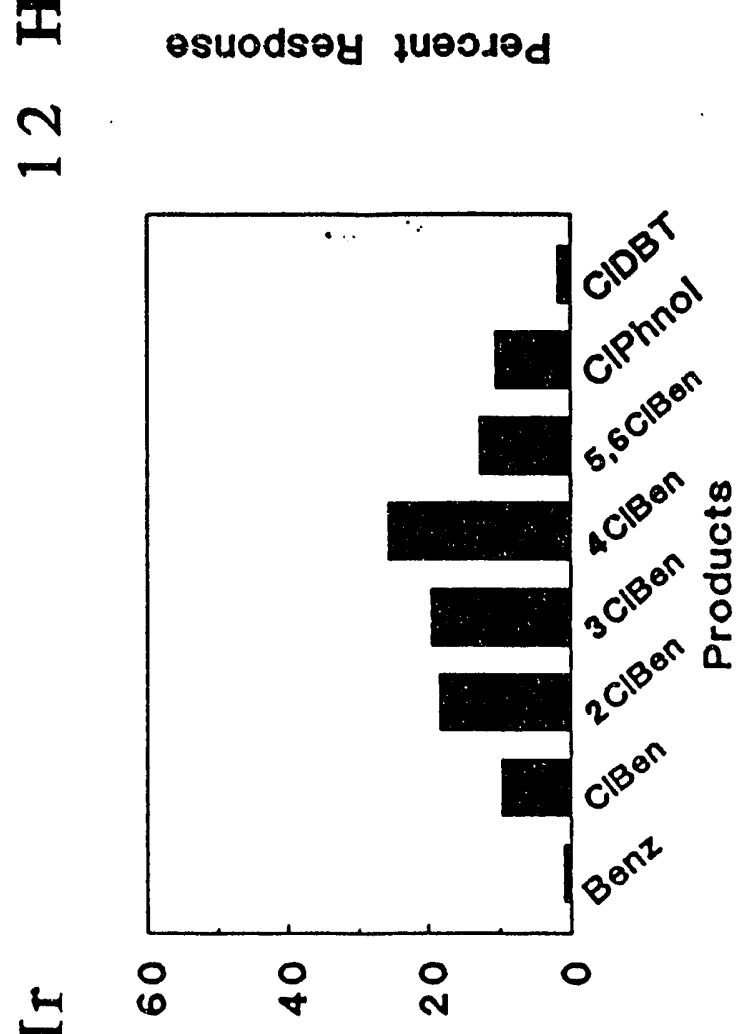

\footnotetext{
$$
\text { әsuodsəy นUәว.jəd }
$$

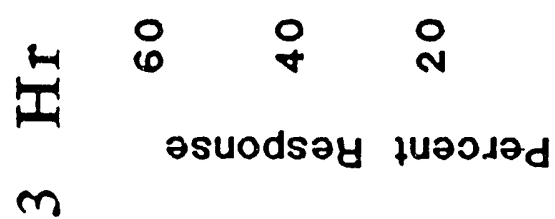

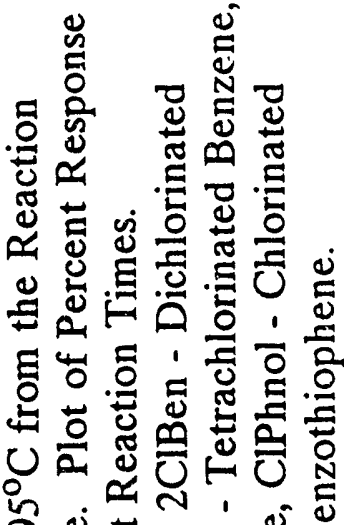

ชิษ

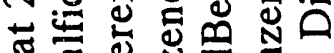

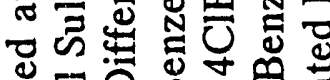
施电

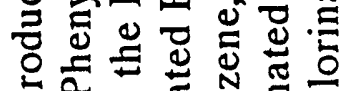

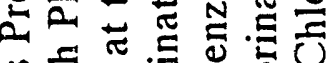
थ

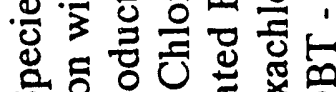

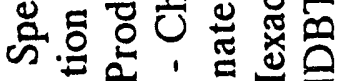

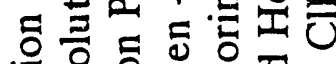

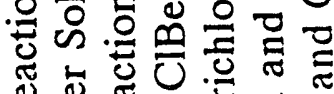
む 屯

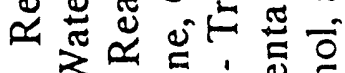

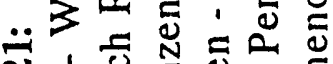
त1

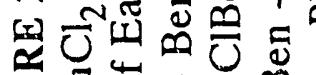

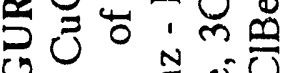
U 正 की 

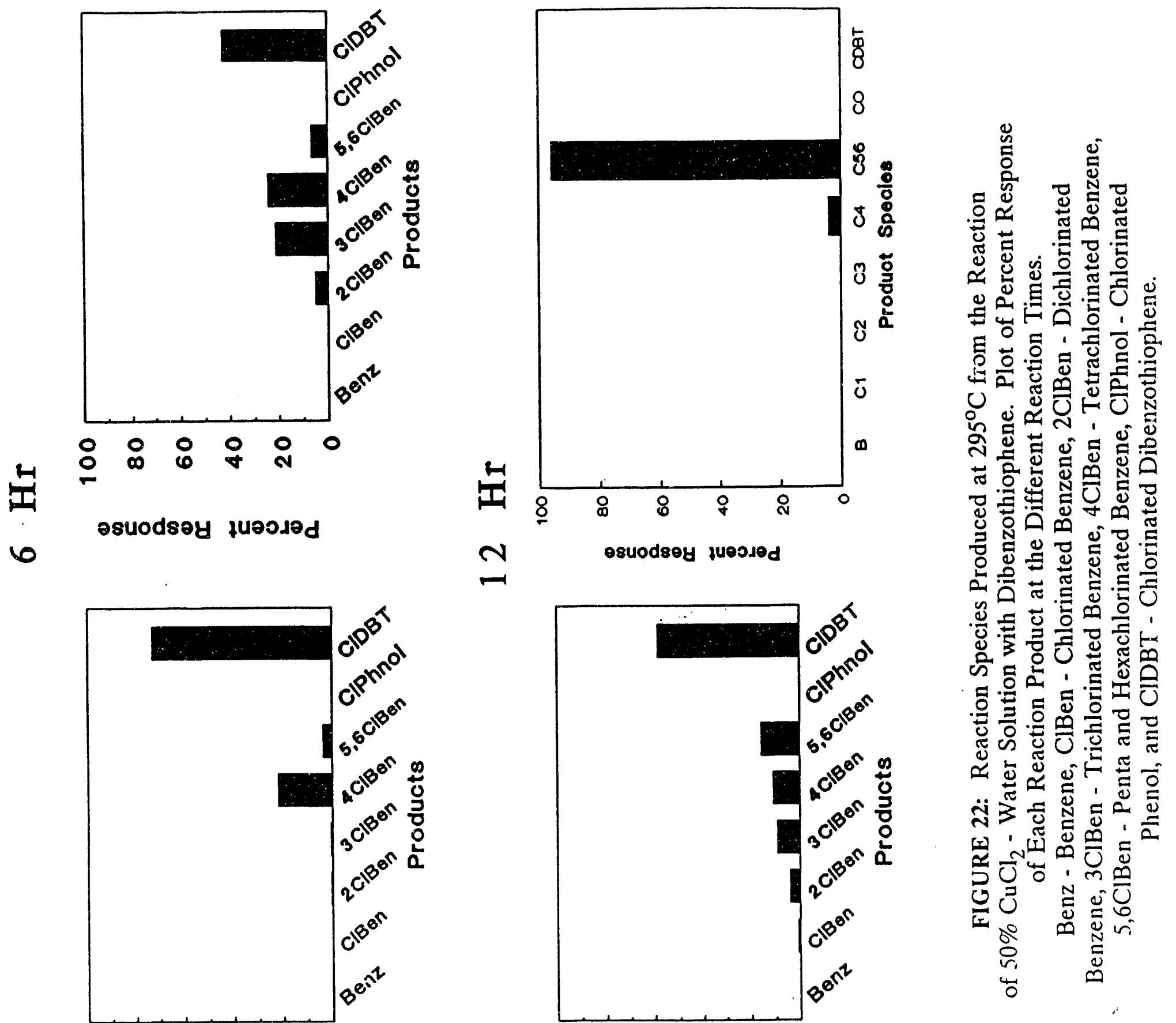

H

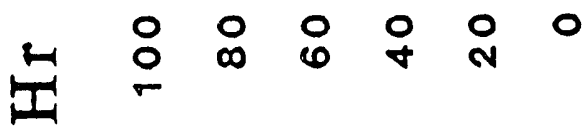

əsuodsəy นuəodəd

$m$ esuodsay fuәolad 
concentration of the chlorinated benzene species increases. At the 12 hour reaction time, the final mean chlorination number of the benzene species is ca. 5 . The extent of chlorination of this compound is much higher than that of the other species examined. The results of reacting benzo[b]thiophene with $\mathrm{CuCl}_{2}$ at $295^{\circ} \mathrm{C}$ were very similar to those of dibenzothiophene. The only major difference in the products were that minimal amounts of chlorinated dibenzothiophene were present in the benzo[b]thiophene reaction and that the final mean chlorination number of the benzene species was about 3.

Control samples were also examined to test the role of the reactant versus the effect of the higher temperatures. In these experiments, no $\mathrm{CuCl}_{2}$ was present in the aqueous solution while heating the model compounds to $295^{\circ} \mathrm{C}$ for the 12 hour reaction times. These experiments demonstrated that only one species, methyl p-tolyl sulfide, showed significant thermal cleavage reactions (toluene and benzene were produced in small quantities) when no oxidant was present at this temperature.

In summary, desulfurization of the organosulfur species is observed at $295^{\circ} \mathrm{C}$, but chlorination on the aromatic ring is also a rapid process.

\section{Results of Aqueous $\mathrm{CuCl}_{2}$ Coal Desulfurization Experiments}

Based upon both the results of the model compounds and the experiments run by other research groups, a $50 \%$ (wt/wt) $\mathrm{CuCl}_{2} / \mathrm{H}_{2} \mathrm{O}$ solution was reacted with a sample of Illinois \#6 coal at $210^{\circ} \mathrm{C}$ for ten hours. The results are listed in Table 3 which lists the amount of sulfur in the coal before and after the reaction. In addition, due to the large increase in ash content, ash is factored out when considering desulfurization efficiency.

The total sulfur content of the Illinois \#6 coal remains almost constant, but does increase slightly. The implication of this data is that the reaction causes considerable degradation of the carbonaceous backbone of the coal matrix. In conjunction with this process, a considerable amount of pyritic sulfur (96\% of the starting pyritic sulfur) is converted to some form detected as an increase in organic 


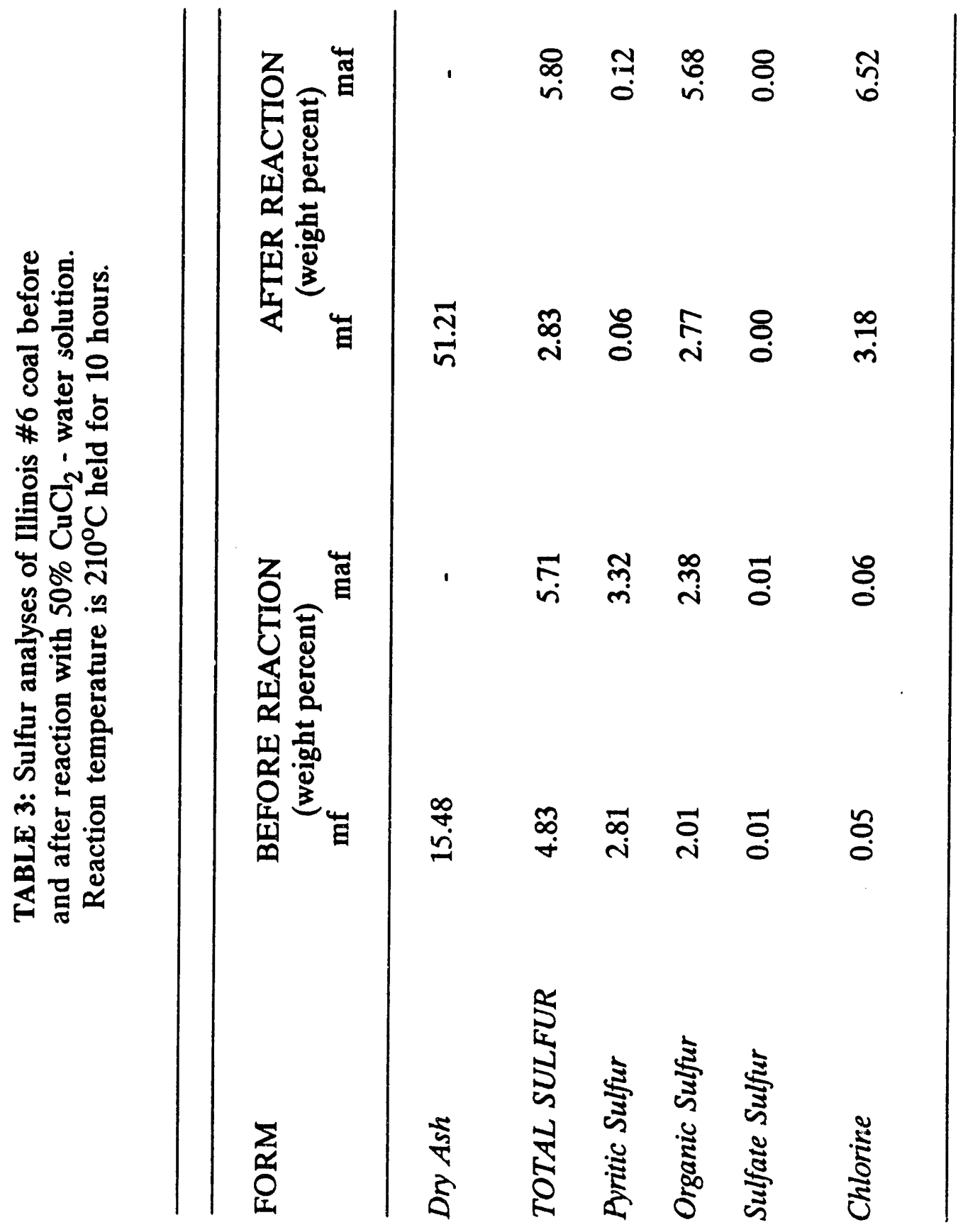


sulfur. This increase could be accounted for in several manners. First, this analysis is done through difference based upon the total sulfur minus the pyritic and sulfate sulfur. If a species existed in the coal matrix which, under the reaction conditions studied, caused sulfate to convert to elemental sulfur, this would lead to an erroneously high organic sulfur result. In addition, a conversion of inorganic sulfur from a pyritic structure to that of a marcasite structure may also effect the products $^{5}$. Marcasite is not detected in the pyritic analysis and would thus be categorized as organic sulfur. A third possible explanation for the increase in organic sulfur, supported by the results of the model coal compounds, is that a polymerization reaction occurs in the coal matrix, and some of the sulfate produced in this reaction is incorporated into the polymeric matrix.

A final significant point to reiterate concerning the Illinois \#6 coal reaction is the dramatic increase in dry ash. The starting coal had a dry ash content of 15.48 $w t \%$, while the treated species had a dry ash content of $51.21 \mathrm{wt} \%$. The principle source of this ash is believed to be an inorganic copper species (most likely either copper metal or copper oxide). This hypothesis was supported by experimental results in which large amounts of inorganic material precipitated onto the walls of the autoclave after the reaction was completed. This suggests that a certain amount of this residue was also deposited into the coal matrix. The above hypothesis is also supported by the fact that the mass of the coal after treatment was approximately one-and-one-half times that of the starting sample. No other reactant was present in the vessel, aside from the copper and chlorine, and chlorine would not be detected as ash.

\section{Reaction Mechanism}

Lompa-Krzymien ${ }^{1}$ originally proposed that the mechanism of the interaction of $\mathrm{CuCl}_{2}$ with thiophenic species in coal at $200{ }^{\circ} \mathrm{C}$ involved oxidation of the sulfur functional group to sulfoxide by the $\mathrm{Cu}^{+2}$ ion, followed by hydrolysis at the 2 and 5 position carbon atoms (which was described as a Pummerer type rearrangement ${ }^{6}$ ). Lompa-Krzymien proposed that further oxidation of the 
sulfoxide to a sulfone occurred. The sulfone was then expected to be expelled from the molecule on heating, producing sulfuric acid and a dialdehyde as reaction products in aqueous solution.

The results of the present study do not support this earlier hypothesis for the interaction of $\mathrm{CuCl}_{2}$ in $\mathrm{H}_{2} \mathrm{O}$ with organosulfur compounds in coal. The reaction which appears to be fastest and most complete is the copper-promoted oxidation of the thiol groups to disulfide linkages. This finding is consistent with other work which has shown that oxidation of the thiol group to a disulfide linkage is facile using a variety of oxidants ${ }^{7}$. Further reaction of $\mathrm{Cu}^{+2}$ and organosulfur compounds appears quite limited, as shown by minimal reaction products at $50{ }^{\circ} \mathrm{C}$ and $130^{\circ} \mathrm{C}$. In order to fully understand the role of the cupric ion in the reaction, an additional series of experiments was conducted on methyl $p$-tolyl sulfide with $\mathrm{CuSO}_{4}$. Replacing the chloride anion with sulfate provides a solution in which the only reactive species should be the $\mathrm{Cu}^{+2}$ cation. The results of these experiments show that no reaction occurred at $50{ }^{\circ} \mathrm{C}$ or $130{ }^{\circ} \mathrm{C}$ with $\mathrm{CuSO}_{4}$. As previously shown, however, the methyl $p$-tolyl sulfide reacts with $\mathrm{CuCl}_{2}$ at both of these temperatures to produce methyl $p$-tolyl sulfoxide. Since the only difference in these two experiments was the anion used, this suggests that the species causing the reaction was chlorine-based. However, previous studies have shown that the $\mathrm{Cl}^{-}$ anion, even at high concentrations, does not react with model coal compounds such as benzothiophene or dibenzothiophene ${ }^{8}$.

To further substantiate our hypothesis that a chlorine-based species caused the reaction, an experiment was undertaken to determine what gases were produced when the $\mathrm{CuCl}_{2} / \mathrm{H}_{2} \mathrm{O}$ solution was heated in a closed container (see experimental section). These experiments revealed that chlorine gas was produced under the experimental conditions studied, even at the lowest temperatures of $50{ }^{\circ} \mathrm{C}$ and $130{ }^{\circ} \mathrm{C}$. $\mathrm{CuCl}_{2}$ is known to partially decompose producing $\mathrm{Cl}_{2}$ at $300{ }^{\circ} \mathrm{C}$ under atmospheric pressure by the following reaction ${ }^{9}$ :

$$
2 \mathrm{CuCl}_{2} \ldots-\cdots>2 \mathrm{CuCl}+\mathrm{Cl}_{2}
$$


The added pressure caused by running this reaction in a closed vessel clearly lowered the decomposition temperature of $\mathrm{CuCl}_{2}$. From this information, we therefore predict that the sulfoxide produced in the reaction with $\mathrm{CuCl}_{2}$ at 50 and $130{ }^{\circ} \mathrm{C}$ is caused primarily by the oxidative chlorinolysis reaction of $\mathrm{Cl}_{2}$ with the organosulfur compound.

At $210^{\circ} \mathrm{C}$, the reaction of $\mathrm{CuSO}_{4}$ with methyl p-tolyl sulfide produced two products: toluene and dimethylbenzene sulfide, as shown in Figure 23. In comparing this result to those of the $\mathrm{CuCl}_{2}$ reaction under the same conditions (figure 12), organic oxidation products are found for the interaction of $\mathrm{CuCl}_{2}$ with organosulfur compounds, but not for the interaction wich $\mathrm{CuSO}_{4}$. Most likely, oxidation in the case of $\mathrm{CuCl}_{2}$ is caused by chlorinolysis, not oxidative interaction with the $\mathrm{Cu}^{+2}$. The only product that is the same in both experiments is toluene. The fraction of the total response of toluene in the $\mathrm{CuSO}_{4}$ experiment increases with time. In the CuiJl reaction, the fraction of the total response for this compound is highest at tive shorter reaction times. This demonstrates that the chlorine reaction, for the production of toluene, has faster kinetics. In addition, at $210^{\circ} \mathrm{C}$, the $\mathrm{CuCl}_{2}$ reaction with methyl $p$-tolyl sulfide, produces chlorination of the aromatic ring, as shown in Figure 12.

Examination of the reaction products of the other organosulfur compounds shows that similar oxidative-desulfurization reactions occur. At 50 and $130^{\circ} \mathrm{C}$, the sulfur atom is clearly oxidized on tetrahydrothiophene as shown by the product formed, tetrahydrosulfoxide (figure 6). Phenyl sulfide is oxidized to Phenyl sulfoxide at $130{ }^{\circ} \mathrm{C}$ (figure 5) and further oxidized to Phenyl sulfone at $210^{\circ} \mathrm{C}$ (figure 14). In addition, benzene (the principle product of the desulfurization of phenyl sulfide) is detected in a chlorinated form. Thiophenol shows considerable oxidative desulfurization as shown by the large concentration of benzene (and chlorinated benzene) at the $210^{\circ} \mathrm{C}$ reaction conditions (figure 8). Thus, it is clear that oxidative desulfurization of the organosulfur compounds occurs. It is believed however that the predominant oxidation reaction is chlorinolysis. A proposed chlorinolysis reaction mechanism is ${ }^{10}$ : 

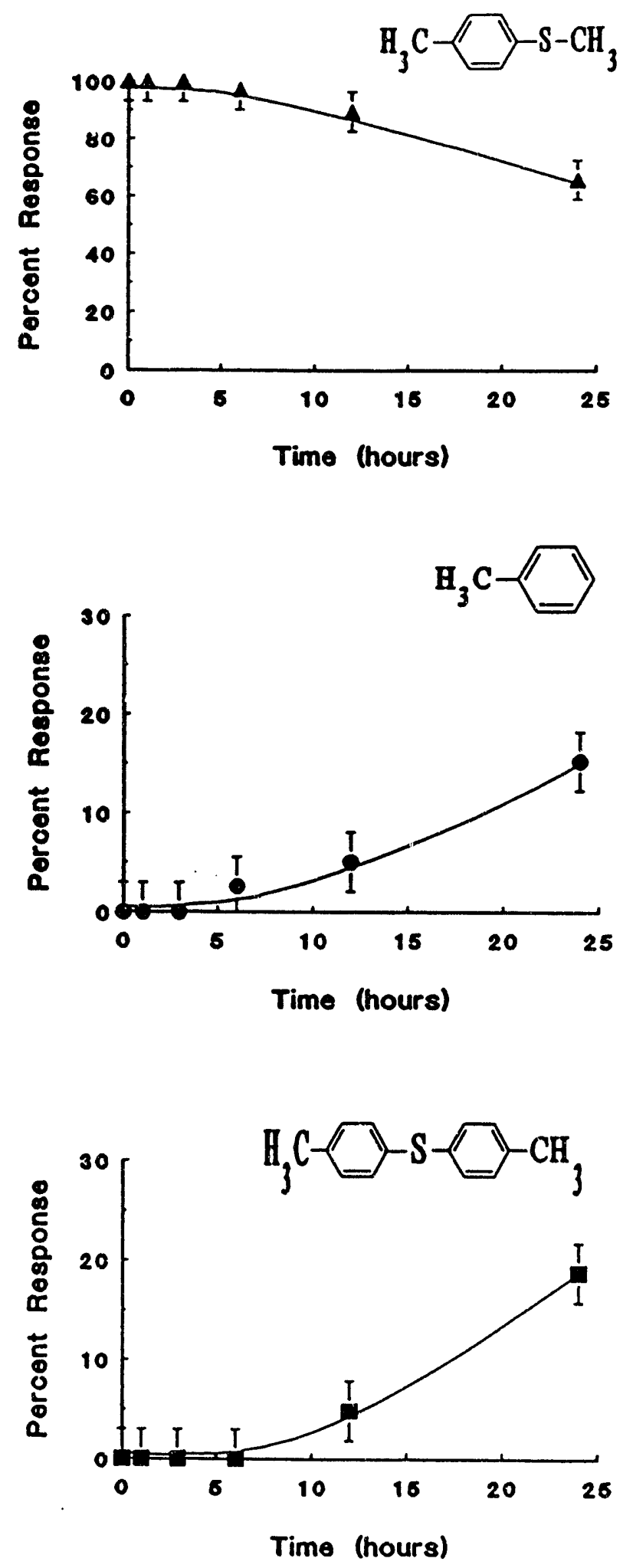

FIGURE 23: Plot of Percentage Response of Organic Products for Reaction of Methyl $p$-tolyl Sulfide with $20 \% \mathrm{CuSO}_{4}$ - Water Solution at $210^{\circ} \mathrm{C}$. 

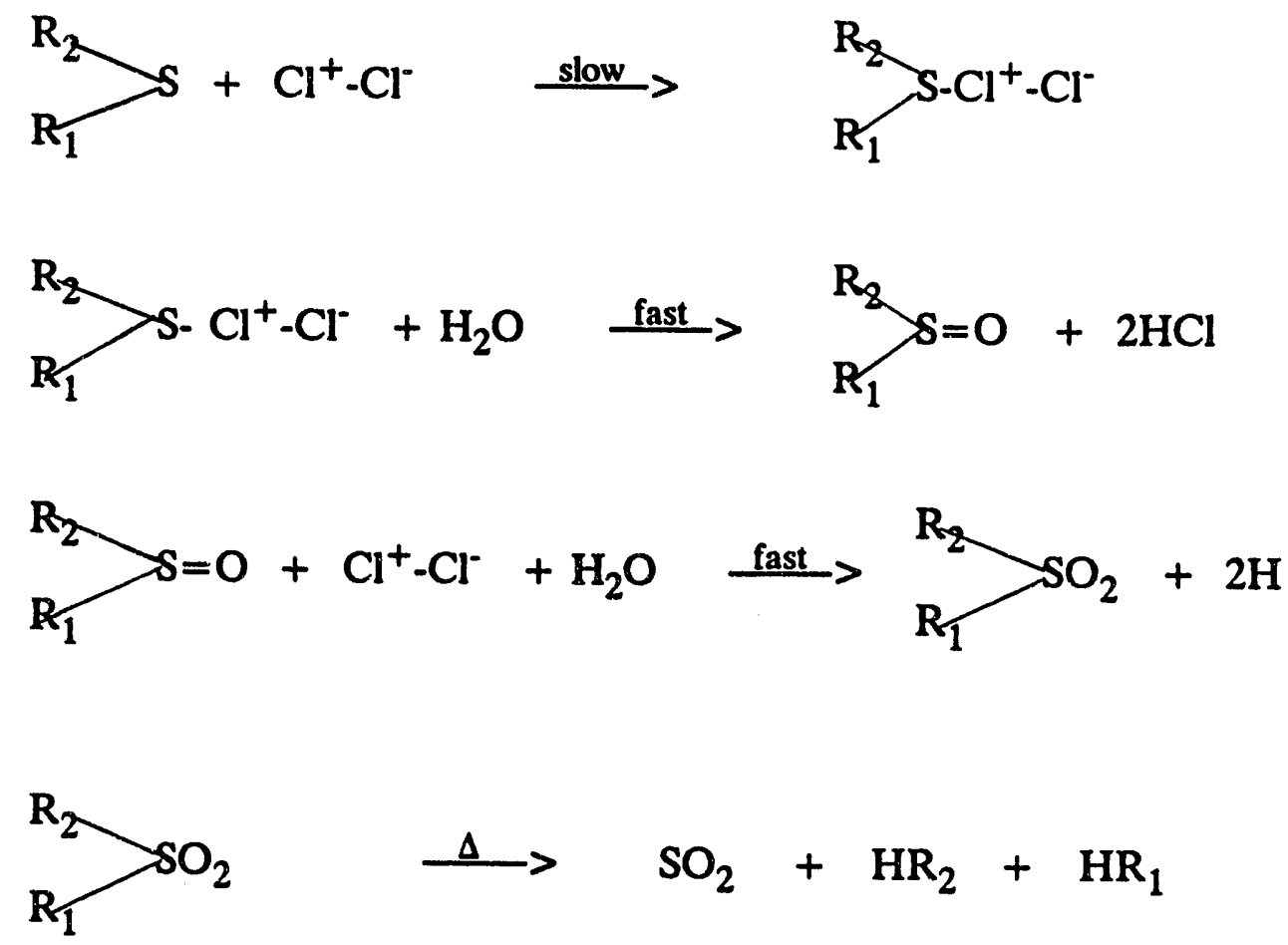

In this scheme, initially the organosulfur species acts as a nucleophile (electron donor) based at the sulfur moiety, while the chlorine gas acts as an electrophile (electron acceptor). Based on earlier researchers' results ${ }^{11}$ and on the similarity between this process and simple chlorination (chlorine substitution on unsaturated carbon atoms), it could be argued that this first process is the rate-limiting step. The above mechanism is consistent with the results of this study, as shown by using methyl $p$-tolyl sulfide as an example. Following the above scheme for methyl p-tolyl sulfide, the two organic compounds that should be produced $\left(R_{1}\right.$ and $\left.R_{2}\right)$ are toluene and methane. Since methane is so low in molecular weight, it would either 
bubble out of the solution or subsequently be masked by the solvent in the GC/MS analysis. However, toluene would show up in the analysis. In fact, it did appear, thus supporting the above reaction scheme.

Unfortunately, a third reaction, chlorination of the organic species, also occurs to a large extent under these reaction conditions. This result is demonstrated by the high concentration of ozganochloro compounds (chlorinated benzene, chlorinated organosulfur compounds, etc.) in the products at $210{ }^{\circ} \mathrm{C}$. Under the $295^{\circ} \mathrm{C}$ reaction conditions, desulfurization is almost complete on all the species; however, the extent of chlorination is severe, especially at the longer reaction times. This competing reaction has also been observed in other chlorinolysis processes ${ }^{12}$.

In conclusion, the use of aqueous $\mathrm{CuCl}_{2}$ as a reactant for the oxidative desulfurization of coal may have potential. This research demonstrated that the original hypothesized reaction mechanism for the desulfurization process was incorrect. Instead, the effect observed here was oxidative desulfurization, mostly by interaction with chlorine gas. It is possible that this may be a viable means of creating chlorine gas for the chlorinolysis reaction.

The variables that control the yield and selectivity of the chlorinolysis reaction are not yet well defined. For example, previous studies show that the solvent used may have a major impact on the desulfurization yield ${ }^{13}$. If the desulfurization yield could be increased for this reaction by changing the solvent and the high ash content could be decreased, then this method will have promise. 


\section{REFERENCES}

1. Lompa-Krzymien, L. Fuel 1982, 61, 871.

2. Singh, S. P. N., Jolley, R. L., and Dickenson, L. S., in 'Coal Science and Technology \#9 - Processing and Utilization of High Sulfur Coal', (Ed. Y. Attia), Elsevier, New York, 1985.

3. Vorres, K. S. Energy Fuels 1990, 4(5), 420.

4. Pryor, W. A. 'Mechanisms of Sulfur Reactions', McGraw-Hill, New York, NY, 1962.

5. Personal communication with David Boron, United States Department of Energy, Pittsburgh Energy Technology Center, Pittsburgh, PA.

6. Russell, G. A. and Mikol, G. J. in 'Mechanisms of Molekular Migrations', Vol 1, (Ed. B. S. Thyagarajam), Interscience, New York, 1968, p. 157.

7. Capozzi, G. and Modena, G. in 'The Chemistry of the Thiol Group', Part 2, (Ed. S. Patai), Wiley, New York, NY, 1974, p. 785.

8. Vasilakos, N. P. and Corcoran, W. H. Fuel 1983, 62, 1111.

9. In 'The Merck Index, 11th Edition' (Ed. S. Budavari) Merck and Co., Inc., Rahway, N. J., 1989, p. 412.

10. Squires, T. G. in 'The Problems of Sulfur/IEA Coal Research', Butterworths, London, 1989, p. 43.

11. Vasilakols, N. P., Bone, R. L., and Corcoran, W. H., Ind. Eng. Chem. Process Des. Dev. 1981, 20, 376.

12. Attar, A. and Corcoran W. H. Ind. Eng. Chem. Prod. Res. Dev. 1978, 17, 102.

13. Saikia, P. C., Sain, B., Baruah, B. P., Bordoloi, C. S., Mazumder, B J. Mines, Met. Fuels, 1988, 36(5), 216. 


\section{FURTHER STUDIES ON THE INTERACTION OF CUPRIC SALTS WITH COAL}

Having gained an understanding of the desulfurization reaction mechanism occurring with aqueous copper(II) chloride, several possible improvements of this reaction were considered. Two experimental parameters were varied in an attempt to increase desulfurization yields: the chemical structure of the reactant was altered and various solvents were studied. The change to the reactant that was studied was exchanging the chloride anion for the hydroxide species. Three solvent systems were examined to determine possible solvent effects on the efficiency of the desulfurization reaction: water, dimethylformamide (DMF), and a mixed system (50\% (v/v) water/DMF). The move toward a different solvent was based on earlier published results which indicated that the solvent may have a major impact on the desulfurization yield ${ }^{1,2}$. Dimethylformamide, a polar, aprotic solvent, may have several distinct advantages over water for the above reactions. Due to the lack of free protons or hydrogen bonding present in this system, anions are not solvated well. They are therefore very reactive, due to this lack of solvent stabilization. In addition, DMF has a dipole moment of 3.82 Debyes, compared to water at 1.85 Debyes. This large dipole moment indicates a greater polarizability, which contributes to solvation of large polar or ionic species, such as the $\mathrm{Cu}^{+2}$ ion. DMF also has the ability, due to its nonpolar group, to solvate a variety of organic species. These factors, coupled with relatively weak interactions between the DMF molecules themselves, allows for a large degree of solvation of the species of interest.

An experiment was also conducted in a supercritical solvent to determine if the desulfurization reaction could be done in the supercritical state. The basis for this work was that the decreased viscosity of the supercritical fluid should allow for greater permeability into the coal matrix.

A final series of experiments were performed comparing actual chlorinolysis desulfurization reactions with and without copper(II) chloride 
present, with the previous work to determine the relative merits of the latter technique with currently established methods. The reactions of model coal compounds and coal solids were both studied.

\section{EXPERIMENTAL}

\section{Chemicals}

The model organosulfur compounds utilized in this study (carbon disulfide, tetrahydrothiophene, cyclohexyl mercaptan, thiophenol, methyl $p$ tolyl sulfide, benzo[b]thiophene, phenyl sulfide, dibenzothiophene, phenyl disulfide, and thianthrene) were analytical grade $(99+\%$ purity) or higher and were obtained from Aldrich Chemical (Milwaukee, WI). Cupric chloride, dimethylformamide, and pentane were reagent grade and were obtained from J.T. Baker Company (Phillipsburg, NJ). Dichloromethane (reagent grade) was obtained from Mallinckrodt Chemical Company (Paris, KT). Distilled water was produced in-house. The coal samples studied were -100 mesh top size Illinois \#6, obtained from the premium coal bank at Argonne National Laboratories $^{3}$ (Argonne, IL).

\section{Reaction and Sample Preparation}

The reaction conditions were based upon earlier experiments, but they also concentrated on using the lowest temperature possible. Previous results indicated that increased reaction temperature causes increased degradation of the organic backbone of the coal matrix. For this reason, the reaction temperatures in the remaining studies ranged from $50^{\circ}-170^{\circ} \mathrm{C}$, with most experiments conducted at the lower temperatures. Reaction times were varied from 1 - 20 hours, allowing for possible modelling of the reaction kinetics and optimization of the desulfurization process.

The model compounds were reacted in pyrex reaction vessels which were produced in-house (see previous experimental section). These vessels were made from $1 / 4^{\prime \prime}$ o.d. (1/8" i.d.) pyrex tubing, were ca. 6" long, and wēre 
initially sealed at one end. The samples were weighed, by difference, in the reaction vessels, and a known amount of reaction solution was added. The vessels were immediately sealed and placed into an oven at the $90^{\circ} \mathrm{C}$ reaction temperature. After the specified reaction ime ( 8 hours for $\mathrm{CuCl}_{2}$ work, 20 hours for $\mathrm{Cu}(\mathrm{OH})_{2}$ work), the vessels were removed and cooled in a refrigerator for approximately 30 minutes. The seals were then broken, and the solution was quantitatively transferred to glass extraction vessels. In order to quantitatively transfer the organic analytes from the $\mathrm{DMF} / \mathrm{H}_{2} \mathrm{O}$ solution, pentane was chosen as the extraction solvent. A series of experiments was run to determine the extraction efficiency of pentane (the solvent used) for these compounds before it was chosen as the appropriate solvent. The results of this work are displayed in Figure 24. This experiment showed that the $\mathrm{DMF} / \mathrm{H}_{2} \mathrm{O}$ solution needed approximately 0.80 mole reacting with water to effectively extract the organosulfur species of interest. Therefore, the samples removed from the reaction vessels were diluted with $5 \mathrm{~mL}$ of water. This dilution produced a solution of at least 0.78 mole fraction water. The total volume of the reaction solution was thus $7 \mathrm{~mL}$. This solution was extracted with four $5 \mathrm{~mL}$ aliquots of pentane. The minimal extraction efficiency (for the benzo[b]thiophene and dibenzothiophene species) is approximately $70 \%$ for this solution when read off the plot in Figure 24. The amount of species extracted into the pentane phase can then be calculated using the distribution equation:

$$
X^{\prime}=X \times K \times \frac{V_{\text {pentane }}}{V_{\text {rxn mix }}}
$$

where:

$$
\begin{aligned}
& \mathrm{X} \quad=\quad \text { Amount of analyte in reaction mixture } \\
& X^{\prime} \quad=\quad \text { Amount of analyte in reaction mixture after }
\end{aligned}
$$


A

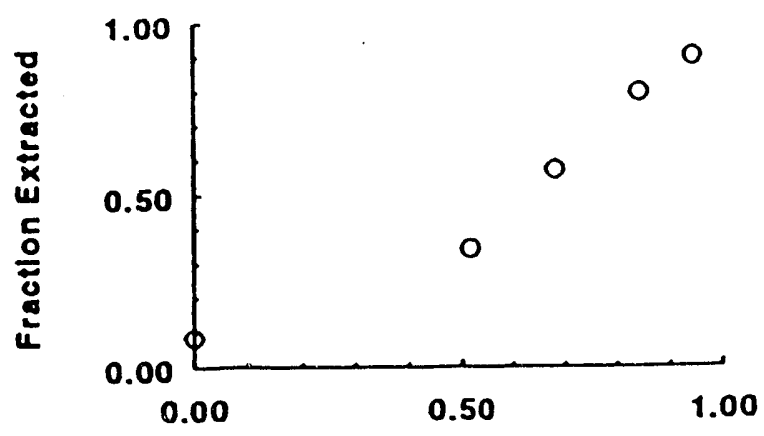

Mole Fraction Water

B

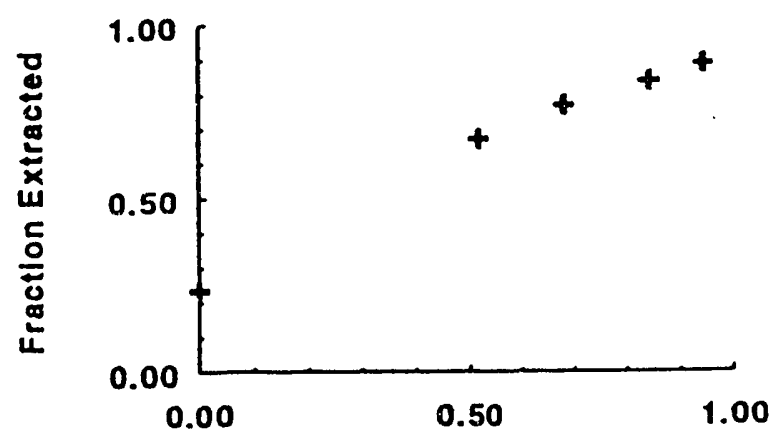

Mole Fraction Water

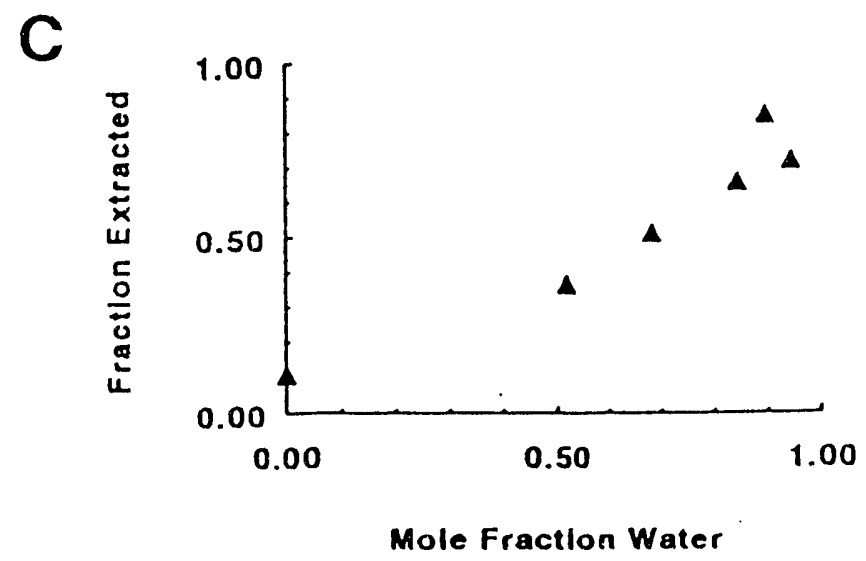

FIGURE 24: Extraction Efficiency of Pentane for Organosulfur Model Compounds from a $\mathrm{DMF} / \mathrm{H}_{2} \mathrm{O}$ Solution versus the Mole Fraction of Water in the Solution.

Model Compounds: (A) thiophenol, (B) methyl $p$-tolyl sulfide, and $(C)$ benzo[b]thiophene. 
$\mathrm{K}=$ Distribution coefficient $(0.70$ for least extractable species)

$\mathrm{V}_{\text {pentane }} \quad=\quad$ Volume of pentane extraction phase $(5 \mathrm{~mL})$

$\mathrm{V}_{\mathrm{rxn} \text { mix }}^{\mathrm{pen}} \quad=\quad$ Volume of reaction mixture $(7 \mathrm{~mL})$

Doing four extractions corresponds to a $95 \%$ removal of the organosulfur compounds from the reaction mixture phase to the pentane mixture phase. Solid precipitates produced in the reactions were separated by vacuum filtration; followed by washing with distilled water.

An experiment was run using a supercritical solvent to investigate this solvent's ability to facilitate the desulfurization reaction. In order to run this experiment, it was necessary to demonstrate the ability to solvate copper(II) chloride in a supercritical solvent. The supercritical solvent chosen was an $11 \%(\mathrm{v} / \mathrm{v})$ mixture of DMF with carbon dioxide. This solvent was chosen based on the relatively low viscosity and critical constants $\left(93^{\circ} \mathrm{C}, 111.5 \mathrm{~atm}\right)$ of the mixture, in addition to its ability to solvate a variety of species due to the presence of DMF.

The solubility of $\mathrm{CuCl}_{2}$ in the supercritical solvent was determined by using a supercritical fluid extraction reservoir attached to an inductively coupled plasma atomic emission spectrometer. The resulting emission spectra is shown in Figure 25, which plots the emission intensity versus pixel number of the diode array. The two peaks correspond to copper emission lines at $324.7 \mathrm{~nm}$ and $327.4 \mathrm{~nm}$ (reading from left to right). It was therefore concluded qualitatively that this solvent did, indeed, solvate the copper species. Copper species solvated were: $\mathrm{CuCl}_{2}, \mathrm{Cu}\left(\mathrm{NO}_{3}\right)_{2}$, and $\mathrm{Cu}$ (benzoyl acetonate). 


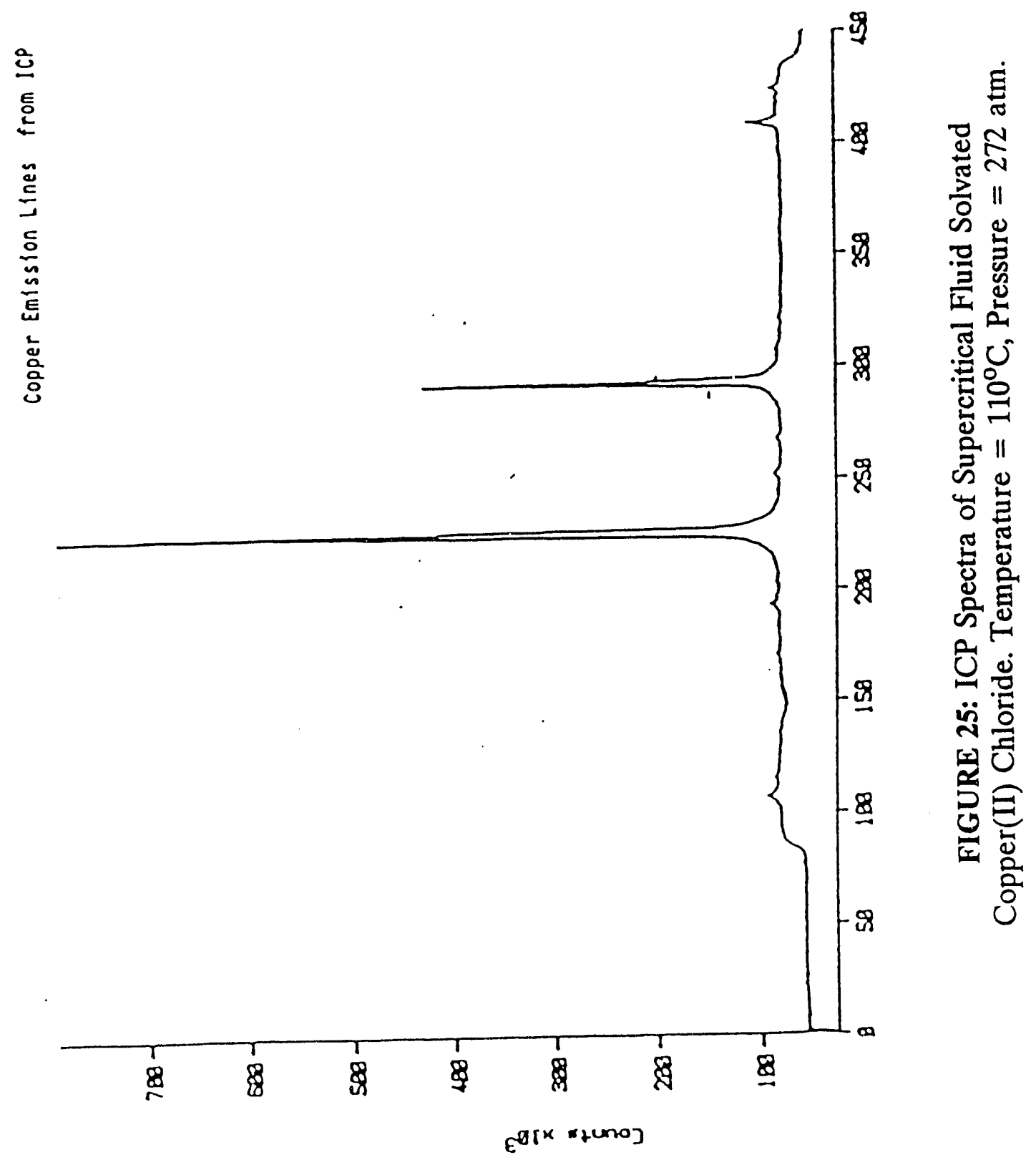


A static supercritical fluid extraction experiment was then designed and conducted to determine if the desulfurization reaction would occur under the following conditions: $4 \mathrm{~mL}$ of a $10 \% \mathrm{CuCl}_{2} / \mathrm{DMF}$ mixture diluted to $40 \mathrm{~mL}$ with carbon dioxide at 132 atm and $90^{\circ} \mathrm{C}$. After allowing this mixture to equilibrate for an hour, $5 \mathrm{~mL}$ of it was introduced into a $5 \mathrm{~mL}$ reaction cell containing 0.2 grams of organosulfur compound (compounds used were methyl $p$-tolyl sulfide, and benzo[b]thiophene). After 10 hours, the resultant mixture was expanded into a chilled vial of pentane, and the extraction cells themselves were washed with pentane. Analysis of the mixtures was performed on both the GC/MS instrument and the SFC/Sulfur Chemiluminescence detector.

The coal desulfurization experiments were conducted in $500 \mathrm{~mL}$ glass reaction vessels which were magnetically stirred and heated in a constant temperature oven $\left( \pm 0.5^{\circ} \mathrm{C}\right)$. All coal samples were prepared according to the following experimental procedure: the coal was first washed with distilled water; about half of the samples were then pretreated by washing with a solution of nitric acid (7:1 $-\mathrm{H}_{2} \mathrm{O}$ : concentrated nitric) for 24 hours at room temperature. All samples were washed with distilled water and rinsed with acetone to remove any volatiles and elemental sulfur (solubility of elemental sulfur in acetone is 2.7 grams sulfur $/ 100$ grams acetone $^{4}$ ). The coal was then reacted in the glass reaction vessels for a designated reaction time and temperature, using the appropriate reaction solution. After the reaction, the 
samples were once again treated with nitric acid to remove any solid copper precipitate (as presented in earlier desulfurization reactions) and rinsed with acetone to again remove any volatiles produced. The vacuum-dried samples were then weighed and analyzed. The analysis of Illinois \#6 samples showed repeatability of these extractions of $\pm 20 \%$.

\section{Analysis}

The methods of analysis utilized in this research were gas chromatography and mass spectrometry using the GC-MSD (Hewlett-Packard, Avondale, PA) previously described. Additional analyses were conducted on the coal samples using the FT-IR spectrometer described previously. The heat content, sulfur, and chlorine analysis of the coal sample was conducted by Black Rock Test Labs (Morgantown, WV) according to standard ASTM procedures.

\section{RESULTS AND DISCUSSION}

$\mathrm{CuCl}_{2}$ Reactions with Model Compounds in Different Solvent Systems

A series of experiments was conducted reacting $\mathrm{CuCl}_{2}$ with several model organosulfur compounds in a dimethylformamide/water solvent to investigate how the aprotic solvent affects the reaction. Figure $26 \mathrm{~A}-\mathrm{D}$ shows the results of a preliminary series of experiments in which several organosulfur compounds: (A) methyl p-tolyl sulfide, (B) benzo[b]thiophene, 

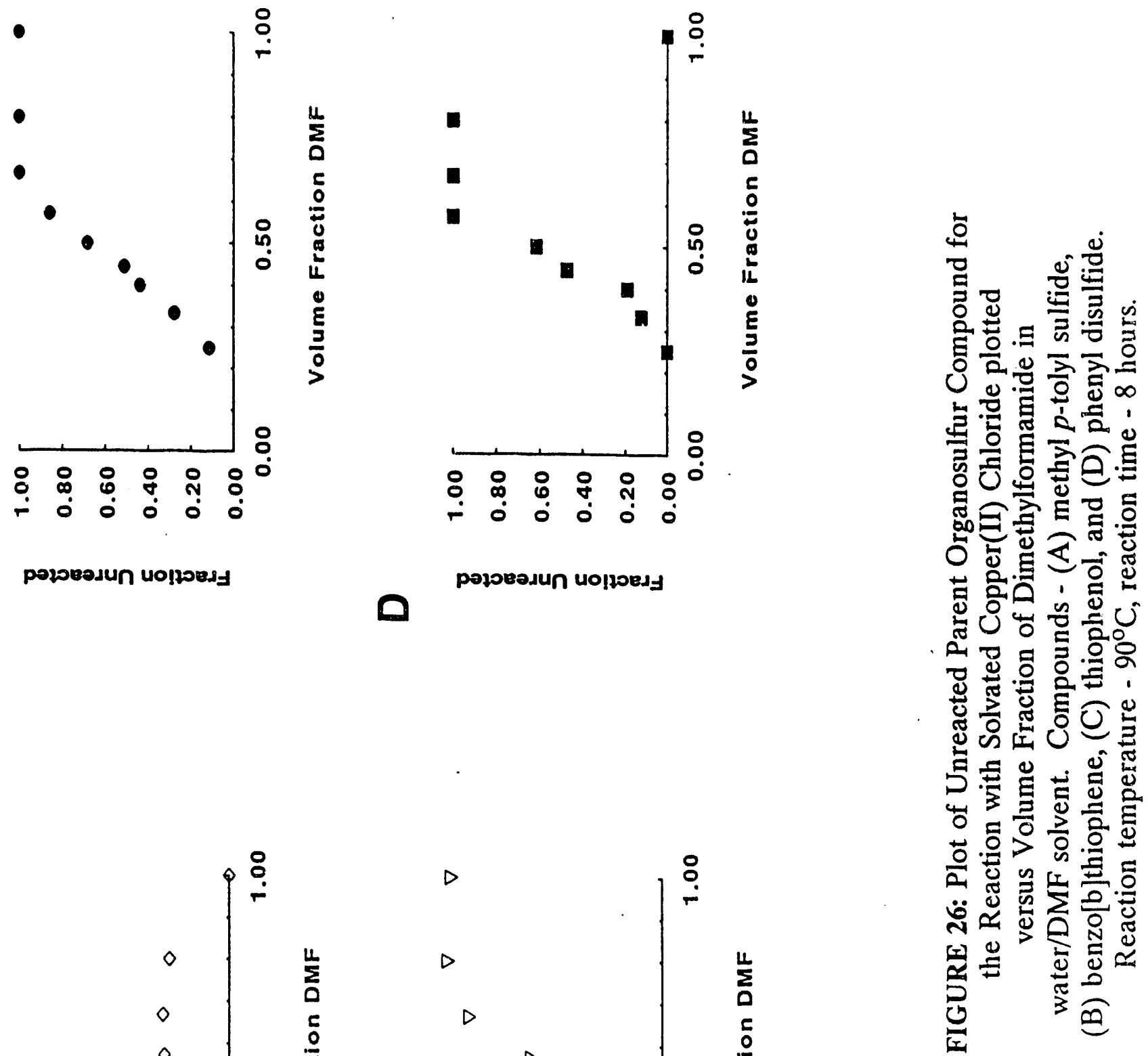

0
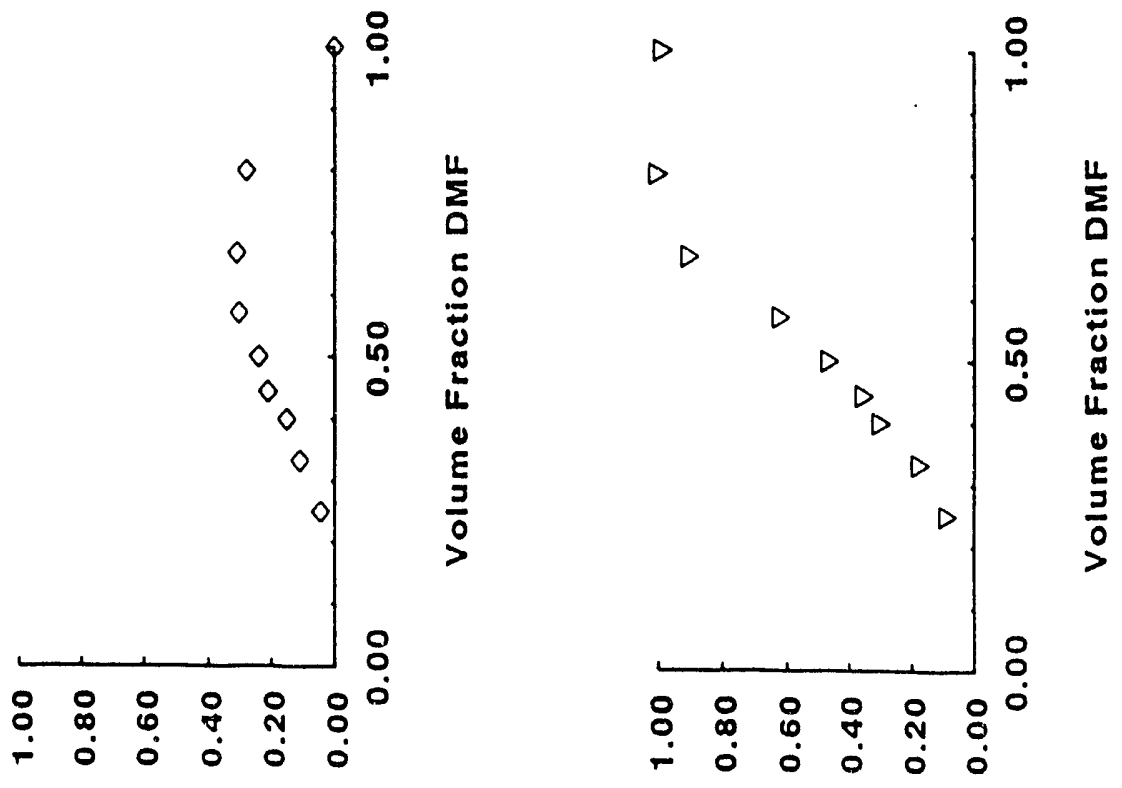

popoesdun vo!loedy 
(C) thiophenol, and (D) phenyl disulfide were reacted with $\mathrm{CuCl}_{2}$ for 8 hours at $90^{\circ} \mathrm{C}$, while varying the solvent. The plots show the fraction of unreacted parent species detected in the GC/MS analysis after the reaction was completed. No detectable reaction products were observed in the organic phase under GC/MS analysis. This finding implies that the reaction products have low enough molecular weights so that they were expelled from the reaction vessel as a gases and therefore were not collected or were masked under the solvent in the chromatography. With this obvious lack of information, the conclusions drawn from these experiments were limited. However, the relative reactivity of the parent organosulfur compounds to the solvated $\mathrm{CuCl}_{2}$ can be predicted.

The common trend observed for most organosulfur compounds is that the reactivity decreases as the volume fraction of DMF increases. A notable exception to this trend is the sulfide species, methyl p-tolyl sulfide. Although it exhibits a slight decrease in reactivity as the volume fraction of DMF increases, in pure DMF it is completely reacted. Another point, which was observed earlier, is that the sulfide species appears the most reactive to the $\mathrm{CuCl}_{2}$ species compared to the other species examined (thiol, disulfide, thiophene). Even under the worst conditions, less than $40 \%$ of the parent species is unreacted.

An unexpected observation concerns that of the thiophenol result. This species, shown to be very reactive to $\mathrm{CuCl}_{2}$ in the aqueous phase, was 
very unreactive in the mixed solvent system. The results for the phenyl disulfide and benzo[b]thiophene agree with the loss of reactivity in the mixed system. However, it is interesting to note that both the phenyl disulfide and the benzo[b]thiophene appear to be very reactive in the mixed system at small volume fractions of DMF. Recall that, under similar reaction conditions, these species were almost completely unreactive to $\mathrm{CuCl}_{2}$ in the pure aqueous environment.

From these crude experiments, two observations can be made. Initially, the addition of small volume fractions of DMF appears to increase the reactivity of the $\mathrm{CuCl}_{2}$ species. Secondly there is a distinct lack of reactivity at greater DMF volume fractions. One possible cause of this behavior is small additions of DMF may aid in solubilization but larger quantities of DMF may compete with the sulfur atom as a copper ligand.

A series of experiments was conducted in a supercritical solvent ( $10 \%$ (v/v) DMF/CO $\mathrm{CO}_{2}$ ) reacting a sulfide (methyl $p$-tolyl sulfide) and a thiophene (benzo[b]thiophene) with $\mathrm{CuCl}_{2}$. Results of the GC/MS analysis of the organic products showed no species present except the starting parent compounds.

\section{$\mathrm{Cu}(\mathrm{OH})_{2}$ Reactions with Model Compounds}

A study into the reactivity of the model organosulfur compounds with solvated $\mathrm{Cu}(\mathrm{OH})_{2}$ in three solvent systems (water, dimethylformamide, and 
$50 \%$ water/DMF) was undertaken to examine the effect of the anion on the desulfurization reactions. Reactions were run at $90^{\circ} \mathrm{C}$ for 20 hours with a $\mathrm{Cu}(\mathrm{OH})_{2}$ concentration of $20 \%$. The solvent was varied between pure water, pure $\mathrm{DMF}$, and a $50 \%$ mix of the two solvents.

As with the previous studies, no other organic-phase species were detected in the GC/MS analysis. Aside from the parent organosulfur species, both the methyl $p$-tolyl sulfide and the benzo[b]thiophene were relatively unreacted under the $100 \%$ and $50 \%(\mathrm{v} / \mathrm{v})$ water solutions. In pure DMF, about $60 \%$ of the parent species was unreacted. Thiophenol appeared to be very reactive in all three solvent systems. It was most reactive in the $50 \%$ water/DMF solvent with no parent species detected in the reaction products. In addition, solid precipitates, to varying degrees, were produced for all species reacted. An interesting observation was the production of a solid yellow precipitate in the thiophenol reaction. When burned, this precipitate produced a blue flame characteristic of sulfur. Unfortunately, due to a lack of any other detectable organic species, and with only a few experiments conducted, very little can be deduced from this work. The two points that can be extracted from this research are that the reactivity of the methyl $p$-tolyl sulfide and the benzo[b]thiophene are greatest in pure DMF, while thiophenol is completely reacted in a $50 \% \mathrm{DMF} /$ water solution. 
Reactive Coal Desulfurization

The use of model compounds to explore possible desulfurization pathways provides the advantage of studying specific molecular interactions with particular sulfur groups. However, due to the very complex nature of coal and possible side reactions which may occur, it is impossible to completely model the actual desulfurization process. Therefore, although previous work has provided insight into possible reaction mechanisms which may occur with organosulfur species present in coal, further work with copper-based species centered on desulfurization of actual coal samples. In addition to monitoring the efficiency of the desulfurization process, the effect on the coal structure was examined. Base examination of the sample coals was conducted using coal pressed in a $\mathrm{KBr}$ pellet (concentration of approximately $1.5 \mathrm{mg}$ per $100 \mathrm{mg} \mathrm{KBr}$, average $60 \mathrm{mg} \mathrm{KBr}$ pellet size). Figure 27 is the FTIR spectra of untreated Illinois \#6 coal with particular bands labeled. This figure is quite characteristic of unreacted, unoxidized coal. Of particular interest are the relative magnitudes of the aliphatic $\mathrm{C}$ $\mathrm{H}$ stretch, $\mathrm{C}=\mathrm{C}$ stretch, $\mathrm{sp}^{2}$ and $\mathrm{sp}^{3} \mathrm{C}-\mathrm{H}$ banding, and the slight presence of aromatic $\mathrm{C}-\mathrm{H}$ indicated in the peak at $800 \mathrm{~cm}^{-1}$. Figure 28 is the FTIR spectra of the same coal treated with nitric acid for 24 hours. One effect of this treatment is shown in the presence of the COO species at approximately $2400 \mathrm{~cm}^{-15,6}$. This value corresponds to previous literature results which documented the production of carboxylic acids upon reacting coal with nitric 


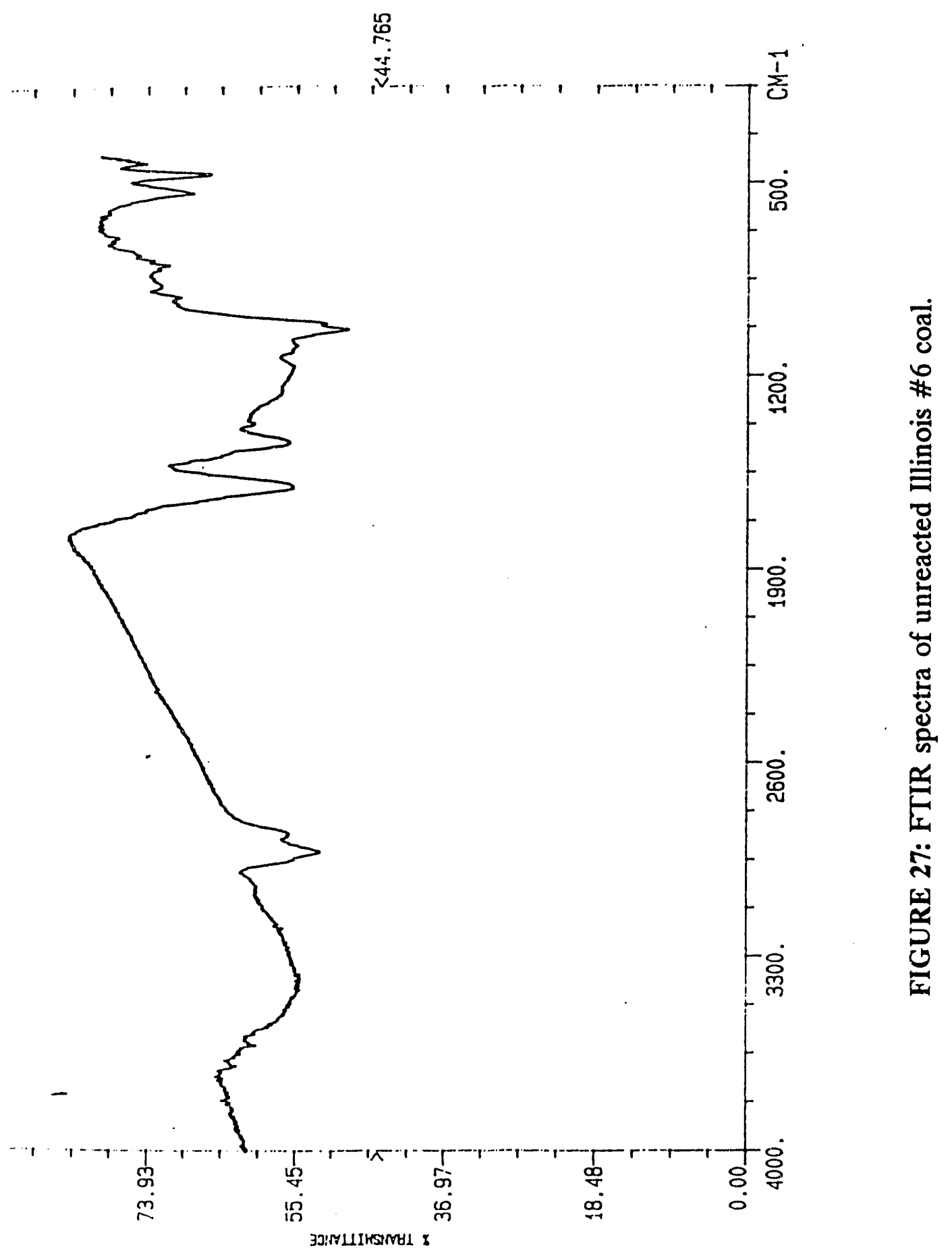




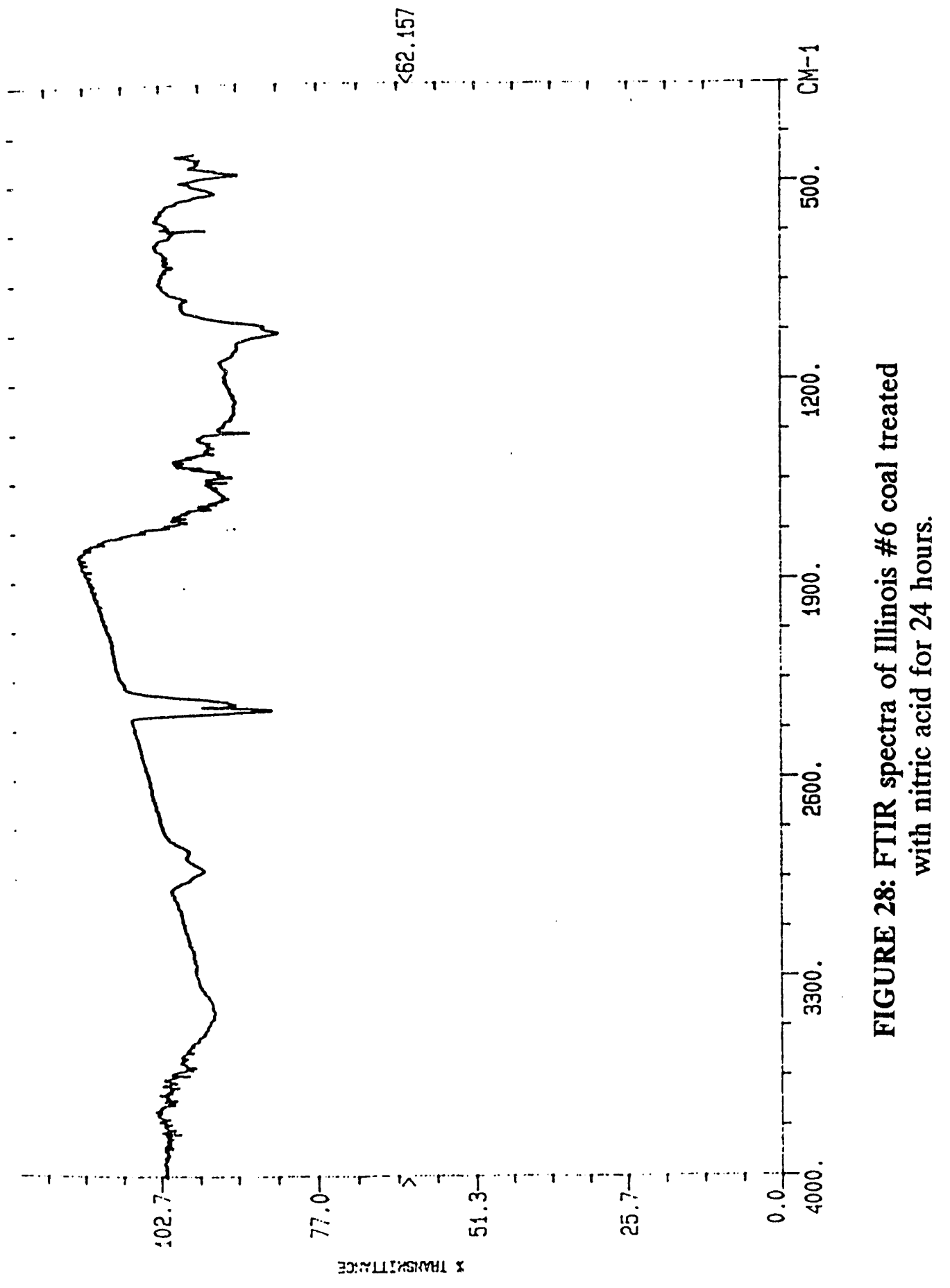


acid 7 .

\section{Solvent Effect on Interaction of Copper(II) Chloride with Coal}

Preliminary experiments utilizing $\mathrm{CuCl}_{2}$ as the reactant for the desulfurization of coal are shown in Table 4. This table compares unreacted coal with the 10 hour reaction of coal with $\mathrm{CuCl}_{2}$ under various reaction conditions. The results demonstrate that the high temperature aqueous reaction removes both a large fraction of the pyritic sulfur; however, it unfortunately appears to be converted to organic sulfur.

The data from the low temperature $\left(90^{\circ} \mathrm{C}\right)$ reaction in the mixed solvent were more promising. Although the pyritic sulfur removal was not as high as with the high temperature reactions, the organic sulfur removal improved. One possible reason for these results is that the oxidative removal of pyritic and organic sulfur is competitive.

A series of experiments was then conducted using nitric acid pretreatment to remove the pyritic sulfur before interaction with $\mathrm{CuCl}_{2}$. The coal was also washed with a nitric acid solution after the reaction with $\mathrm{CuCl}_{2}$ to remove any remaining inorganic cupric material from the coal. Unfortunately, the expected increase in organic sulfur removal was not realized (see Table 4). This could be due to several possibilities. First, even though the coal sample was designated as coming from the same lot, differences in sulfur content may have existed. This problem was avoided in all future experiments, stich as the nitric acid pre-treated species, by mixing 


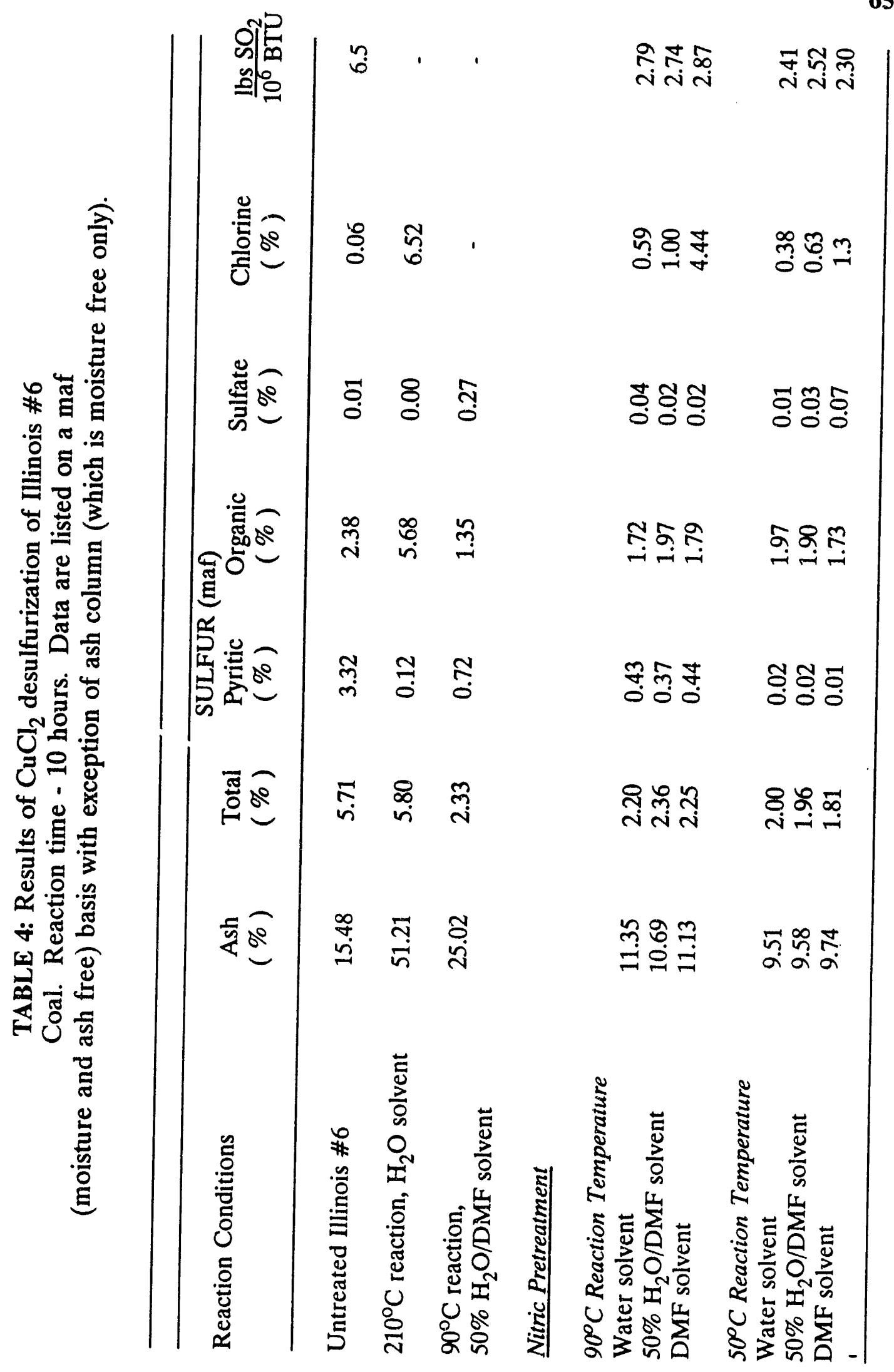


all the coal together prior to the experiment and then removing 5 gram aliquots for reaction from this base sample. A second reason for this result may be that the nitric acid is reacting either with the organic sulfur, or with the coal matrix proximal to the organic sulfur in a manner which makes this species less reactive. The FTIR data already shown illustrates the production of carboxylic acid groups (see $\mathrm{COO}^{-}$band at $2400 \mathrm{~cm}^{-1}$ in Figure 28) on the nitric acid treated coal. A third possibility may exist -- that the analyses were not conducted properly. However, this explanation is unlikely due to the precision of analyses conducted at Black Rock Test Labs and the magnitude of the difference. Black Rock Test Labs indicates a precision of 3 significant figures. One interesting point to be noted from Table 4 under both temperature conditions for the nitric acid pretreated samples is that the greatest degree of organic desulfurization occurs using DMF with no water. This point is interesting since it contradicts the information gained in the model compound work, thus suggesting that the model compounds do not always accurately model actual coal desulfurization. With respect to the other sulfur forms, no clear pattern appears. However, the extent of chlorination obviously increases with increasing dimethylformamide concentration. This is not surprising since small anions, such as chlorine, are less stabilized in DMF and thus become much more reactive. No additional significant peaks were found in the FTIR spectra except that of the nitric acid washed coal. All spectra of the coal samples reacted with $\mathrm{CuCl}_{2}$ are very similar to this 
spectra.

\section{Interaction of Copper Hydroxide Reactant with Coal}

The desulfurization of organically bound sulfur when reacted with $\mathrm{Cu}(\mathrm{OH})_{2}$ was greatly favored at the lower reaction temperatures as shown in Table 5. This table also demonstrates the poorer desulfurization yield of pyritic sulfur as the reaction temperature decreased (note these samples were not pretreated with nitric acid).

A second series of experiments was conducted with nitric acid pretreatment and with varying solvent mixtures, as shown in Table 5 . These data demonstrate a minimal effect on the desulfurization yield due to solvent composition, although a slightly greater degree of desulfurization appears to occur in the mixed solvent. It should also be noted that the desulfurization yield is still greater at lower temperature conditions $\left(50^{\circ} \mathrm{C}\right.$ versus $90^{\circ} \mathrm{C}$ with nitric acid pretreatment), which is also demonstrated in Table 5. The FTIR spectra for all these coal samples was very similar to that of the nitric acid treated coal (figure 28).

\section{$\mathrm{CuCl}_{2}$ Assisted Chlorinelysis Reaction with Coal}

A final series of experiments were conducted using chlorine gas to desulfurize the coal. The reaction temperature used was $50^{\circ} \mathrm{C}$, and the solvent was methanol, with a chlorine gas flow rate of approximately 300 


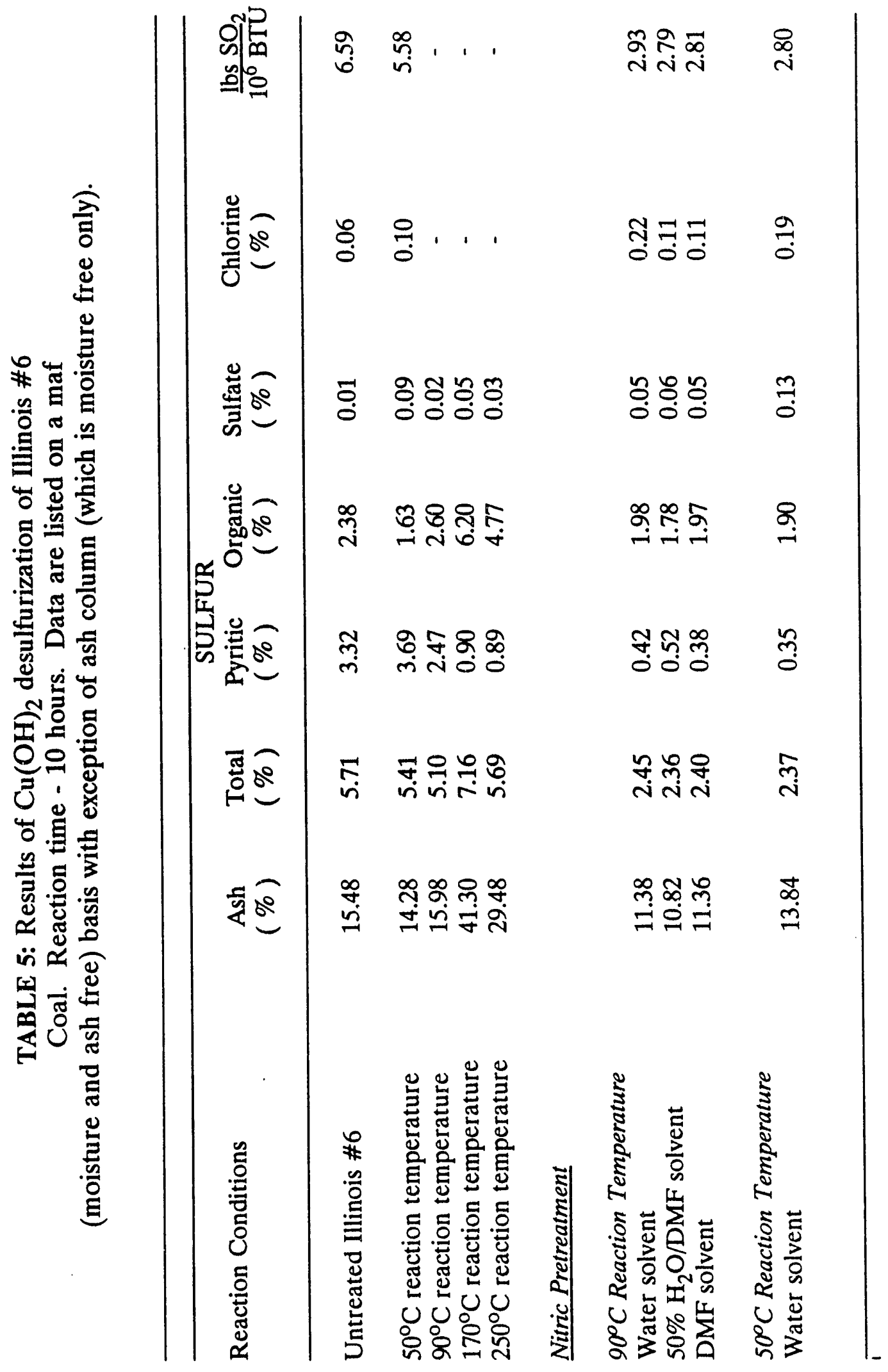


$\mathrm{L} / \mathrm{min}$ (conditions taken from previous work done by Vasilakos and Corcoran). Methanol was chosen as a solvent due to earlier work which demonstrated it provided maximum effectiveness ${ }^{7,6}$. Table 6 summarizes the desulfurization results of these reactions. In addition to the pure chlorinolysis reaction, a series of tests were conducted using a $10 \% \mathrm{CuCl}_{2}$ solution as a catalyst. The addition of this species produced a substantial increase in desulfurization of organic sulfur.

This suggests that the addition of the $\mathrm{CuCl}_{2}$ species to the chlorinolysis reaction acts as an effective catalyst for removal of organically bound sulfur. In addition, the FTIR spectra of the chlorinated coal (figure 29) shows minimal introduction of the $\mathrm{COO}^{-}$species. This contradicts earlier published work which showed a large increase of $\mathrm{COO}^{-}$formation upon chlorinolysis $^{10,11}$. The copper(II) chloride catalyzed coal is also the first species produced in this study to qualify at New Source Polution Standards (maximum sulfur emission of $1.2 \mathrm{lbs} \mathrm{SO}_{2}$ /million BTU).

One possible explanation for the increased desulfurization of the organically bound sulfur due to the copper species centers on the possitle reaction intermediate. It is believed the desulfurization of organic sulfur through chlorinolysis is based on a chlorosulfonium salt intermediate ${ }^{7,8,3}$. sirer the initial formation of this intermediate, formation of the sulfoxide (and subsequent sulfone) occurs in the presence of a base ${ }^{9,10}$. It is therefore possible that the presence of the copper (II) ion enhances the initial 


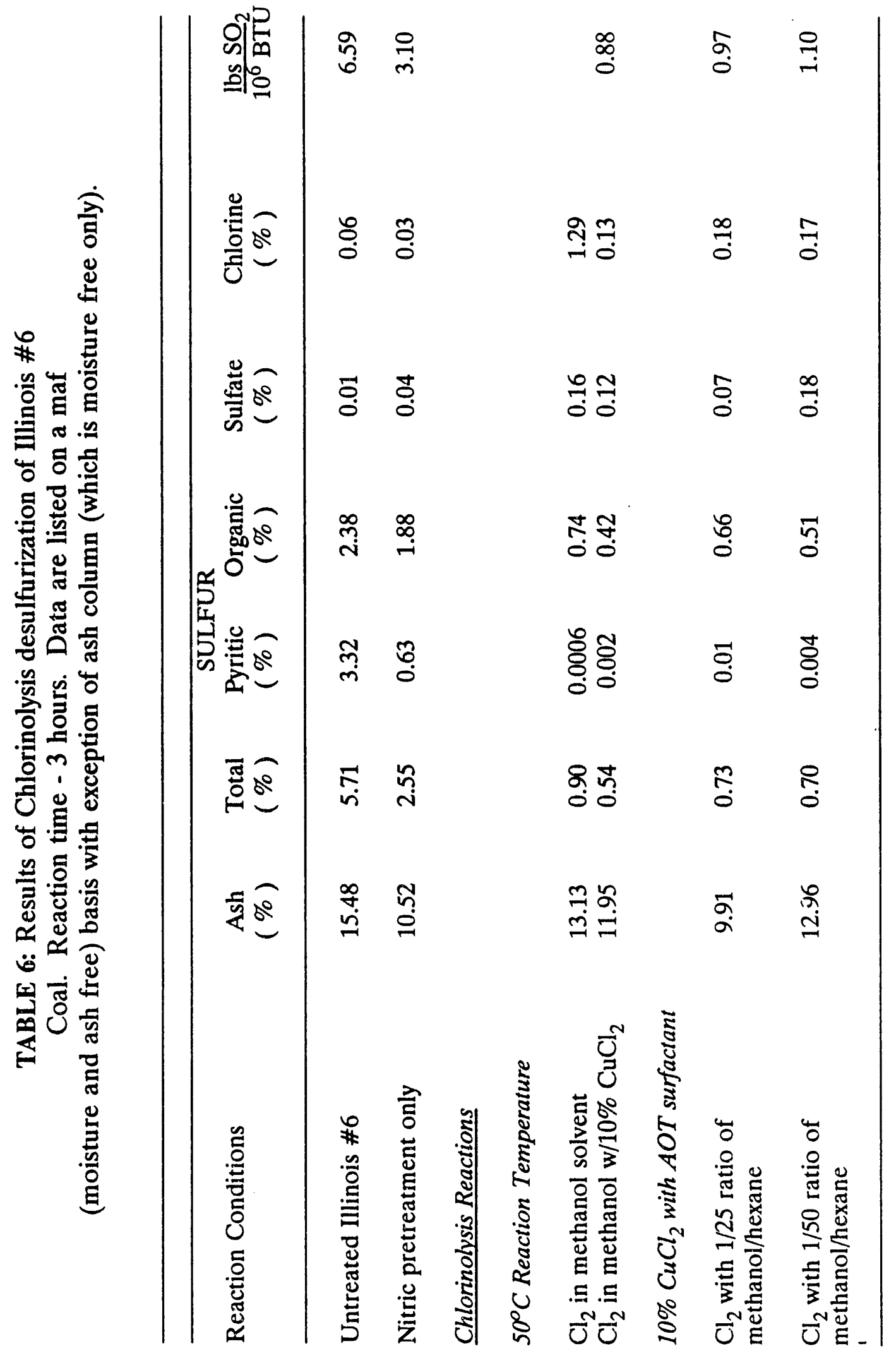




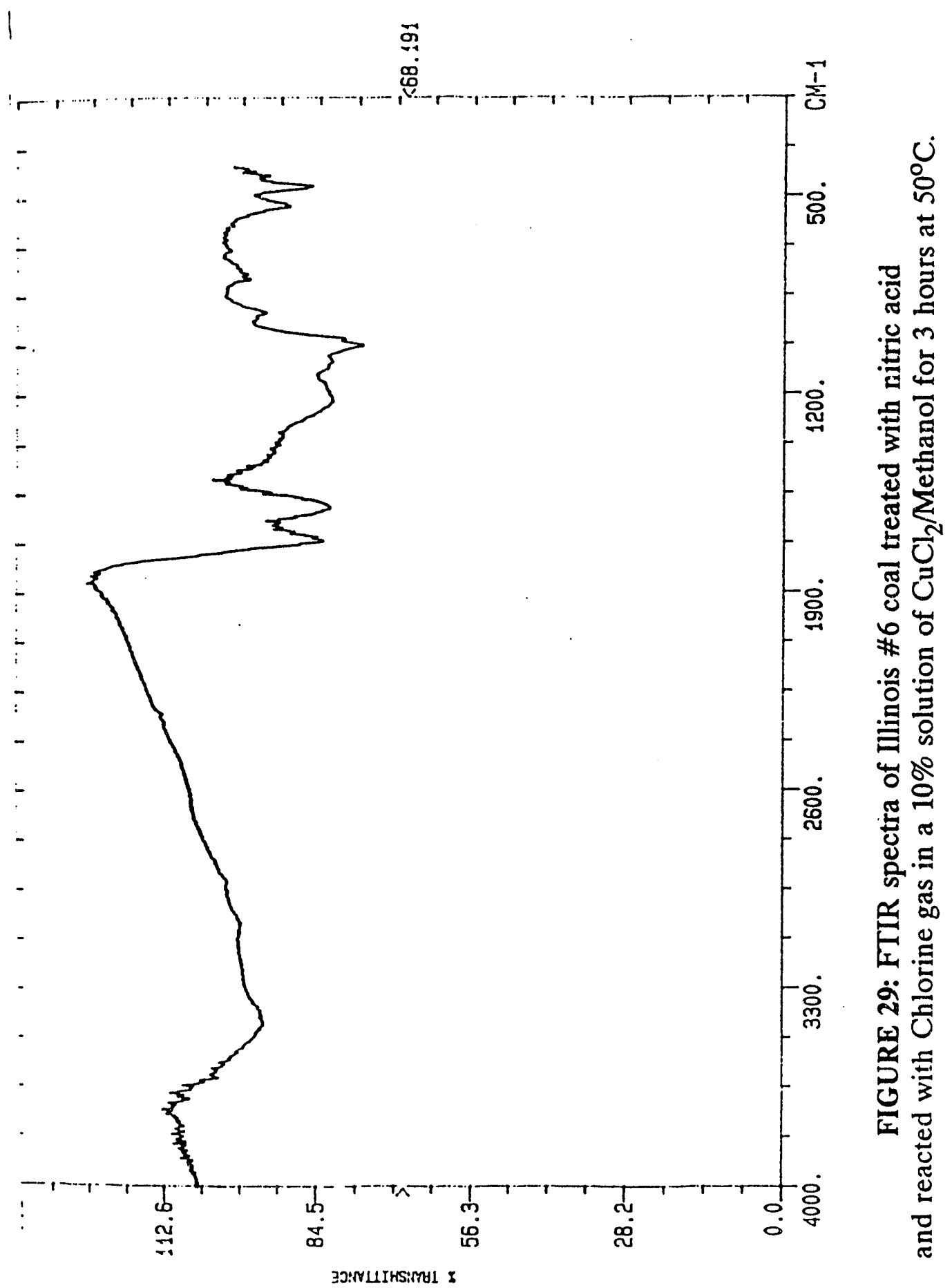


formation of the chlorosulfonium salt and/or enhances the subsequent conversion to the corresponding sulfoxide. More thorough studies are needed to determine conclusively the cause of the improved desulfurization.

A final set of chlorinolysis experiments were conducted with $\mathrm{CuCl}_{2}$, using a micelle-based solvent system of the surfactant AOT (bis-2ethylhexylsulfosuccinate sodium salt), methanol, and hexane. The purpose of these tests was to examine the effect of reacting the coal species in a micelle system. The results indicate that the organic sulfur removal is not aided in this system compared with utilizing the $\mathrm{CuCl}_{2}$ /methanol system. However, the organic sulfur removal is increased over that of chlorinolysis alone. In addition, the FTIR spectra of the coal after this reaction also shows minimal introduction of the $\mathrm{COO}^{-}$species while maintaining the aromatic portion of the coal.

In order to understand the significance of these experiments, a comparison with other researcher's recent results is shown in Table 7. This table lists desulfurization efficiency according to process type and sulfur form. One point to note is that the chlorinolysis desulfurization reaction is $98 \%$ completed at the 2 hour reaction time ${ }^{11}$. Therefore, although comparison of our 3 hour reaction time with other researchers results is not completely accurate, it has some merit. Comparison of this work with other, non-Illinois \#6 coal work, however, is weak. It has been demonstrated that there is considerable variation in desulfurization yields for different coal types. The 
TABLE 7: Comparison of Desulfurization Efficiency with Other Researchers Current Work in Chlorinolysis

\begin{tabular}{|c|c|c|c|}
\hline \multirow[b]{2}{*}{ REACTION CONDITIONS } & \multicolumn{3}{|c|}{$\%$ Sulfur Removed } \\
\hline & Total & Organic & Pyritic \\
\hline \multicolumn{4}{|l|}{ This Research - Illinois \#6 Coal } \\
\hline $\begin{array}{l}\text { Chlorinolysis in Methanol, } \\
3 \mathrm{hr} \text { rxn time, } 50^{\circ} \mathrm{C}\end{array}$ & 84 & 68 & 99 \\
\hline$+10 \% \mathrm{CuCl}_{2}$ & 91 & 82 & 99 \\
\hline$+10 \% \mathrm{CuCl}_{2}, \mathrm{AOT} \# 1$ & 87 & 72 & 99 \\
\hline$+10 \% \mathrm{CuCl}_{2}, \mathrm{AOT} \# 2$ & 88 & 79 & 98 \\
\hline \multicolumn{4}{|c|}{ Other Researcher's Work with Illinois \#6 Coal } \\
\hline \multicolumn{4}{|l|}{ Chlorinolysis, $2 \mathrm{hr}$ rxn time, $50^{\circ} \mathrm{C}$} \\
\hline $\mathrm{H}_{2} \mathrm{O} /$ Methanol solvent & 43 & 29 & 76 \\
\hline Methanol solvent & 41 & 36 & 87 \\
\hline Methanol/CCl 4 & 55 & 44 & 85 \\
\hline \multicolumn{4}{|c|}{ Chlorinolysis Work Using Other Coals } \\
\hline Balkaya Coal, $3 \mathrm{hrs}, 70^{\circ} \mathrm{C}$ & 60 & 30 & 97 \\
\hline \multicolumn{4}{|l|}{ Can K4 Lignite, 3 hrs, $74^{\circ} \mathrm{C}$} \\
\hline $\begin{array}{l}\text { water solvent } \\
\text { methyl chloroform twater }\end{array}$ & 22 & 40 & 13 \\
\hline methyl chloroform/water & 32 & 17 & 47 \\
\hline \multicolumn{4}{|l|}{$\begin{array}{l}\text { A } \cdots \text { Coal Sample, } 70^{\circ} \mathrm{C}, 4 \mathrm{hr} \text { rn time } \\
\mathrm{CCl}_{4} / \mathrm{H}_{2} \mathrm{O} \text { solvent } \\
\text { Sample } \# 1\end{array}$} \\
\hline Sample \#1 & 28 & 13 & 100 \\
\hline Sample \#2 & 56 & 49 & 100 \\
\hline $\begin{array}{l}\text { Sample \#3 } \\
\text { Dry Chlorinolusis }\end{array}$ & 24 & 18 & 100 \\
\hline Sample \#2 & & & \\
\hline Sample \#3 & $\begin{array}{l}26 \\
13\end{array}$ & $\begin{array}{c}16 \\
6\end{array}$ & $\begin{array}{l}80 \\
70\end{array}$ \\
\hline \multicolumn{4}{|l|}{$\begin{array}{l}\text { Assam Coal, } 4 \mathrm{hr} \text { rxn time, } \\
\text { Ternp = boiling pt of solvent }\end{array}$} \\
\hline $\mathrm{CCl}_{4}$ solvent & 54 & 45 & 98 \\
\hline Methanol solvent & 56 & 46 & 98 \\
\hline methanol/water solvent & 52 & 42 & 98 \\
\hline
\end{tabular}


purpose of these comparisons is merely to provide a marker for what is currently the industry standard for desulfurization. It is clear from this table that this research has conducted preliminary investigations into a method of desulfurizing coal which is currently better than other methods of chlorinolysis which currently exist.

In summary, as shown in the coal desulfurization results discussed in this last section, the use of $\mathrm{CuCl}_{2}$ or $\mathrm{Cu}(\mathrm{OH})_{2}$ as a reactive agent for removing sulfur from coal is not highly effective. However, the utilization of $\mathrm{CuCl}_{2}$ as a catalyst for the chlorinolysis reaction enhances desulfurization efficiency. 


\section{REFERENCES}

1. Saikia, P.C., Sain, B., Baruah, B.P., Bordoloi, C.S., and Mazumder, B., J. Mines, Met. Fuels, 1988, 36(5), 216.

2. Vasilakos, N.P. and Corcoran, W.H., FUEL, 1983, 62, 1111-1115.

3. Vorres, K. S. Energy Fuels 1990, 4 420-426.

4. Narayan, Ramani, Kullerud, Gunnar, and Wood, Karl V., Fuel Division Preprints197th ACS National Meeting of American Chemical Soc., 1989 193-199.

5. Gonzalez de Andres, Ana I., Moinelo, Sabino, R., Bermejo, Jenaro, and Tascon, Juan M.D., FUEL, 1990, 69, 867-872.

6. Gonzalez de Andres, Ana I., Moinelo, Sabino, R., Bermejo, Jenaro, and Tascon, Juan M.D., FUEL, 1990, 69, 873-877.

7. Vasilakos, N.P., Bone, R.L., and Corcoran, W.H., Ind. Eng. Chem. Process Des. Dev., 1981, 20, 376-379.

8. Wilson, Jr., E., Tetrahedron, 1982, 38(17), 2597-2625.

9. Szmant, H., Organic Sulfur Compounds (Edited by N. Kharasch), 1961, 1, 154.

10. Ranky, W., and Nelson, D., Organic Sulfur Compounds (Edited by N. Kharasch), 1961, 1, 170.

11. Ozdemir, M., Bayrakceken, S., Gurses, A., Gulaboglu, S., Fuel Processing Technology, 1990, 26, 15-23. 


\section{SELECTIVE SOLVOLYSIS WITH SUPERCRITICAL ETHANOL}

\section{PREVIOUS WORK}

Supercritical fluids were first used to liquify coal by the National Coal Board of the United Kingdom ${ }^{1}$. Later Ross and Blessing ${ }^{2}$ showed that supercritical alcohols can be used to effectively liquefy coal. Their initial work involved the study of supercritical isopropyl alcohol and methanol ${ }^{3}$. When base was added to promote the conversion with supercritical methanol the resultant product was completely soluble in pyridine. Also, in the first study of liquefaction with supercritical alcohols ${ }^{2}$ the organic sulfur content was also found to be lowered by $50 \%$ in the liquified coal.

Chen et al. ${ }^{4}$ were the first to consider using supercritical alcohols to desulfurize coals. Since this initial work they have studied the extent of inorganic and organic desulfurization that is possible by using supercritical alcohol solvents. Their work to date includes the study of desulfurization of coals using supercritical methanol and ethanol ${ }^{5}$. Although a substantial portion of their work involved the study of desulfurization using supercritical methanol.

\section{PROJECT OBJECTIVE}

The prime objective of the work described herein was to more thoroughly study the selective extraction of organosulfur compounds from coal using supercritical ethanol. Reactions of model coal compounds with supercritical ethanol were studied. This was followed by a study of coals which documented the extent of desulfurization obtained when extracting with supercritical ethanol. The extent of inorganic and organic desulfurization of Illinois \#6 was quantified. In addition, the compounds present in the ethanol solvent were characterized with the hope that this information would help explain the mechanism of desulfurization. 


\section{EXPERIMENTAL}

\section{Model Compound Studies}

The model coal compounds studied were: phenyl sulfide ( $98 \%$ pure), thiophenol ( $97 \%$ pure), cyclohexyl mercaptan (99\% purity), dibenzothiophene (98\% pure). These compounds were used as purchased from Aldrich Chemical Company (Milwaukee, WI). The purity of each model coal compound was verified and the identity of the impurities was determined by GC/MS analysis. Absolute Ethanol (dehydrated, USP) as received from Midwest Grain Corporation was utilized throughout these studies.

Stainless steel $40 \mathrm{ml}$ or $4 \mathrm{ml}$ extraction cells were used throughout these studies. In every case, the quantity of sample added was such so that the concentration of the sample in the supercritical ethanol solution was always $6.25 \% \mathrm{vol} / \mathrm{vol}$. The reactions were carried out in stainless steel tubes cut to have an internal volume of $4 \mathrm{~mL}$ or stainless steel sample cylinders with $40 \mathrm{~mL}$ volume as supplied by Whitey. Both ends of the extraction vessel were fitted with a Valco filter union (Valco Instruments, Houston, TX) with a 2 micron screen to help contain the coal inside of the extraction vessel. One side of the extraction vessel was connected to a high pressure Isco syringe pump (ISCO, Lincoln, NE) that contained ethanol and the other end of the extraction cell was connected to a stainless steel restrictor.

The extraction process proceeded in the following way. The compound was placed inside of the extraction vessel with a small quantity of ethanol and then the extraction vessel was sealed. At this point, the extraction cell was placed inside of the oven and then connected to the high pressure syringe pump. The other end of the extraction vessel was connected to a high pressure SSI valve (Scientific Systems, Inc., State College, PA) and then connected to the stainless steel restrictor. The pressured liquid ethanol was then placed in the vessel under pressure conditions that were lower than the final reaction conditions. The vessel was heated to thle desired temperature and then the vessel pressure was raised to the final reaction conditions. The pressure of the system was regulated with the pressure control system of the syringe pump. After the system reached the reaction pressure and temperature, the model coal compounds were extracted for $\mathbf{3 0}$ minutes. After this period, the extraction cell was cooled to room temperature and the contents of the vessel were 
exhausted into a liquid ethanol solution. The reaction vessel was flushed with liquid ethanol and the resultant extracts were combined in a receiving vessel. The total volume of the solution in the receiving vessel was then diluted to a constant volume of $20 \mathrm{~mL}$. A $1 \mu \mathrm{L}$ aliquot of this solution was then injected onto the capillary gas chromatographic column. The reaction products were then identified by GC/MS. The experimental parameters for the GC/MS were the same as described previously in Table 2.

The critical pressure and temperature of the ethanol are $78.5 \mathrm{~atm}$ and $240{ }^{\circ} \mathrm{C}$. Six different sets of reaction conditions were chosen. These conditions are:

1) $275^{\circ} \mathrm{C}$ and $\left.204 \mathrm{~atm}, 2\right) 320^{\circ} \mathrm{C}$ and $\left.238 \mathrm{~atm}, 3\right) 350{ }^{\circ} \mathrm{C}$ and $\left.238 \mathrm{~atm}, 4\right) 400{ }^{\circ} \mathrm{C}$ and $238 \mathrm{~atm}, 5) 425^{\circ} \mathrm{C}$ and $238 \mathrm{~atm}$ and 6) coal compounds were heated to $350{ }^{\circ} \mathrm{C}$ in absence of ethanol. The low reaction conditions of set \#1 were chosen to allow comparison to the higher temperature data. Free radical bond cleavage was deemed highly unlikely under these conditions. Condition \#6 was chosen to allow comparison of the high temperature solvolysis results with conditions where only thermal degradation products are possible. These reaction conditions also include the range of reaction conditions used previously for coal extraction work ${ }^{3}$. However, the work on the model coal compounds described herein spans an expanded range to lower and higher temperatures than previously studied.

\section{Coal Studies}

Three different coals, Illinois No. 6 (high-vol bit.), Upper Freeport (med-vol bit.), and Pittsburgh No.8 (high-vol bit.), from the Argonne Premium Coal Sample Program were used in this study. The Illinois \#6 coal samples were used for all benchmark experiments which better defined further experiments on the other coals. All coal samples were received as -20 mesh particles. Each sample, (7-8 grams) was extracted in a stirred $300 \mathrm{~mL}$ extraction cell (Autoclave Engineerings, Inc.). Therefore, the ratio of fluid to coal was ca. $40: 1$.

The extraction process proceeded in the following way. The coal sample was placed inside of the extraction vessel with a small quantity of ethanol, and then the extraction vessel was sealed. The heater unit on the autoclave was initiated. The inlet of the extraction cell was connected to the high pressure syringe pump and the outlet was 
connected to flow restrictor in a similar fashion as described above for the model coal compound studies. The extraction vessel was equilibrated to the desired temperature then the system pressure was raised to the appropriate pressure. After attaining the extraction conditions, the coal samples were dynamically extracted for 30 minutes. (Note: A dynamic extraction involves the supercritical solvent flowing continuously across the solid matrix for a defined period of time.) The products were collected from the end of the restrictor which was placed in a chilled ethanol solution.

After the extraction process was completed, the vessel was allowed to cool and the coal was removed. The coal was vacuum filtered to remove any of the extract that still remained in the vessel. The coal was then rinsed with copious amounts of absolute ethanol and dried under a nitrogen atmosphere. After the drying process was completed, the coal samples were weighed. The remaining coal was analyzed for ash content, total sulfur, pyritic sulfur, sulfate sulfur, and organic sulfur content by a commercial laboratory (Black Rock Test Labs, Morgantown, WV). The data from the commercial test lab was precise to $\pm 0.01 \%$.

Compounds that were extracted and collected in the ethanol solvent were analyzed by a combination of analytical techniques. The concentration of the analytes in the ethanol were increased by evaporating away some of the ethanol. This was done by keeping the solution chilled and blowing a slow stream of nitrogen across the solvent. The extract volume was lowered by a factor of ten before analysis of the analytes. A survey of extracted organsulfur compounds was first done by gas chromatography/mass spectrometry. The range of organosulfur compounds in the extract was then determined by gas chromatography/flame photometric detection (FPD) and gas chromatography/sulfur chemiluminescence detection (SCD).

The chromatographic separations were attained by using a 30-meter DB-17 column, as well as a 30 meter DB-Wax column. Both columns were $250 \mu \mathrm{m}$ i.d. with a $0.25 \mu \mathrm{m}$ stationary phase film thickness (J\&W Scientific, Folsom, CA). The mobile phase used for these separations was high purity helium. The flame gas conditions for FPD were $20 \mathrm{~mL} / \mathrm{min}$ oxygen and $75 \mathrm{~mL} / \mathrm{min}$ hydrogen. The temperature program for the DB-17 column is as follows: The initial temperature, $40^{\circ} \mathrm{C}$, was held for 10 minutes, the 
temperature was then ramped at $2{ }^{\circ} \mathrm{C} / \min$ to $90^{\circ} \mathrm{C}$, next the temperature was ramped at $1^{\circ} \mathrm{C} /$ min to $140^{\circ} \mathrm{C}$, next the temperature was ramped at $5^{\circ} \mathrm{C} / \mathrm{min}$ to $280^{\circ} \mathrm{C}$. Finally, this temperature was held for $2 \mathrm{~min}$. The total separation time was 115 minutes. The temperature program for the DB-Wax column was: The initial temperature, $40^{\circ} \mathrm{C}$, was held for 25 minutes, the temperature was ramped at $2{ }^{\circ} \mathrm{C} / \mathrm{min}$ to $180^{\circ} \mathrm{C}$, next the temperature was ramped at $4{ }^{\circ} \mathrm{C} / \mathrm{min}$ to $240{ }^{\circ} \mathrm{C}$ and finally this temperature was held for 5 minutes.

For some studies the pyrite was removed before extraction. The pyrite was removed by washing the coal with dilute nitric acid following ASTM Method D2492. The dilute nitric acid consisted of one part concentralied nitric acid added to seven parts distilled water. Approximately 15 grams of each coal sample was mixed with $200 \mathrm{~mL}$ of the dilute nitric acid solution for a $24 \mathrm{hr}$ period. Coal samples were then vacuum filtered and then rinsed with copious amounts of absolute ethanol, dried and stored in a nitrogen atmosphere.

\section{RESULTS AND DISCUSSION}

\section{Interaction of Supercritical Ethanol With Model Coal Compounds}

Significant bond cleavage was found only for thiophenol under the supercritical conditions studied. Less than $5 \%$ yield was found for the observed reaction products for all the other organosulfur compounds. The hydrogen sulfur bond in thiophenol is clearly the weakest of those studied and therefore it is the easiest to rupture. Also, a general trend was observed. The solvolysis reaction products, such as ethylphenylsulfide, were the products initially formed at lower temperatures. At higher temperatures the reaction products were those typically produced from bimolecular association reactions of free radicals, such as phenyl sulfide for the thiophenol sample. This type of reaction would be expected in pyrolysis reactions.

Bimolecular reaction between organosulfur compounds would not be expected when the reaction is occurring at the surface of the solid coal matrix. With the coal matrix, the probability of the extracted organosulfur radicals having such bimolecular is quite low since two radicals extracted from the surface of the coal would need to associate in solution after the surface extraction. Also none of the observed reactions of the model coal compounds would lead to sulfur removal of the heteroatom from coal. As mentioned earlier, previous 
research has shown that supercritical ethanol does desulfurize coal. This seems to indicate that the reactions of the compounds chosen are not indicative of the coal reaction chemistry. Organosulfur polymers would be better models than the organosulfur compounds studied.

TABLE 8 Interaction of Supercritical Ethanol with Model Compounds

1) Reactions of Phenyl sulfide (98\% pure)

Impurities were dibenzothiophene and biphenyl.

Reaction conditions

$275^{\circ} \mathrm{C}, 204 \mathrm{~atm}$

$320^{\circ} \mathrm{C}, 238 \mathrm{~atm}$

$350{ }^{\circ} \mathrm{C}, 238 \mathrm{~atm}$

$400^{\circ} \mathrm{C}, 238 \mathrm{~atm}$

$425^{\circ} \mathrm{C}, 238 \mathrm{~atm}$

Sample heated to $350^{\circ} \mathrm{C}$ for $30 \mathrm{~min}$
Reaction Products

Diphenyldisulfide

Diphenyldisulfide

Diphenyldisulfide

no detectable products

no detectable products
$\%$ Conversion of

Reactants to

Products
ca. $5 \%$
ca. $1 \%$
ca. $1 \%$

no detectable products 
TABLE 8 (cont.) Interaction of Supercritical Ethanol with Model Compounds

2) Reactions of Thiophenol (97\% pure)

Impurities were diphenyldisulfide and iodobenzene.

Reaction conditions Reaction Products

$275^{\circ} \mathrm{C}, 204 \mathrm{~atm}$

Ethylphenylsulfide

Diphenyldisulfide

Phenylsulfide

$320^{\circ} \mathrm{C}, 238 \mathrm{~atm} \quad$ Ethylphenylsulfide

Diphenyldisulfide

Phenylsulfide

$350^{\circ} \mathrm{C}, 238$ atm Ethylphenylsulfide

Diphenyldisulfide

Phenylsulfide

$400{ }^{\circ} \mathrm{C}, 238 \mathrm{~atm} \quad$ Ethylphenylsulfide

Phenylsulfide

$425^{\circ} \mathrm{C}, 238 \mathrm{~atm} \quad$ Ethylphenylsulfide

Phenylsulfide

Sample heated to Diphenylsulfide

$350{ }^{\circ} \mathrm{C}$ for $30 \mathrm{~min}$ Phenylsulfide
\% Conversion of

Reactants to Products

ca. $10 \%$

ca. $10 \%$

ca. $2 \%$

ca. $7 \%$

ca. $3 \%$

ca. $3 \%$

ca. $12 \%$

ca. $5 \%$

ca. $10 \%$

ca. $20 \%$

ca. $40 \%$

ca. $20 \%$

ca. $50 \%$

ca. $5 \%$

ca. $15 \%$ 
TABLE 8 (cont.) Interaction of Supercritical Ethanol with Model Compounds

3) Reactions of Cyclohexyl mercaptan (99\% pure) Impurity was dicyclohexyl propanedinitrile

Reaction conditions

$275^{\circ} \mathrm{C}, 204 \mathrm{~atm}$

$320^{\circ} \mathrm{C}, 238 \mathrm{~atm}$

$350{ }^{\circ} \mathrm{C}, 238 \mathrm{~atm}$

$400{ }^{\circ} \mathrm{C}, 238 \mathrm{~atm}$

$425{ }^{\circ} \mathrm{C}, 238 \mathrm{~atm}$

Sample heated to

$350^{\circ} \mathrm{C}$ for $30 \mathrm{~min}$
Reaction Products

no reaction products

Ethylthiocyclohexane

Ethylthiocyclohexane

no detectable products

no detectable products

no detectable products
$\%$ Conversion of Reactants to Products

<a. $4 \%$

<a. $4 \%$ 
TABLE 8 (cont.) Interaction of Supercritical Ethanol with Model Compounds

4) Reactions of Methyl p-tolyl sulfide (99.9\% pure) Impurity was ethyl p-tolylsulfide

Reaction conditions

$275^{\circ} \mathrm{C}, 204 \mathrm{~atm}$

$320^{\circ} \mathrm{C}, 238 \mathrm{~atm}$

$350^{\circ} \mathrm{C}, 238 \mathrm{~atm}$

$400{ }^{\circ} \mathrm{C}, 238 \mathrm{~atm}$

$425^{\circ} \mathrm{C}, 238$ atm

Sample heated to

$350 \circ \mathrm{C}$ for $30 \mathrm{~min}$
Reaction Products

phenyl acetic acid

phenyl sulfide

no detectable products

no detectable products

no detectable products

no detectable products

no detectable products
\% Conversion of Reactants to Products

$1 \%$

$0.5 \%$ 
TABLE 8 (cont.) Interaction of Supercritical Ethanol with Model Compounds

5)

Reactions of Dibenzothiophene (98\% pure)

No impurities detected.

Reaction conditions

$275^{\circ} \mathrm{C}, 204 \mathrm{~atm}$

$320^{\circ} \mathrm{C}, 238 \mathrm{~atm}$

$350{ }^{\circ} \mathrm{C}, 238 \mathrm{~atm}$

$400{ }^{\circ} \mathrm{C}, 238 \mathrm{~atm}$

$425^{\circ} \mathrm{C}, 238 \mathrm{~atm}$

Sample heated to

$350{ }^{\circ} \mathrm{C}$ for $30 \mathrm{~min}$
Reaction Products

no detectable products

no detectable products

no detectable products

no detectable products

no detectable products

no detectable products
\% Conversion of Reactants to Products 
Interaction of Supercritical Ethanol With Coal

The ethanol extraction conditions that were used in the coal extraction studies were $400{ }^{\circ} \mathrm{C}$ and $238 \mathrm{~atm}$. These conditions were chosen because $400{ }^{\circ} \mathrm{C}$ is above the temperature where the weaker bonds in coal should begin to scission $\left(350^{\circ} \mathrm{C}\right)$, but not substantially above; and, the pressure is above the compressible region in the supercritical fluid. Under these conditions, ethanol has liquid-like densities but retains the gas-like viscosities. In addition, from surveying the resultant products from the studies on the interaction of cyclohexyl mercaptan, more products that are probably pyrolytic in nature appear above $400{ }^{\circ} \mathrm{C}$.

Table 9 shows the initial data obtained from the dynamic interaction/extraction of Illinois \#6 with supercritical echanol under these conditions for 30 minutes. The total sulfur was decreased by $28.4 \%$ in the remaining coal solids. However, the measured organic sulfur increased by $46.3 \%$ and the ash in the resultant coal solid also increased. The removal of pyritic sulfur from the coal samples using supercritical ethanol was quite efficient.

Two possible causes for the measured increase in organic sulfur are: 1) some of the pyritic sulfur was converted to marcasite from the interaction with supercritical ethanol, or 2) the solvated pyritic material could be reacting with the organic matrix under these conditions which caused further incorporation of the sulfur atoms into the organic matrix.

TABLE 9: Sulfur Analysis of Illinois \#6 Coal and Coal Extracts

All values are moisture and ash free (maf) except ash which is only moisture free.

$\begin{array}{lllll}\text { COAL ASH TOTAL-S PYR-S SULF-S ORG-S } & \end{array}$

\begin{tabular}{llllll}
\hline \hline ILL \#6(ar) & 15.48 & 5.71 & 3.32 & 0.01 & 2.38 \\
ILL \#6(ae) & 20.83 & 4.44 & 0.65 & 0.01 & 3.77
\end{tabular}

(ar) $=$ as received from the coal bank

$(\mathrm{ae})=$ after extraction process 
Dunkerton et al. ${ }^{6}$ recently presented data showing the type of sulfur transfer reaction between the pyrite and the organic matrix in hydrogenation reactions.

To determine if the pyritic sulfur was interacting with the organic matrix, the pyrite was removed from the Illinois \#6 coal samples before extraction with supercritical ethanol. The pyrite was removed from the coal by the interaction with dilute $\mathrm{HNO}_{3}$ as described in the experimental section.

Tabie 10 shows the results from this extraction of Illinois \#6. The sulfur analysis of the resultant coal solids in this case showed significant desulfurization of organic sulfur. The ash content continued to increase after interaction with the supercritical ethanol. The same pretreatment procedure was then used in the desulfurization of the Upper Freepcrt and the Pittsburgh \#8 Coals. For both coals the interaction of supercritical ethanol caused desulfurization of the organic sulfur and increased ash content. However the quantity of organic sulfur removed (only ca. 15\%) was not as high for these coals as that found for the Illinois \#6 sample (see Table 10). Previous studies of coal desulfurization with supercritical methanol have shown similar results ${ }^{7}$. The ratio of pyrite/organic sulfur in the coal was thought to be controlling the final extraction yield of organic sulfur. However, since the pyrite was removed in the studies shown herein, perhaps a better exp'anation of this result is that when coals are inherently low in sulfur, the organosulfur functionality is less easily removed. For example, a higher percentage of thiophenic sulfur may be present in low sulfur coal. Table 11 shows a comparison of the coal solid recovery for each of the samples studied. Illinois \#6 had the lowest recovery of coal solids. Rank has often been used to explain the relative extent of dissolution of coal. The coals in this study, Illinois \#6, Pittsburgh \#8 and Upper Freeport were med-volatile bituminous, high volatile bituminous, and high volatile bituminous, respectively. Consequently, if rank were controlling the dissolution in this study, then Pittsburgh \#8 and Illinois \#6 should have had similar dissolution yields. Other factors must be involved. 
TABLE 10: Efrect of $\mathrm{HNO}_{3}$ Pretreatment on Sulfur Removal

All values are moisture and ash free (maf) except ash which is only moisture free.

COAL ASH TOTAL-S PYR-S SULF-S ORG-S

\begin{tabular}{lccccc}
\hline IL \#6(ar) & 15.48 & 5.71 & 3.32 & 0.01 & 2.38 \\
IL \#6(pr) & 8.32 & 2.07 & 0.01 & 0.07 & 2.00 \\
IL \#6(ae) & 11.72 & 1.25 & 0.01 & 0.02 & 1.22 \\
& & & & & \\
U. Freeport(ar) & 13.18 & 2.32 & 1.77 & 0.01 & 0.54 \\
U. Freeport(pr) & 9.98 & 0.68 & 0.05 & 0.00 & 0.63 \\
U. Freeport(ae) & 10.47 & 0.56 & 0.01 & 0.01 & 0.54 \\
& & & & & 0.81 \\
Pitt \#8(ar) & 9.25 & 2.19 & 1.37 & 0.01 & 0.75 \\
Pitt \#8(pr) & 6.45 & 0.78 & 0.02 & 0.01 & 0.63 \\
Pitt \#8(ae) & 7.83 & 0.65 & 0.00 & 0.01 & \\
\hline \hline
\end{tabular}

$(a r)=$ as received from the coal bank

(pr) $=$ pyrite removed, but no extraction

$(\mathrm{ae})=$ pyrite removed sample after extraction 
TABLE 11: Comparison of Organic Sulfur Removal

COAL Organic Sulfur Removed

\begin{tabular}{lll}
\hline \hline IL \#6 & $39 \%$ & $69.1 \%$ \\
U. Freeport & $14 \%$ & $87.8 \%$ \\
Pitt \#8 & $16 \%$ & $78.6 \%$ \\
\hline
\end{tabular}

To understand the mechanism of interaction of supercritical ethanol with these coals, the chemical composition of the ethanol extracts were analyzed. Tables 12 and 13 list the compounds that were identified in the ethanol extracts of Illinois \#6. Two chromatographic columns of different polarity were used to provide efficient separation of a broad range of compound polarity. Table 12 lists the data obtained when using a nonpolar DB-17 stationary phase, and Table 13 lists the data when a polar DB-Wax stationary phase was used.

The extraction of molecules from coal in hydrogen donor solvents over the temperature range of $300-400{ }^{\circ} \mathrm{C}$ has been attributed to ether bond cleavage; and in the temperature range of $400-500{ }^{\circ} \mathrm{C}$, methylene bonds attached to phenyl rings being to cleave $^{8}$. However, Wilhelm and Hedden ${ }^{9}$ cited the temperature region between $300-420$ ${ }^{\circ} \mathrm{C}$ as a region where mild pyrolysis may occur with resulting extraction of the products.

The phenolic compounds identified in Tables 12-13 are representative of products expected when cleavage of ether bonds occurs in a H-donor solvent; and, aromatic and heteroaromatic compounds are representative of mild pyrolysis. Also a large number of the identified compounds had ethyl or methyl side chains which may be indicative of chemical reactions occurring between ethanol and the coal matrix. One other point of interest is the effect of the $\mathrm{HNO}_{3}$ pretreatment on the extracted compounds. No major difference in types of compounds extracted were observed after pyrite removal with $\mathrm{HNO}_{3}$ (Table 14).

The focus of this project was to study coal desulfurization. Very few organosulfur 
compounds were identified by GC/MS. To determine the extent of organosulfur compound present, the extracts were separated using the same chromatographic columns and conditions, but a flame photometric detector (FPD) was used as a sulfur selective detector. Standard organosulfur compounds were separated on the two columns. The chromatograms of the standards on DB-Wax and DB-17 are shown in Figures 30 and 31, respectively. Under the same chromatographic conditions the compounds in the ethanol extracts were separated. From a comparison of the retention times, the organosulfur compounds in the extracts were identified. In the extract of Illinois \#6 the following cumpounds were identified: thiophenol, methyl p-tolyl sulfide, ethyl sulfide, ethyl disulfide and phenyl sulfide. Twenty-one organosulfur compounds could not be conclusively identified. Figures 32 and 33 are the chromatograms of the Illinois \#6 extract separated on the DB-Wax and DB-17 columns respectively and detected by FPD. The identified compounds can be attributed primarily to products of chemical reactions between ethanol and the coal matrix. Additional reference standard are necessary if the other organosulfur compounds are to be identified. A higher fraction of the extracted organosulfur compounds must be identified before the mechanism of extraction of organosulfur compounds can be clarified. Figures 34 and 35 are the chromatograms obtained when from the Illinois \#6 (pyrite removed) extracts on the DB-Wax and DB-17 columns, respectively. In comparing Figures 34 and 35 to Figures 32 and 33, it is apparent that the number of organosulfur compounds resulting from the depyritized coal is lower than from extraction of whole coal. The higher molecular weight organosulfur compounds do not seem to be as easily extracted in the pyrite-removed coal samples as in the whole coals. However, recall that the previous bulk analyses showed that the extent of desulfurization of the organic matrix was highest when pyrite was removed first. One should note that the chromatograms provide qualitative information on the types of different compounds present. Quantitative information is very difficult to obtain using a flame photometric detector since its response does not vary linearly with sulfur concentration.

Figures 36 and 37 are the GC/FPD chromatograms obtained with the DB-Wax and DB-17 chromatographic columns, respectively for the Pittsburgh \#8 ethanol extracts (with pyrite remove samples). The number of organosulfur compounds in these chromatograms 
is comparable to those of Illinois \#6 (with pyrite removed samples). Figures 38 and 39 are the chromatograms obtained with the DB-Wax and DB-17 chromatographic columns respectively for the Upper Freeport coal samples with the pyrite removed before extraction. The number of organosulfur compound extracted for this coal is much smaller than for the other two types. The Upper Freeport higher ranked coal than the other two coals (med-vol bituminous compared to high vol. bituminous) perhaps this is the cause of the diminished number of organosulfur compounds that was extracted but more types of coal should be tried for verification of this possible cause.

In summary, the extraction of organosulfur compounds from Illinois \#6, Upper Freeport and Pittsburgh \#8 with supercritical ethanol at $400^{\circ} \mathrm{C}$ and $238 \mathrm{~atm}$ seems to be due to solvolysis and mild pyrolysis reactions. This study found that the extent of desulfurization under these conditions was much higher for the Illinois \#6 coal than for Upper Freeport or Pittsburgh \#8 coal. The reason for this difference may be the relative proportions of different types of organosulfur compounds in the coal. Substantial differences in the types of compounds detected were observed for the three coals. In addition, the removal of pyritic sulfur before the extraction of the coal with supercritical ethanol was found to be highly beneficial. One other point of significance should be noted, the extent of organosulfur desulfurization of Illinois \#6 samples in this study (41.4\%) is comparable to the best extraction results on the same coal when more strenuous extraction conditions were used ${ }^{6}$. The obvious differences between the two studies are that the reference studied utilized supercritical methanol and the extraction pressure was lower. 
TABLE 12: Compounds Identified by GC/MS of Illinois \#6 Extract Using 30 Meter DB-17 Column

Pyridines

pyridine

4-methyl pyridine

2-methyl pyridine

2-ethyl pyridine

3,5-dimethyl pyridine

3-ethyl pyridine

2-propyl pyridine

4-propyl pyridine

5-ethyl-2-methyl pyridine

3-ethyl-4-n-propyl pyridine
Phenols

phenol

3-methyl phenol

2,6-dimethyl phenol

2-ethyl phenol

2,3-dimethyl phenol

2,4-dimethyl phenol

4-ethyl phenol

3-ethyl phenol

2-ethyl-6-methyl phenol

diethyl phenol
Napthalenes

1,3-dimethyl naphthalene 1,6-dimethyl naphthalene 2,7-dimethyl naphthalene 1,6,7-trimethyl naphthalene

Saturated Hydrocarbons

pentacosane

eicosane

heneicosane
Esters

ethyl ester butanoic acid ethyl ester hexanoic acid ethyl ester octanoic acid diethyl ester butanedioic acid

Others

2-hexanol

1,2,6-trimethyl piperidine diethyl disulfide

2-methyl benzoxazole

1-ethylidene-1H-indene

hexadecane 
TABLE 13 Compounds Identified by GC/MS of Illinois \#6 Extract Using a 30 Meter DB-Wax Column

Phenols

3,5-dimethyl phenol

2-ethyl-6-methyl phenol

5-methyl-2-(1-methyl ethyl) phenol phenol

2-ethyl-4,5-dimethyl phenol

2-(1,1-dimethyl ethyl)-5-methyl phenol

2-ethyl phenol

4-methyl phenol

3-methyl phenol

4-ethyl-2-methyl phenol

4-ethyl-3-methyl phenol

2-ethyl phenol

3-ethyl phenol

2,3,5-trimethyl phenol

diethyl phenol

3,5-diethyl phenol

2-ethyl-4-methyl phenol

Benzenes

1-methyl-4-(methylthio) benzene

1,3-diethyl-5-methyl benzene
Napthalenes

naphthalene

2-methyl naphthalene

2,7-dimethyl naphthalene
Alcohols

2-butanol

2-pentanol

2-buten-1-ol

Indenes

\section{2,3-dihydro-1H-indene}

$1 \mathrm{H}$-indene

Others

\section{Undecane}

Benzo[b]thiophene

1,2,3,4,5,6-hexamethyl-1,3-cyclohexadiene 
TABLE 14: Compounds Identified by GC/MS of Illinois \#6 After Pyrite Removal Using a 30 Meter DB-Wax Column

\author{
Alcohols \\ 2-butanol \\ 2-pentanol \\ 2-buten-1-ol \\ 2-hexanol \\ 2-ethyl-1-butanol \\ 1-hexanol \\ p-cymen-8-ol
}

Phenols

2-ethyl-6-methyl phenol

2-ethyl-5-(1-methyl ethyl) phenol

2-ethyl-4,5-dimethyl phenol

2-ethyl phenol

4-methyl phenol

2,4-dimethyl phenol

2-ethyl-5-methyl phenol

4-ethyl-3-methyl phenol

3-ethyl phenol

2,3,6-trimethyl phenol

phenol

Others

diethyl disulfide

1-ethylidene-1II-indene

ethyl ester butanoic acid
Pyridines

4-methyl pyridine

2,4-dimethyl pyridine

2-propyl pyridine

5-ethyl-2-methyl pyridine

3-ethyl-5-methyl pyridine

4-propyl pyridine

3-methyl-5-propyl pyridine

2,3,6-trimethyl pyridine

Napthalenes

2-methyl naphthalene

1,5-dimethyl naphthalene

1,4,6-trimethyl naphthalene

Acids

-..--

acetic acid

butanoic acid 


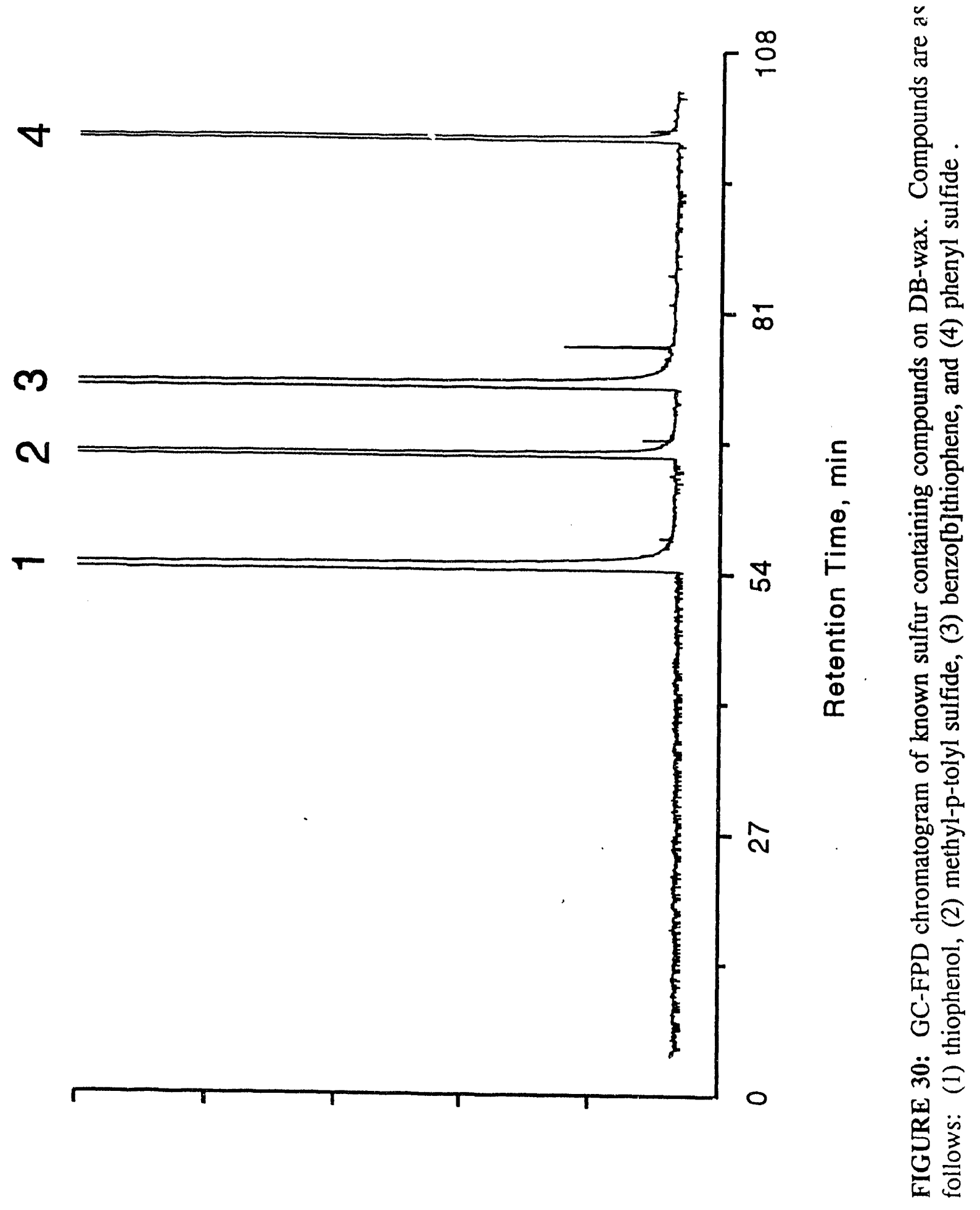




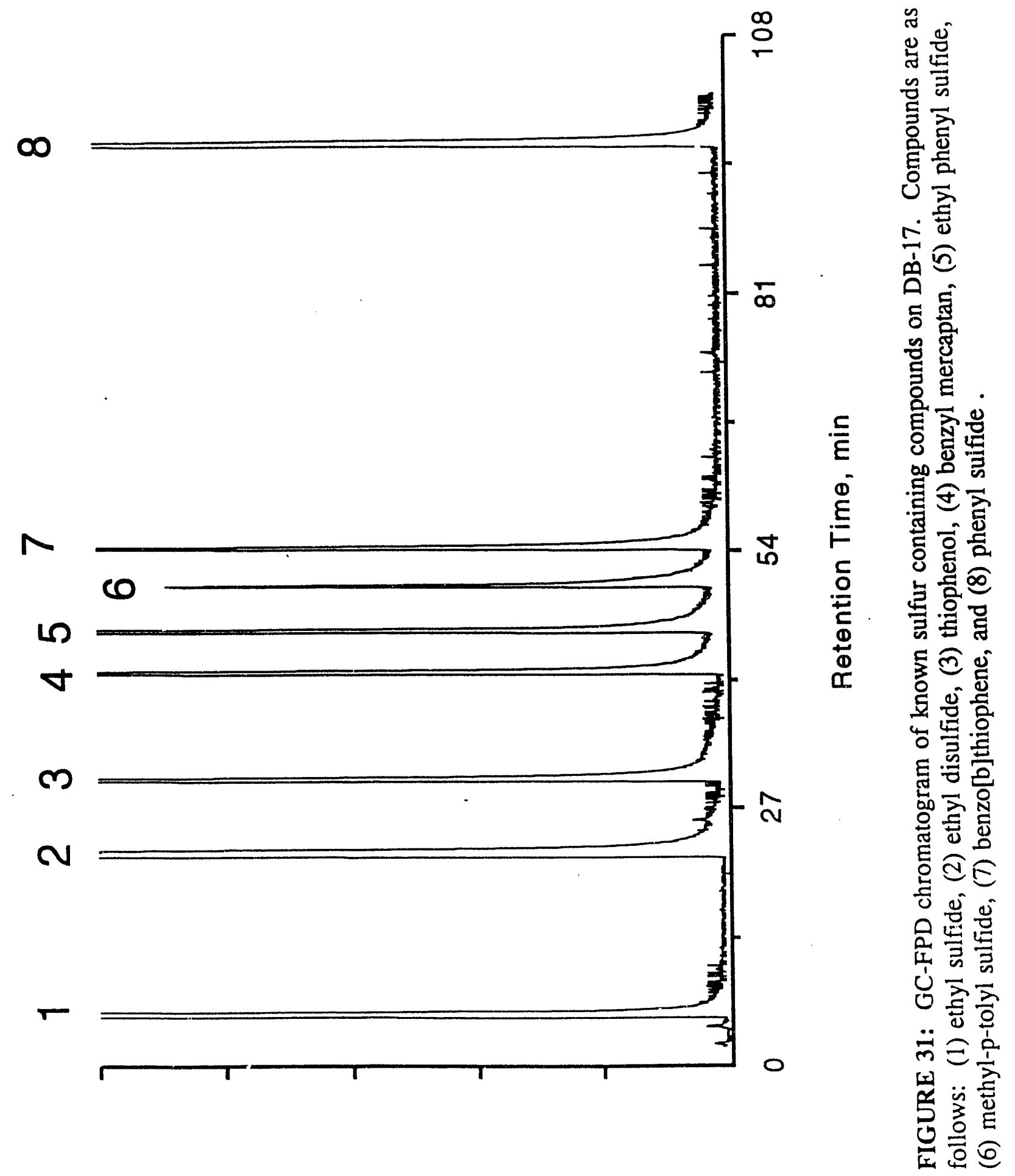




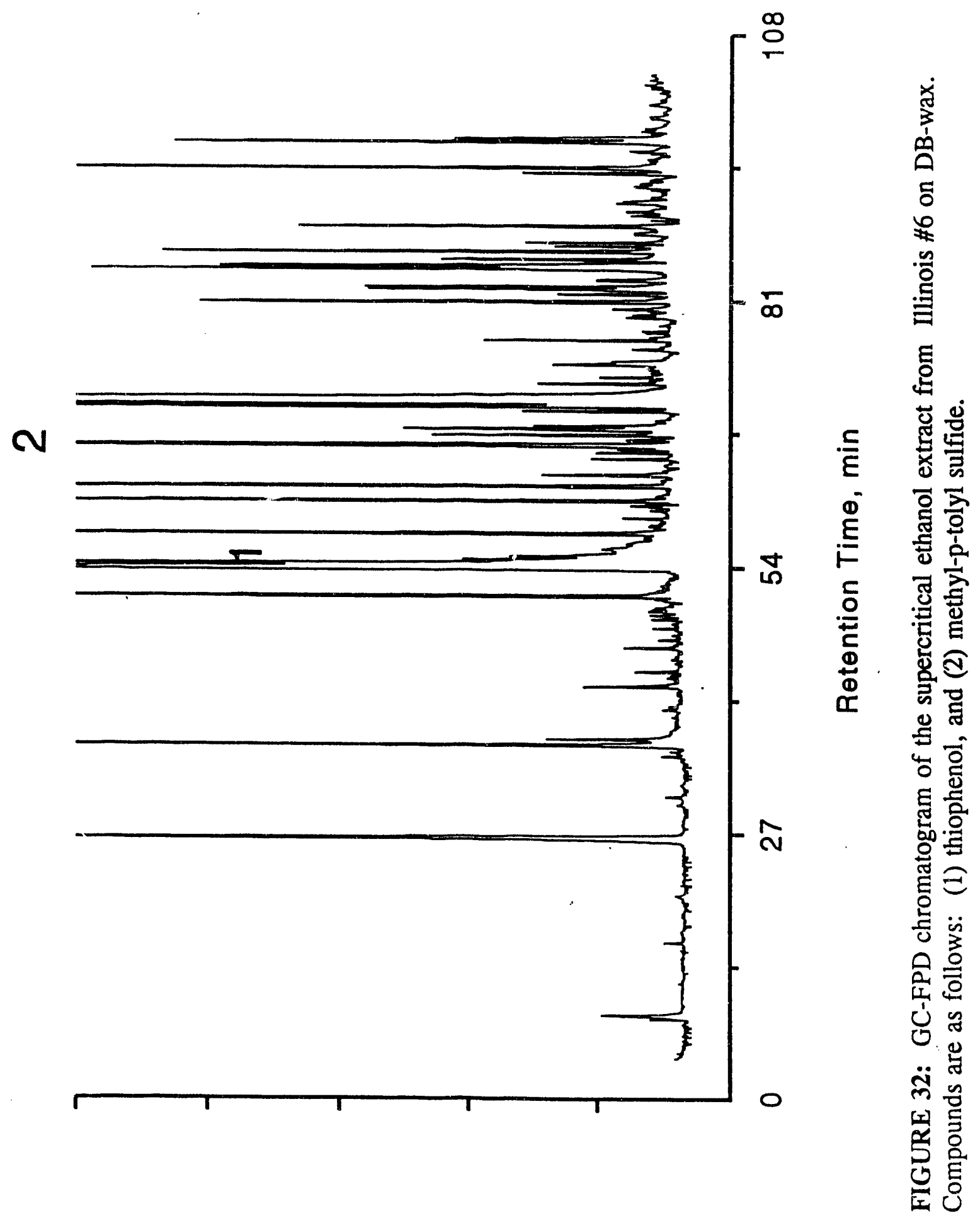




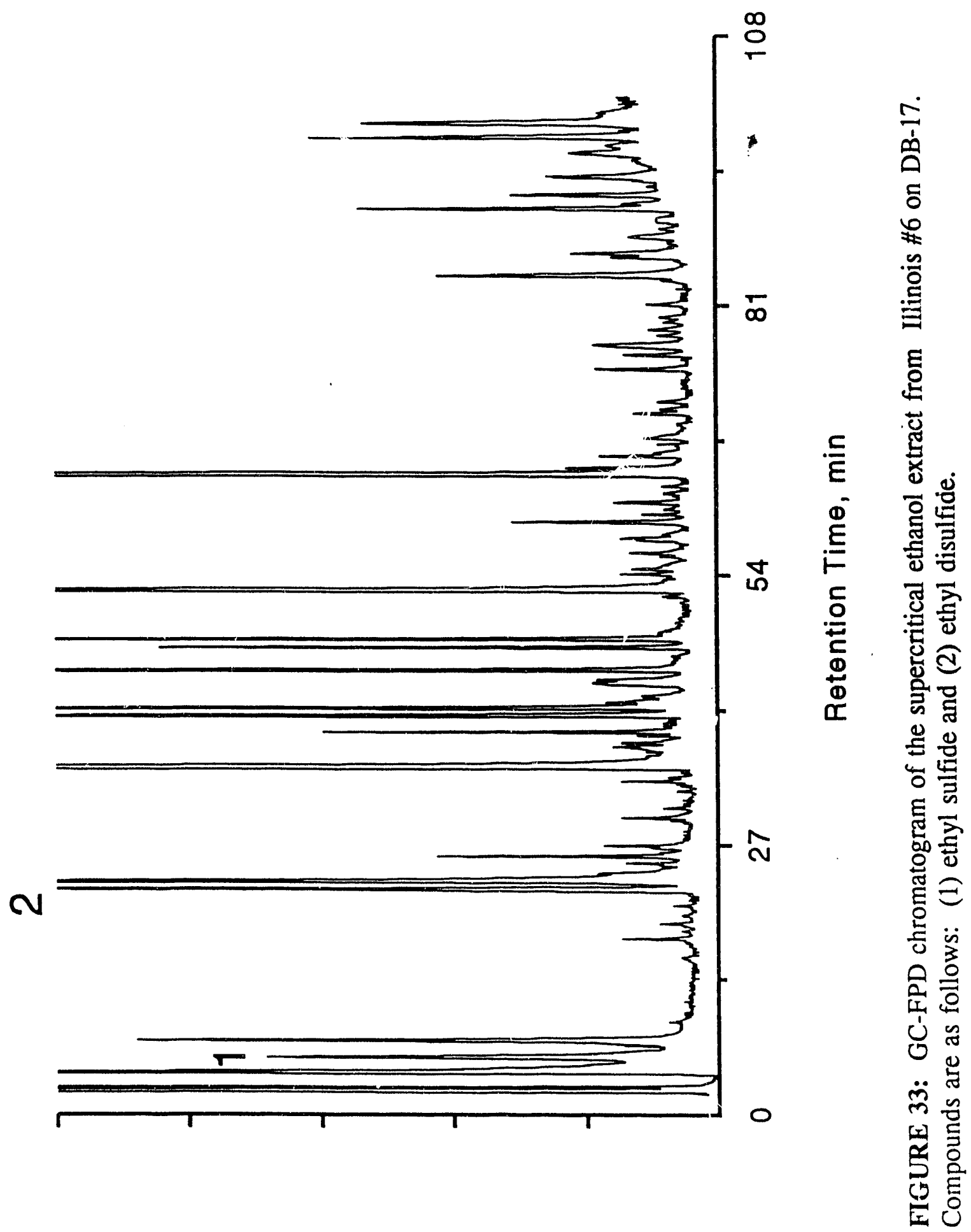




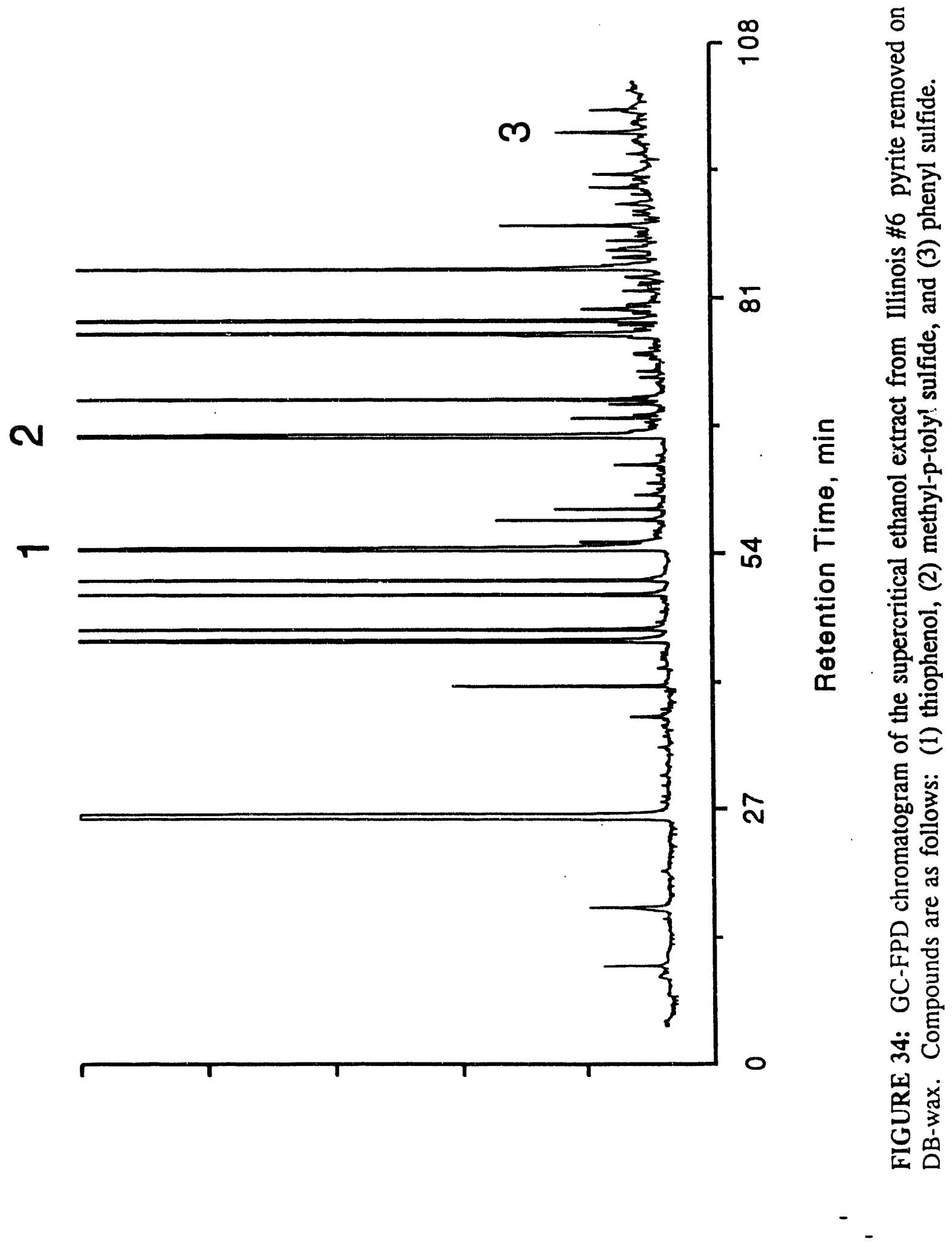




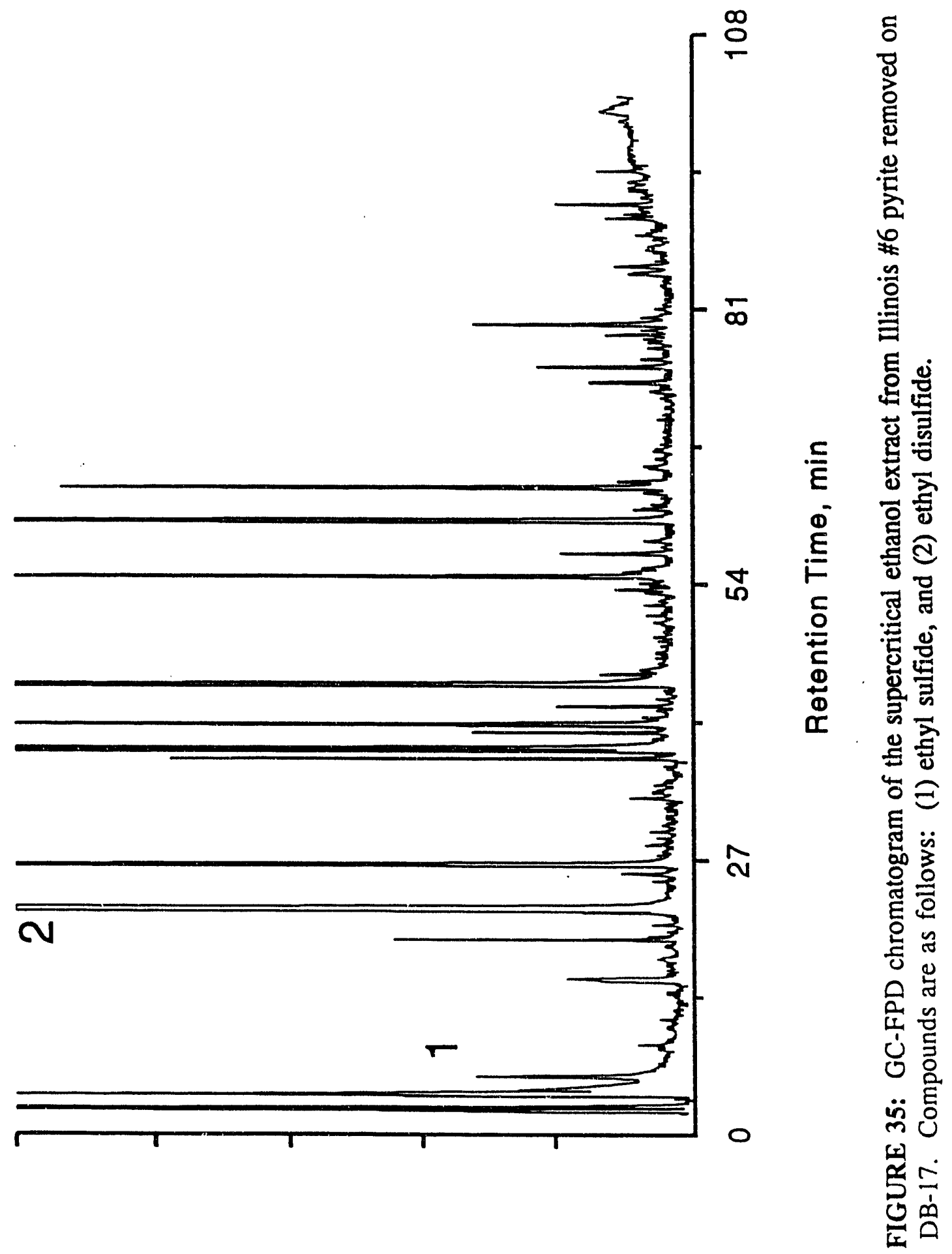




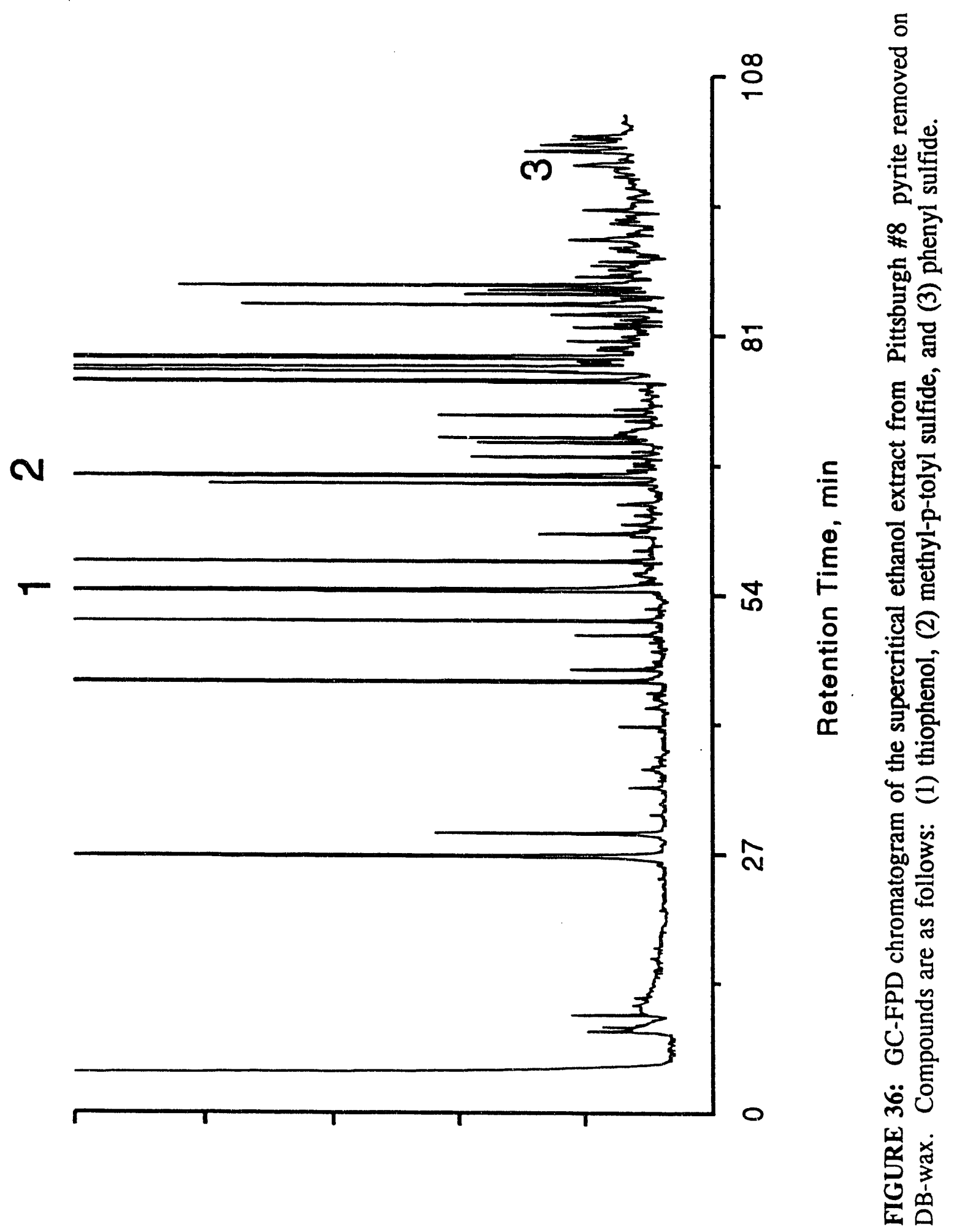




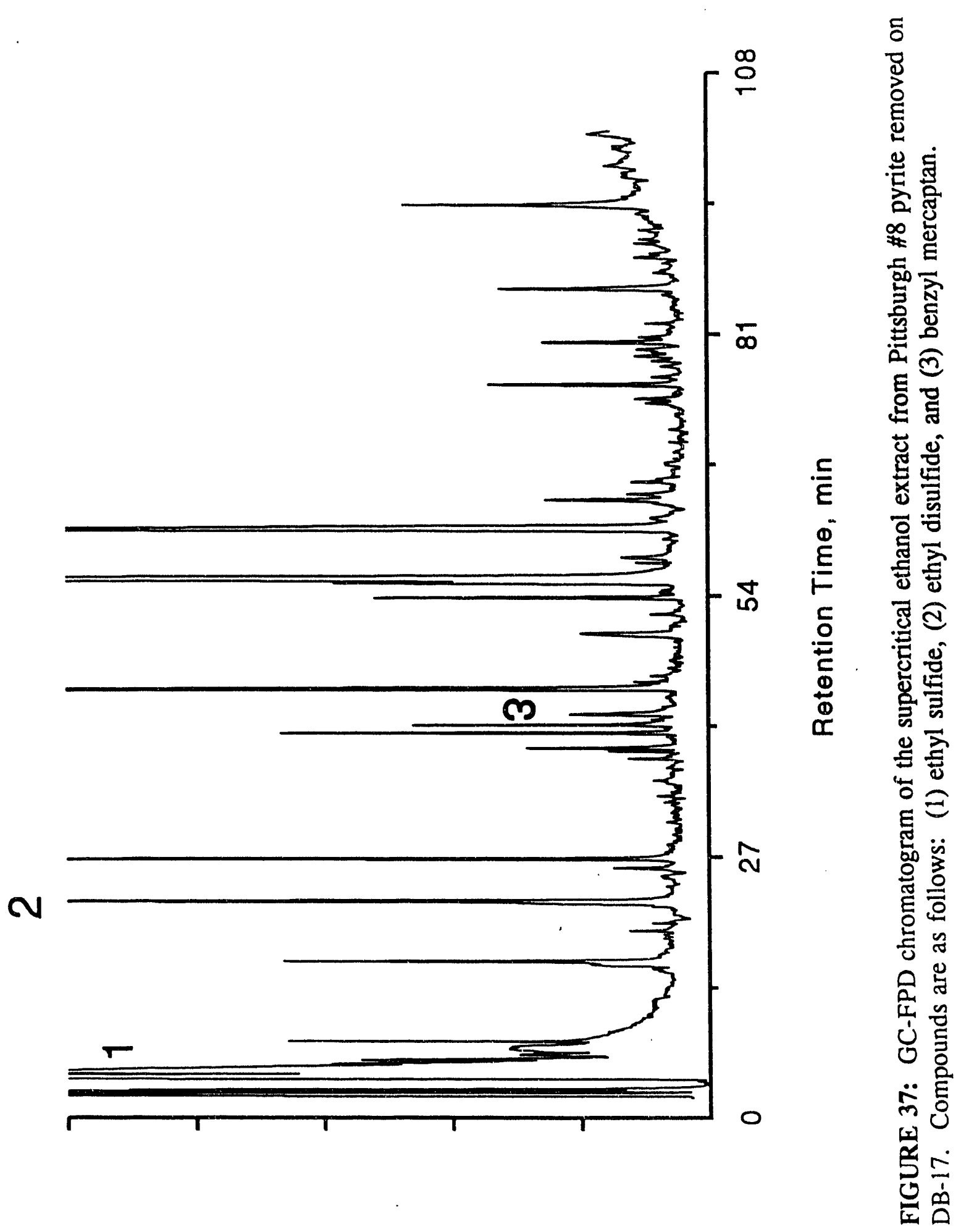




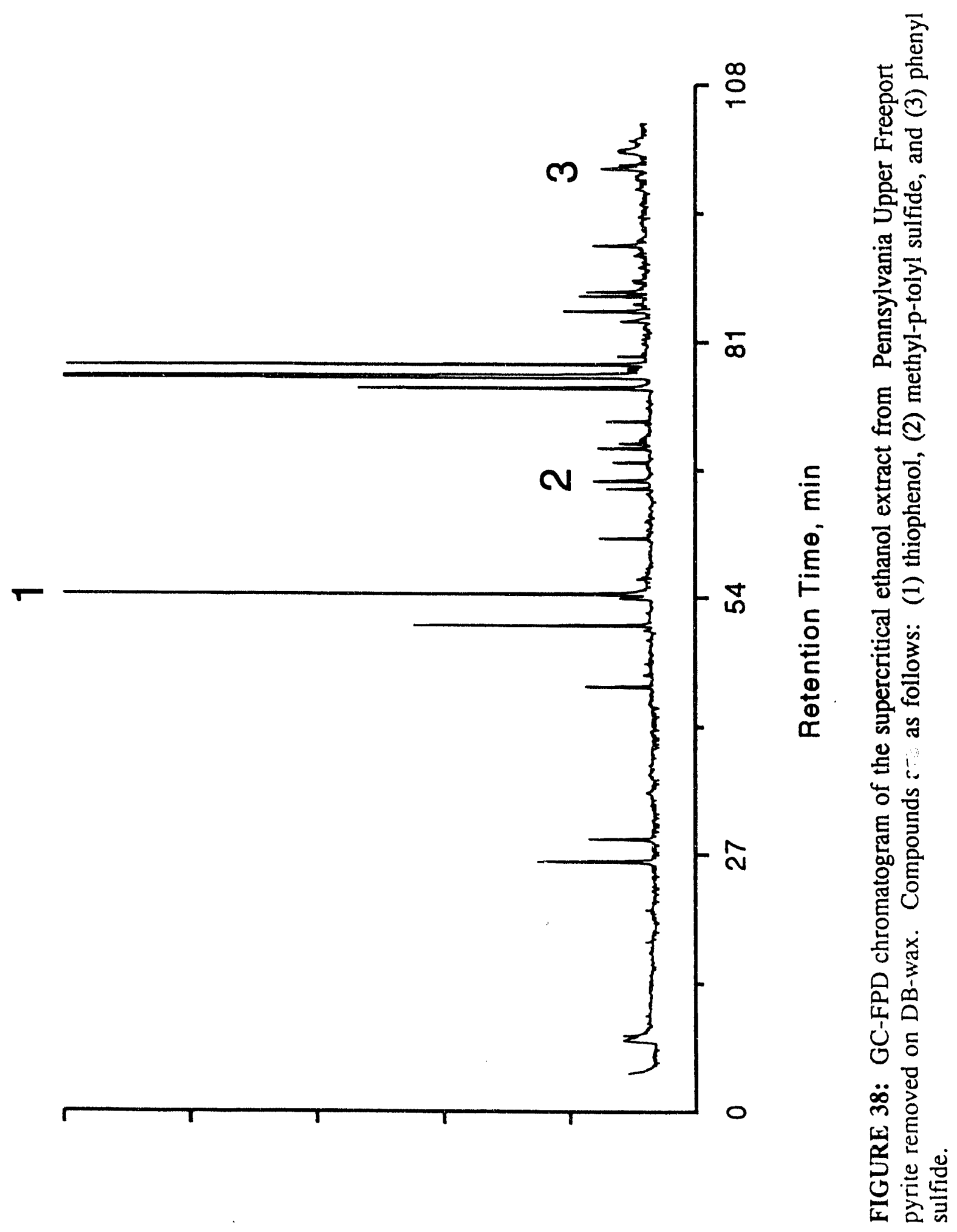




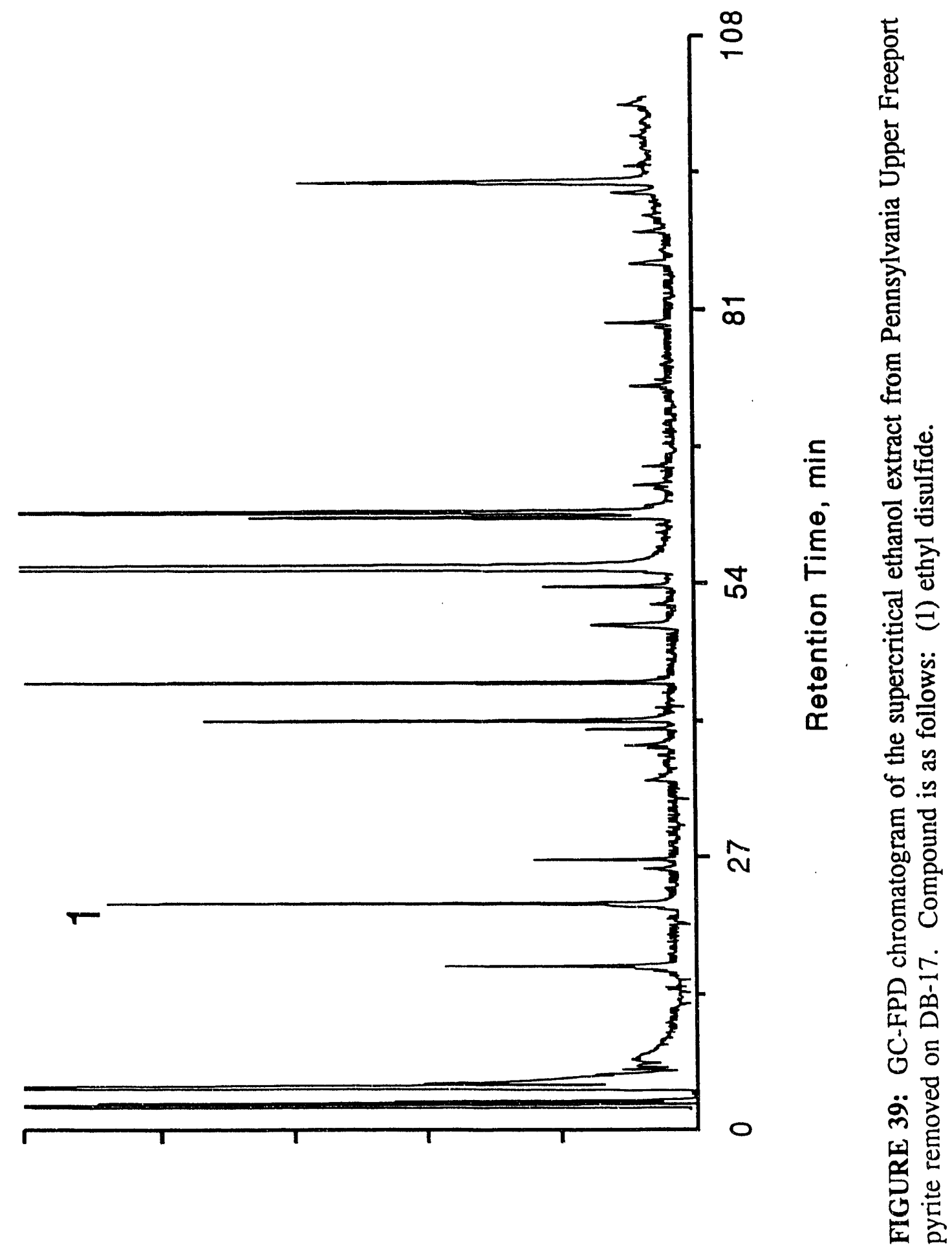




\section{REFERENCES}

1. Whitehead, J.C., Williams, D.F. J. Inst. Fuel 1975, 48, 182.

2. Ross, D.S., Blessing, J.E. Fuel, 1979, 58, 433.

3. Ross, D.S., Blessing, J.E. Fuel 1979, 58, 438.

4. Chen, J.W., Muchmore, C.B., Kent, A.C., Chang, Y.C. Am. Chem. Soc., Div. Fuel Chem., Prepr. 1985, 30 (3) 173.

5. Muchmore, C.B., Chen, J.W., Kent, A.C., Tempelmeyer, Am. Chem. Soc., Div. Fuel Chem., Prepr. 1985, 30 (2) 24.

6. Dunkerton, L.V., Nigam, A., Mitra, S., Phillips, J.B., Smith, G.V., Wiltowska, T., In "Mixing of Sulfur Between Pyritic and Organic Phases During Coal Conversion Processes", Final Report to U.S. Department of Energy Contract \# DE-FC2286PC91272, May 1987.

7. Hippo, E.J., Crelling, J.C. Fuel Processing Tech. 1991, 27, 287.

8. Kuhlmann, E., Boerwinkle, E., Orchin, M. Fuel 1981, 60, 1002.

9. Wilhelm, A., Hedden Fuel, 1986, 65, 1209. 

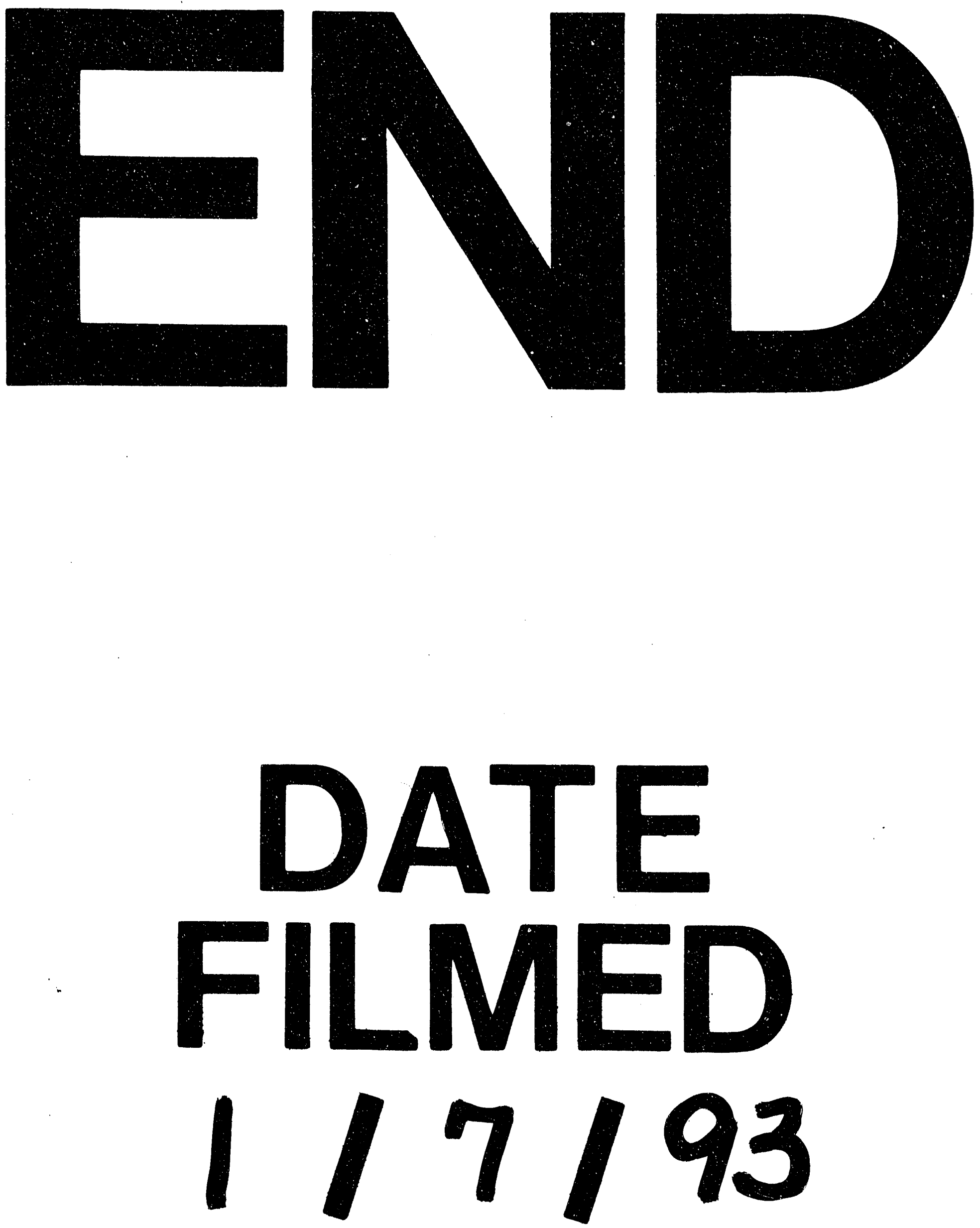

1 
